\title{
Anti-Inflammatory Effects of Omega-3 Fatty Acids in the Brain: Physiological Mechanisms and Relevance to Pharmacology
}

\author{
Sophie Layé, Agnès Nadjar, Corinne Joffre, and Richard P. Bazinet
}

Institut National pour la Recherche Agronomique and Bordeaux University, Nutrition et Neurobiologie Intégrée, UMR 1286, Bordeaux, France (S.L., A.N., C.J.); and Department of Nutritional Sciences, University of Toronto, Ontario, Canada (R.P.B.)

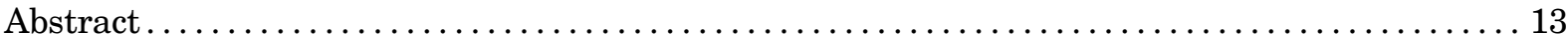

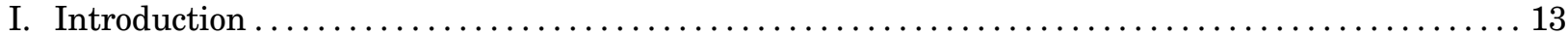

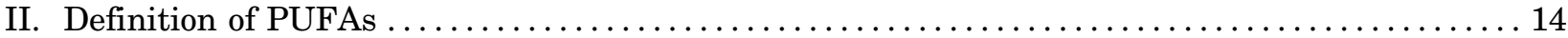

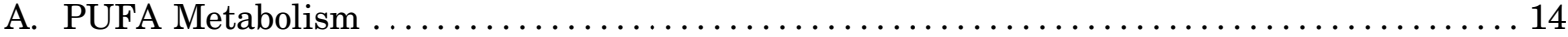

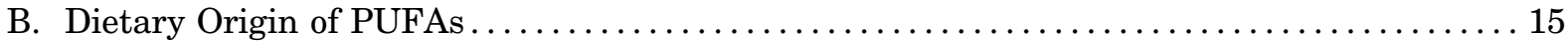

C. Accumulation and Regional Distribution in the Brain ........................ 15

D. Intrinsic (Age, Sex) and Extrinsic (Diet) Factors Influencing Brain PUFA Content....... 16

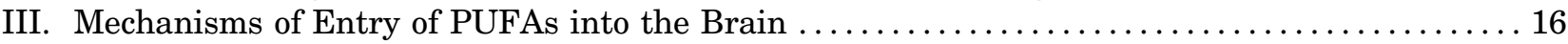

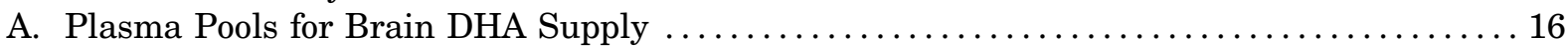

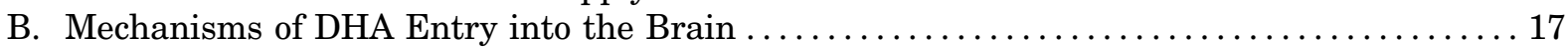

IV. Anti-Inflammatory Activities of n-3 PUFAs in the Brain $\ldots \ldots \ldots \ldots \ldots \ldots \ldots \ldots \ldots \ldots \ldots \ldots$

A. General Evidence in Humans and Animal Models of Brain Pathologies............... 17

B. Overview of DHA Anti-Inflammatory/Proresolving Mechanisms . . . . . . . . . . . . . 18

1. Membrane and Signaling Effects. .................................... 18

2. N-3 LC-PUFA Derivatives... . . . . . . . . . . . . . . . . . . . . . . . . . . . . . . . 19

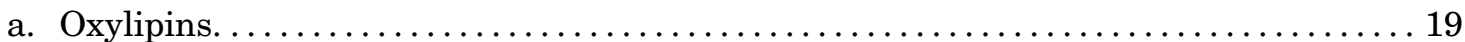

b. Endocannabinoids. ........................................... 19

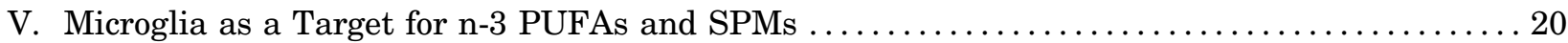

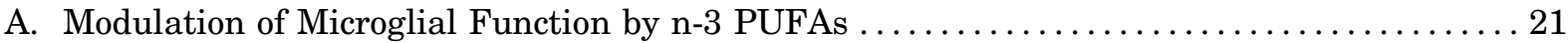

1. In Vitro Evidence. ............................................. 21

2. In Vivo Evidence.................................................... 22

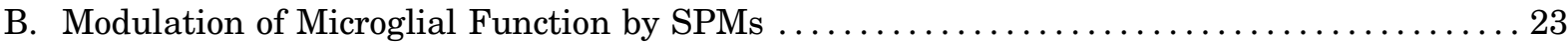

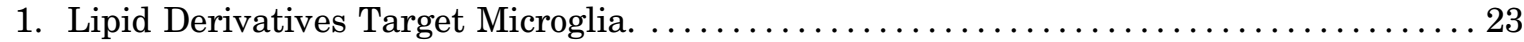

2. Lipid Derivatives and Their Receptors................................ 24

C. A Link between n-3 PUFAs and Microglial Extracellular Vesicles? ................. 24

D. Sex, Age, and Regional Differences in the Relationship between Microglia and n-3

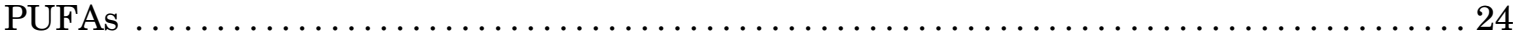

1. Evidence for Sexual Dimorphism of Microglia............................ 24

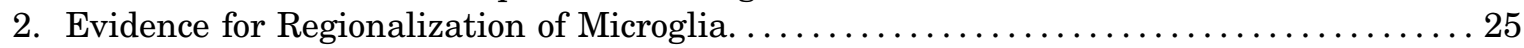

3. Evidence for Age Dependence of Microglia. .......................... 25

VI. Pharmacological Considerations on the Use of LC-PUFAs or SPMs as Effective Anti-

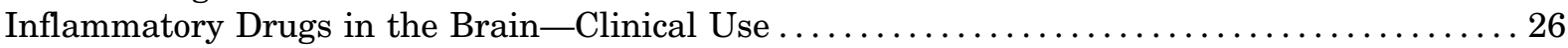

A. LC-PUFA Dietary Interventions to Limit Neuroinflammation in Humans . . . . . . . . . 26

1. LC-PUFA Dietary Intervention and Neuroinflammation in AD Patients. ........... 26

2. LC-PUFA Dietary Intervention and Neuroinflammation in Patients with Mood

Disorders. . . . . . . . . . . . . . . . . . . . . . . . . . . . . . . . . . . . . . . . . . . . 27

S.L., C.J., and A.N. are supported by Institut National pour la Recherche Agronomique, Bordeaux University, Foundation for Medical Research (DRM.20101220441), and the French Foundation (FDF, \#00070700). R.P.B. is supported by the Canadian Institutes of Health Research and the Natural Sciences and Engineering Council of Canada, and holds the Canada Research Chair in Brain Lipid Metabolism.

Address correspondence to: Dr. Sophie Layé, NutriNeuro Institut National pour la Recherche Agronomique and Bordeaux University, UMR 1286, 146 rue Léo Saignat, 33076 Bordeaux, France. E-mail: sophie.laye@inra.fr

https://doi.org/10.1124/pr.117.014092. 
B. The Use of SPMs or n-3 PUFA-Derived Fatty Amides to Target Brain Neuro-

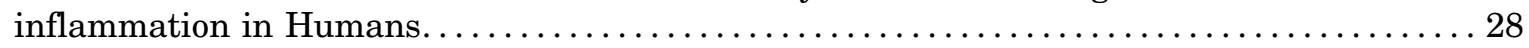

C. Pharmacological Strategy to Promote Endogenous SPM Production in the Brain: Combination of PUFAs and Anti-Inflammatory Drugs ..................... 29

D. The Use of COX or Lipoxygenase Inhibitors to Target Neuroinflammation: a Paradox? . . . 30

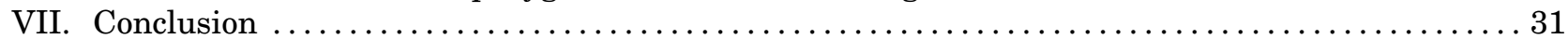

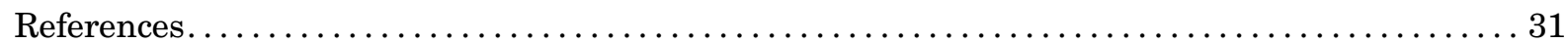

\begin{abstract}
Classically, polyunsaturated fatty acids (PUFA) were largely thought to be relatively inert structural components of brain, largely important for the formation of cellular membranes. Over the past 10 years, a host of bioactive lipid mediators that are enzymatically derived from arachidonic acid, the main n-6 PUFA, and docosahexaenoic acid, the main n-3 PUFA in the brain, known to regulate peripheral immune function, have been detected in the brain and shown to regulate microglia activation. Recent advances have focused on how PUFA regulate the molecular signaling of microglia, especially in the context of neuroinflammation and behavior. Several active drugs regulate brain
\end{abstract}

lipid signaling and provide proof of concept for targeting the brain. Because brain lipid metabolism relies on a complex integration of diet, peripheral metabolism, including the liver and blood, which supply the brain with PUFAs that can be altered by genetics, sex, and aging, there are many pathways that can be disrupted, leading to altered brain lipid homeostasis. Brain lipid signaling pathways are altered in neurologic disorders and may be viable targets for the development of novel therapeutics. In this study, we discuss in particular how n-3 PUFAs and their metabolites regulate microglia phenotype and function to exert their antiinflammatory and proresolving activities in the brain.

\section{Introduction}

Polyunsaturated fatty acids (PUFAs) are generally considered to be essential fatty acids, meaning they are necessary for maintaining normal physiology, but cannot be produced by mammals and need to be provided by the diet (Bazinet and Layé, 2014). There are two main families of PUFAs, the n- 6 and n-3 PUFAs (also referred as omega 6 and omega 3 ). Linoleic acid (LA; 18:2n-6) is the dietary-essential shorter-chain n-6 PUFA precursor of arachidonic acid (AA), whereas $\alpha$-linolenic acid (ALA; $18: 3 n-3)$ is the dietary-essential shorter chain n-3 PUFA precursor of eicosapentaenoic acid (EPA) and docosahexaenoic acid (DHA). AA, DHA, and EPA are also consumed in the diet, although as distinct sources. The major dietary sources of ALA are green plant tissues, nuts, flaxseed, and rapeseed oil, whereas oily fish is the main source of EPA and DHA.

PUFAs from the diet are absorbed from the gut to the blood and are available for storage (in the adipose tissue), conversion into longer-chain PUFA (mainly in the liver), or energy production through $\beta$-oxidation. LA and ALA biosynthetic pathway to AA and EPA and DHA, respectively, involves a series of desaturation, elongation occurring in the endoplasmic reticulum (Fig. 1). The last step in DHA formation involves $\beta$-oxidation, occurring in peroxisomes. As ALA and LA use the same metabolic pathways to generate long-chain (LC) PUFA, there is a competition between these two pathways, with end products generated, at least somewhat, proportional to their precursors.

Generally speaking, LA and ALA poorly accumulate in tissues, as compared with AA and DHA, which is in line with their role as precursors to longer-chain PUFA. The rate of synthesis of ALA into EPA and DHA occurring mainly in the liver is considered to be low, with about $8 \%$ of ALA being converted to EPA and $1 \%$ to DHA. The enzymes necessary to metabolize ALA are present in the brain; however, the brain's major source of DHA is coming from the blood, as discussed later.

The brain is highly enriched in AA and DHA (Bazinet and Layé, 2014). Both n-3 and n-6 PUFAs are esterified in the sn-2 position into phospholipids, which are well known to play critical role in the structures and functions of brain cell membranes. Brain cell membrane contains mainly phosphatidylcholine, phosphatidylethanolamine, phosphatidylserine, phosphoinositides, and plasmalogens with specific PUFA profiles. At the level of the membrane, PUFAs undergo turnover due to the activity of phospholipase A2 (PLA2) and acyl-CoA lysophospholipid transferases. Two distinct groups of PLA2 are involved in the release of PUFA, namely the

\footnotetext{
ABBREVIATIONS: AA, arachidonic acid; AD, Alzheimer's disease; AEA, anandamide; ALA, $\alpha$-linolenic acid; AT, aspirin triggered; $\mathrm{A} \beta$, amyloid- $\beta$; BBB, blood-brain barrier; CNS, central nervous system; COX, cyclooxygenase; CSF, cerebrospinal fluid; DHA, docosahexaenoic acid; DHEA, docosahexaenoyl ethanolamide; DPA, docosapentaenoic acid; eCB, endocannabinoid; EFOX, electrophilic oxo-derivatives; EPA, eicosapentaenoic acid; EPEA, eicosapentaenoyl ethanolamide; ER, estrogen receptor; EV, extracellular vesicle; FABP, fatty acid-binding protein; FATP, fatty acid transport protein; GPR, G-coupled receptor; IL, interleukin; iNOS, inducible NO synthase; KO, knockout; LA, linoleic acid; LB, lipid bodies; LC, long chain; LOX, lipoxygenase; LPS, lipopolysaccharide; LT, leukotriene; lysoPC, lysophosphatidylcholine; LxA4, lipoxin A4; MaR, maresin; MHC, major histocompatibility complex; MMP, matrix metalloproteinase; NF, nuclear factor; NO, nitric oxide; NPD1, neuroprotectin D1; NSAID, nonsteroidal anti-inflammatory drug; PBMC, peripheral blood mononuclear cell; PG, prostaglandin; PLA2, phospholipase A2; PPAR, peroxisome proliferator-activated receptor; PUFA, polyunsaturated fatty acid; Rv, resolving; SPM, specialized proresolving mediator; TLR, Toll-like receptor; TNF, tumor necrosis factor; TX, thromboxane.
} 


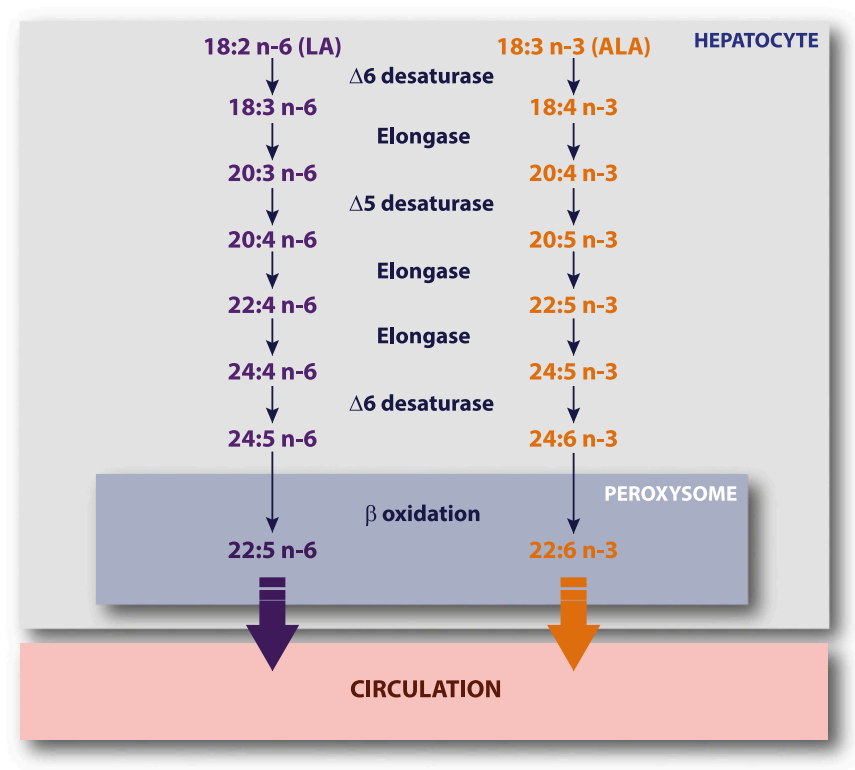

Fig. 1. Metabolic pathways of PUFAs. The precursors LA and ALA are metabolized into LC-PUFAs via several cycles of elongation and desaturation and one step of $\beta$-oxidation within the peroxisome. From there, LC-PUFAs are released into the bloodstream to reach target organs.

group IV cytosolic PLA2, which releases AA, and group VI calcium-independent phospholipase, which releases DHA. The free forms of PUFA are metabolized into specific derivatives [eicosanoids, specialized proresolving mediators, specialized proresolving mediator (SPMs), and endocannabinoids (eCBs)], which are key regulators of inflammation (Lukiw and Bazan, 2000; Buckley et al., 2013; Serhan, 2014; Calder, 2015; DiMarzo et al., 2015; Witkamp, 2016). AA derivatives mainly display proinflammatory activities, albeit there are some exceptions, whereas DHA derivatives are anti-inflammatory and proresolving.

More recently, particular attention has been paid to these derivatives in the regulation of neuroinflammation. Neuroinflammation is a double-edged sword that exerts both beneficial and detrimental effects on neurons. Microglia, the brain-resident innate immune cells, are thought to be protective when properly activated. However, inadequate activation worsens neuropathological processes and increases neuronal death, as observed in neurodegenerative diseases. The complexity of the microglia phenotype and its regulation may account for its protective and detrimental effects toward neurons, as discussed elsewhere. An increasing body of evidence suggests that PUFA and their derivatives may be involved in microglia regulation and the control of neuroinflammation (Layé, 2010; Bazinet and Layé, 2014). Furthermore, because of the high quantity of PUFA in the brain, specific alterations in PUFA metabolism in the brain may play an important role in neuroinflammatory events.

In this review, we will present recent updates on the metabolism and role of endogenous AA, DHA, and their bioactive derivatives involved in the resolution of neuroinflammation, with a specific focus on microglial cells. In particular, we will discuss how PUFAs can be used to target microglia and how drugs targeting PUFA metabolism regulate neuroinflammation. We will highlight recent controversies and examine adverse events.

\section{Definition of PUFAs}

Lipids represent $33 \%-40 \%$ of the energy intake in France and the United States (Malvy et al., 1999; Simopoulos, 2011). They are essentially found (90\%-95\%) in the form of triacylglycerides, a structure consisting of a glycerol backbone and three fatty acids. They are also found in the form of phospholipids, in which the fatty acid in the three position on the glycerol is replaced by a phosphorylated functional group. The structure of a triacylglyceride and a phospholipid is shown in Fig. 2. Fatty acids have many physiologic roles. They are the primary source of energy storage for tissues and, as components of membrane phospholipids, play a structural role. Fatty acids of phospholipids are also mobilized by the cells as precursors of lipid mediators, which regulate many physiologic processes, such as inflammation. There are three families of fatty acids classified according to the number of double bonds on their carbon chain they contain: the saturated ones (no double bond), the monounsaturated ones (one double bond), and the polyunsaturated ones (two or more double bonds). In rodents, the brain contains $36 \%-46 \%$ saturated fatty acids, $18 \%-33 \%$ monounsaturated fatty acids, and 18\%-28\% PUFAs (Joffre et al., 2016).

\section{A. PUFA Metabolism}

As previously described, PUFAs are classified into two main categories, the n-6 PUFAs and the n-3 PUFAs. LA (18:2 n-6) and ALA (18:3n-3) are, respectively, the precursors of these two series. They are called essential fatty acids because mammals cannot synthesize them. In vivo, these precursors can be metabolized by series of elongation, desaturation, and a $\beta$-oxidation-producing PUFA with additional unsaturations and/or carbon atoms sometimes refered to as LC-PUFA (Fig. 1). LC-PUFA biosynthesis requires position-specific $\Delta 6$ and $\Delta 5$ desaturases and elongases, and the participation of both microsomes and peroxisomes (Sprecher, 2000). LC-PUFA biosynthesis takes place predominately in the liver, despite the brain possessing the enzymatic equipment necessary for their synthesis. Both n-6 and n-3 PUFA share the same enzymatic equipment for the biosynthesis of the LC-PUFAs and can thus compete (Simopoulos, 2011). The main metabolites for the n-6 and n-3 family are AA (20:4 n-6) and DHA (22:6 n-3), respectively (Kitajka et al., 2004; Joffre et al., 2016). EPA (20:5 n-3) is also an important n-3 PUFA metabolite, despite its low level in the brain because of its rapid $\beta$-oxidation (Chen and Bazinet, 2015). Docosapentaenoic acid (DPA; 22:5 n-6) for the $n-6$ 

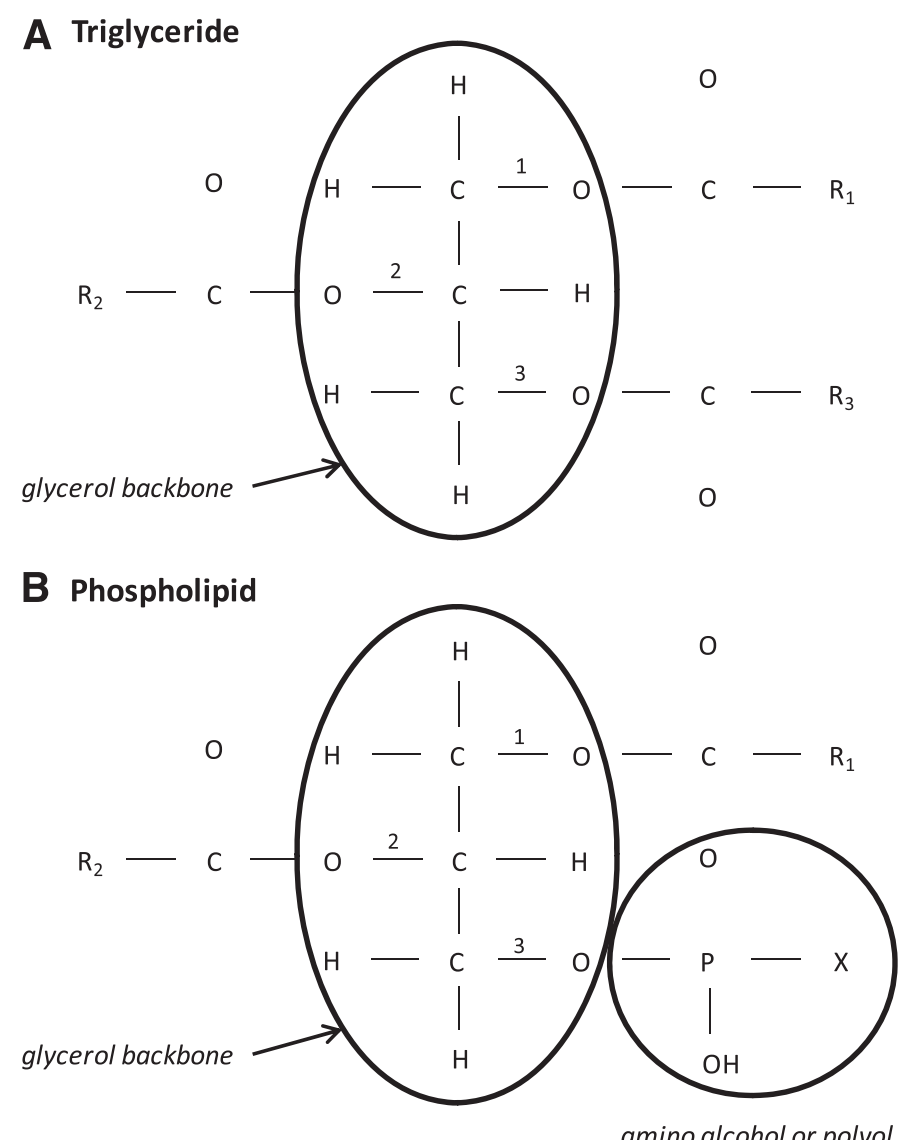

Fig. 2. Structure of the two main forms of lipids in food, the triacylglyceride (A) and phospholipid (B). Triacylglycerides and phospholipids contain a glycerol backbone on which fatty acids are esterified (R1, $\mathrm{R} 2$, and R3 in positions 1,2 , and 3 for the triglyceride and R1 and R2 for the phospholipid). On the third position of the phospholipid was esterified a phosphate group associated to a radical, which may be an amino alcohol or a polyol.

family is also relevant because it replaces DHA during dietary n-3 PUFA deficiency.

\section{B. Dietary Origin of PUFAs}

AA and DHA come mainly from the diet. Although humans can synthesize them from LA and ALA, respectively, that are found in vegetables, the conversion efficiency is very low $(<1 \%)$ even in healthy adults (Kidd, 2007; Plourde and Cunnane, 2007). In the western diet, there is thought to be an imbalance between $n-6$ and $n-3$ PUFAs, leading to a n-3 PUFA consumption 12-20 times lower than n-6 PUFA consumption (Simopoulos, 2002, 2011). This is due to the increased industrialization in the developed nations accompanied by changes in dietary habits. It is particularly characterized by an increase in LA, abundant in many vegetable oils (60\%-65\% in sunflower oil for example) (Orsavova et al., 2015 ) and AA, found in meats (5\%-10\%) and eggs (15\%) (Taber et al., 1998; Meyer et al., 2003), together with relatively low intakes of ALA, found in some green vegetables, rapeseed oil (10\%) (Lewinska et al., 2015), and nuts, and EPA and DHA abundant in fatty fish (18.7\%
EPA plus DHA in salmon, 32.9\% EPA plus DHA in tuna) (Strobel et al., 2012). A high intake of LA associated with a low intake of ALA leads to the accumulation of n-6 PUFA, including AA. In the case of severe n-3 PUFA deficiency, the expression of desaturases and elongases is upregulated in the liver to compensate and provide DHA to the brain (Igarashi et al., 2007). In addition, under dietary n-3 PUFA deficiency, the half-life of brain DHA is increased by twofold (Demar et al., 2004).

Although not universally accepted, several dietary recommendations state a ratio LA/ALA close to 4-5 and a $\sim 500 \mathrm{mg} / \mathrm{d}$ supply in EPA and DHA sufficient to meet the n-3 PUFA needs of the body and to protect against cardiovascular disease risk (Burdge, 2004; Lucas et al., 2009). Preclinical and clinical studies indicate that increasing dietary ALA and reducing LA are beneficial in increasing n-3 LC-PUFA bioavailability (Blanchard et al., 2013; Taha et al., 2014). Concerning the bioavailability of dietary EPA/DHA in the form of phospholipids (krill oil source) or triacylglycerides (fish oil source), no clear evidence actually identifies a better source (Salem and Kuratko, 2014; Yurko-Mauro et al., 2015) to date.

\section{Accumulation and Regional Distribution in the Brain}

AA and DHA accumulate during brain development, especially during the perinatal period: in humans between the beginning of the third trimester and 2 years of age and in rodents between the 7 th and the 21st postnatal day (Clandinin et al., 1980). These periods correspond to the rapid neuronal maturation, synaptogenesis, and gray matter expansion (Morgane et al., 1993; Giedd et al., 1999).

LC-PUFAs vary across brain regions (Delion et al., 1994; Carrié et al., 2000; McNamara et al., 2009; Joffre et al., 2016). For example, in the adult C57BL6/J mice, the highest level of AA is found in the hippocampus (10.2\%), followed by the prefrontal cortex (9.7\%), the hypothalamus $(8.5 \%)$, the cortex $(7.7 \%)$, the cerebellum $(6.5 \%)$, and the brain stem (5.5\%) (Joffre et al., 2016). The highest level of DHA is found in the prefrontal cortex (14.3\%) and in the hippocampus (13.7\%), followed by cerebellum $(12.2 \%)$, cortex (11.9\%), hypothalamus (10.1\%), and brain stem (8.2\%) (Joffre et al., 2016). Then the AA/DHA ratio varies from 0.75 to 0.85 in the hypothalamus and hippocampus to 0.54 in the cerebellum. These variations may be due to different LC-PUFA entry mechanisms into the brain or to different incorporation into membranes of cells composing the structure considered.

Brain DHA levels are comparable in human and mice: between $12.3 \%$ and $15.9 \%$ in the prefrontal cortex of rats and mice (Moriguchi et al., 2001; Xiao et al., 2005; Joffre et al., 2016) and between $14.1 \%$ and $15.9 \%$ in postmortem frontal cortex in human (Hamazaki et al., 2015, 2016). However, Cortie et al. (2015) reported that mouse mitochondria contain higher levels of PUFA as compared with those from humans. 
Differences in brain DHA levels depending on brain structures, dietary intake, gender, and aging may have consequences on inflammatory processes because n-3 LC-PUFAs have immunomodulatory properties (Layé, 2010).

\section{Intrinsic (Age, Sex) and Extrinsic (Diet) Factors Influencing Brain PUFA Content}

The brain LC-PUFA levels fluctuate with differential extrinsic and intrinsic factors. Brain LC-PUFA levels are modified by the fatty acid composition of the diet (Calder, 2007). Indeed, low consumption in n-3 PUFAs induces a decrease in brain DHA levels (Connor et al., 1990; Carrié et al., 2000; Larrieu et al., 2012; Joffre et al., 2016) and an increase in brain DPA (22:5n-6) and often AA levels (Connor et al., 1990; Larrieu et al., 2012), whereas genetic-driven enrichments in n-3 PUFAs induce the opposite (He et al., 2009; Boudrault et al., 2010; Orr et al., 2010; Bousquet et al., 2011; Joffre et al., 2016). These modifications impact all brain structures, but some of them are more affected than others: the prefrontal cortex and the hippocampus, which contain the highest DHA content and are the most sensitive, whereas the hypothalamus, which contains the lowest DHA, is the least sensitive. These differences may be attributed to the evolution of brain performance (Crawford et al., 1999; Broadhurst et al., 2002).

Furthermore, several studies conducted in humans and rodents suggest that LC-PUFA levels vary with gender. Indeed, DHA is higher in females than in males, independently of the status of dietary n-3 PUFA (Lin et al., 2016). This gender difference is attributed to the levels of hormones that increase the mRNA expression of fatty acid desaturase 2 , the gene encoding $\Delta 6$ desaturase (Giltay et al., 2004; Magnusardottir et al., 2009). It was specifically found that DHA was higher in phosphatidylcholine and phosphatidylethanolamine of platelets in women (Geppert et al., 2010). Differences between males and females are also reported in rat liver and cerebral cortex (Extier et al., 2010).

In addition, age influences brain LC-PUFA levels, as aging is often characterized by a decrease in LC-PUFAs (Calderini et al., 1983; Lopez et al., 1995; Zhang et al., 1996; Favreliere et al., 2003; Little et al., 2007; McNamara et al., 2008; Labrousse et al., 2012; Ledesma et al., 2012; Moranis et al., 2012). The decrease in brain DHA is accentuated in aged animals fed a n-3 PUFA-deficient diet (Joffre et al., 2016).

\section{Mechanisms of Entry of PUFAs into the Brain}

\section{A. Plasma Pools for Brain DHA Supply}

As previously mentioned, the brain is enriched with PUFAs, particularly DHA and the n-6 PUFA AA. Although the brain can synthesize saturated and monounsaturated fatty acids, it must rely on uptake of either the preformed DHA and AA or their dietary precursors,
ALA and LA, respectively, which can be converted to DHA and AA within the brain. Whereas the brain does have the capacity to synthesize DHA and AA, their rate of synthesis relative to uptake from the plasma is low, suggesting that uptake from plasma and not synthesis within the brain is the major source (DeMar et al., 2006; Igarashi et al., 2007). Furthermore, although the liver can upregulate its ability to synthesize DHA, especially under conditions of low dietary n-3 PUFA intake, the brain does not upregulate DHA synthesis under these conditions, further demonstrating the need for a constant plasma supply to the brain (Igarashi et al., 2007).

Within the blood, DHA can be free (sometimes refered to as unesterified) or esterified to triacylglycerides, phospholipids, and cholesteryl esters. Whereas red blood cells contain esterified DHA, this pool is generally not thought to contribute DHA, at least not directly, to the brain. The vast majority of DHA that is esterified in the blood occurs as circulating lipoproteins, but there are small pools of free esterified DHA, especially lysophosphatidylcholine containing DHA (Rapoport et al., 2001). The plasma pools that contribute DHA to the brain have been and remain somewhat controversial (for review, see Mitchell and Hatch, 2011), and, below, we will attempt to highlight potential reasons for disagreement. Although it was originally hypothesized that lipoprotein containing DHA was the major source supplying the brain with DHA, knockout (KO) of either the low-density or very-low-density lipoprotein receptors does not decrease brain DHA (or AA) concentrations (Chen et al., 2008; Rahman et al., 2010). However, caution must be taken with interpreting these lifelong $\mathrm{KO}$ studies as compensation via another mechanism could maintain brain DHA concentrations. However, it is clear that these lipoprotein receptors are not necessary for maintaining brain DHA levels and other mechanisms must exist. As an attempt to identify the major plasma pools for supplying DHA to the brain, we used a kinetic model in combination with labeled DHA, in rats, where unesterified DHA is infused i.v. to achieve a steady state, and calculated the rate of uptake of unesterified DHA to the brain (Chen et al., 2015). We then administered radiolabeled DHA by gavage, which labels multiple plasma pools as well as the brain. We found that the coefficient of uptake or the rate of uptake from the unesterified pool, alone, was sufficient to explain the rate of uptake of all the labeled plasma pools upon oral administration. Or more, simply put, it appeared as if the unesterified pool was the major source, if not the only source, supplying the brain upon oral administration. We then used another kinetic model to calculate the rate at which DHA enter the brain and found the rate of DHA exiting the brain to be similar to the uptake rate from the plasma unesterified pool. Because DHA is not accumulating in the adult rodent brain, this suggested that unesterified DHA is, again, the major pool supplying the brain. Importantly, 
it had been reported that upon acute i.v. administration of labeled unesterified DHA or DHA esterified to lysophosphatidylcholine (lysoPC), more radioactivity, presumably from DHA, was present in the brain of rodents receiving lysoPC-containing DHA upon several hours (Thies et al., 1994; Lagarde et al., 2001). Furthermore, evidence that Mfsd2a, a protein that facilitates the uptake of lysoPC containing DHA into the brain, KO had lower brain DHA levels compared with wild-type controls combined with observation of more radiolabeled DHA entering the brain suggested that lysoPC containing DHA was the major plasma source supplying the brain (Nguyen et al., 2014). However, upon close examination, it was determined that i.v. administered lysoPC containing DHA has a longer plasma half-life than unesterified DHA; thus, more of it is directed to the brain, albeit at a much slower rate than unesterified DHA (Chen et al., 2015). This is of significance as, although the net rate of plasma lysoPC containing DHA is lower than unesterified DHA in vivo, i.v. lysoPC containing DHA would be useful for targeting the brain with DHA and possibly other lipids (Chauveau et al., 2011; Lo Van et al., 2016).

\section{B. Mechanisms of DHA Entry into the Brain}

Similar to the plasma pools that supply the brain, there has been considerable debate on the mechanisms by which DHA is uptaken into the brain. Some of the confusion may be the result of studies that have failed to differentiate direct transport from uptake, which is often coupled to metabolism. Although it is clear that fatty acids, including DHA, do not need a protein to cross the cell membrane, several proteins have been implicated in facilitating the uptake of DHA. These include members of the fatty acid transport protein (FATP) family, CD36, Mfsd2a, and fatty acid-binding proteins (FABP).

Whereas earlier work suggested a role of FATPs in the uptake of fatty acids, and hence their naming, it was later realized that they possessed acyl CoA synthetase activity and were, likely, quenching fatty acids and/or facilitating their metabolism, which led to an increase in fatty acid uptake, but not transport per se (DiRusso et al., 2005; Jia et al., 2007; Mashek et al., 2007). An analogy can be drawn from hexokinase or glucokinase, which phosphorylates glucose, increasing glucose uptake, whereas glucose transport is mediated by the GLUT proteins. Furthermore, it is important to note that the transport of fatty acids across the membrane occurs at rates commonly measured in the low msec range, and studies lasting several seconds, let alone minutes, do not have the temporal resolution to separate transport from uptake and metabolism, especially in in vivo studies (Hamilton 1998). Nevertheless, it has become clear that members of the FATP family, especially FAPT1, are important for DHA uptake (Ochiai et al., 2017). CD36 has remained more elusive in the transport of fatty acids, but recent studies suggest that CD36 is not a fatty acid transporter and, likely, also facilitates the uptake of fatty acids secondary to changes in metabolism (Xu et al., 2013a; Jay and Hamilton 2016). KO of Mfsd2a leads to approximately $50 \%$ less neurons and brain DHA as compared with wild-type controls, and Mfsd2a appears critical for the brain uptake of LPC, including those esterified with DHA (Nguyen et al., 2014). However, similar to the previously mentioned proteins, caution must be taken, as the studies do not have the temporal resolution to distinguish between transport and uptake secondary to changes in metabolism. Members of the FABP family facilitate the uptake of fatty acid secondary to their metabolism and are important in the trafficking of fatty acids, the regulation of eCB signaling among others, and we refer the reader to several recent reviews (Moulle et al., 2012; Elsherbiny et al., 2013; Schroeder et al., 2016). Of particular interest are recent studies on FAPB-5, which facilitates the uptake of DHA into the brain, and KO reduces brain DHA by approximately $15 \%$ and is associated with impaired working and shortterm memory (Pan et al., 2015, 2016). Although the precise mechanisms by which DHA is transported and uptaken into the brain have been and still are of considerable debate, it is evident that numerous candidate mechanisms have been identified that could be targeted to alter the uptake of DHA into the brain and ultimately brain levels affecting neuronal survival and behavior.

\section{Anti-Inflammatory Activities of n-3 PUFAs in the Brain}

\section{A. General Evidence in Humans and Animal Models of Brain Pathologies}

Inflammation in the brain is beneficial to maintain organ homeostasis in response to infection. Brain inflammation involves microglial cells, the resident macrophages of the central nervous system (CNS) (Aloisi, 2001). When activated, these cells produce pro- and anti-inflammatory cytokines. However, when the production of proinflammatory cytokines is sustained, these molecules become neurotoxic, leading to neuronal damage involved in many brain pathologies (Woodroofe and Cuzner, 1993; Woodroofe, 1995; Blais and Rivest, 2003; Laye, 2010; Solito and Sastre, 2012). Hence, limiting inflammation is of great importance, and the identification of mediators able to do that may provide new targets in brain damage prevention and treatment.

A large number of studies support the hypothesis that n-3 LC-PUFAs or their products are candidates for limiting neuroinflammation. Indeed, n-3 LC-PUFAs downregulate inflammatory gene expression, such as those of cytokine or enzymes involved in the synthesis of eicosanoids, while inducing lipid mediators involved in the resolution of inflammation (Calder, 2006; Serhan, 2014). 
In animal models of acute and chronic inflammation, the effects of n-3 LC-PUFAs and their bioactive mediators have been demonstrated at the periphery (Serhan and Chiang, 2013) and in the brain (Orr and Bazinet, 2008; Rapoport, 2008; Layé, 2010; Bazinet and Layé, 2014). In humans, higher n-3 LC-PUFA consumption is associated with a lower risk of inflammation-associated neurologic disorders (reviewed in Orr and Bazinet, 2008; Layé, 2010; Bazinet and Layé, 2014). Several epidemiologic and observational studies report that subjects with higher n-3 LC-PUFA levels in blood have lower proinflammatory cytokine production (Ferrucci et al., 2006; KiecoltGlaser et al., 2007, 2011; Farzaneh-Far et al., 2009; Alfano et al., 2012). Moreover, supplementation of patients diagnosed with Alzheimer's disease (AD) with a DHA-rich diet led to a reduced release of proinflammatory cytokines from blood mononuclear leukocytes (Vedin et al., 2008). In vivo, high levels of brain DHA are linked to reduced expression of proinflammatory cytokines in several rodent models of acute or chronic neuroinflammation, such as systemic administration of the bacterial endotoxin lipopolysaccharide (LPS), brain ischemia-reperfusion, spinal cord injury, or aging (see Orr et al., 2013b for review). In addition, a diet rich in EPA attenuates the production of the proinflammatory cytokine interleukin (IL)- $1 \beta$ and improves synaptic plasticity impairment in the hippocampus of old rats (Martin et al., 2002; Lynch et al., 2007). Aged mice exposed to a diet rich in EPA/DHA for 2 months express less proinflammatory cytokine [IL-1 $\beta$, IL-6, and tumor necrosis factor (TNF)- $\alpha$ compared with mice fed with a diet with a ratio of LA/ALA of 5] (Labrousse et al., 2012). Importantly, the reduction of neuroinflammation linked to diets enriched in n-3 LC-PUFA is associated with improvement of spatial memory deficits (Song et al., 2004; Labrousse et al., 2012). Moreover, increasing brain DHA by genetic or dietary means is associated with protection against LPS-induced proinflammatory cytokine production induced by LPS (Mingam et al., 2008b; Delpech et al., 2015a,b), brain ischemiareperfusion (Lalancette-Hebert et al., 2011), or spinal cord injury (Huang et al., 2007; Lu et al., 2013). DHA's protective activity on neuroinflammation is linked to its direct effect on microglia, as suggested by in vitro studies. For example, DHA decreases the LPS-induced nuclear factor $(\mathrm{NF}) \kappa \mathrm{B}$ activation and, as a consequence, the production of IL- $1 \beta$ and TNF- $\alpha$ (De Smedt-Peyrusse et al., 2008) and chemokines ( $\mathrm{Lu}$ et al., 2013) by microglia. In addition, DHA enhances phagocytosis of AD-related amyloid- $\beta(\mathrm{A} \beta)$ 42 by human microglial and decreases inflammatory markers (Hjorth et al., 2013). Moreover, DHA is able to normalize the LPS-induced abnormalities in microglia (Chang et al., 2015). N-3 PUFA activity on microglia is discussed later.
Conversely, low dietary intake of n-3 PUFA has deleterious consequences in the brain, especially during the perinatal period of brain development. For instance, dietary n-3 PUFA deficiency beginning at the first day of gestation decreases DHA level, alters microglia phenotype and motility, and increases brain proinflammatory cytokine IL- 6 and TNF- $\alpha$ expression in the offspring's brain of mice and rats (McNamara et al., 2010; Madore et al., 2014). In mice, the early-life exposure to a n-3 PUFA-deficient diet leads to spatial memory impairment at adulthood (Moranis et al., 2012), whereas this is not the case in adult mice with a n-3 PUFA deficiency starting at weaning (Delpech et al., 2015b). However, adult mice fed a n-3 PUFAdeficient diet starting at weaning are more vulnerable to inflammatory insult as spatial memory, synaptic plasticity, microglia phenotype, and brain cytokine production is altered in response to LPS (Delpech et al., 2015b). Altogether these results pinpoint the role of dietary n-3 PUFA deficiency in regulating brain proinflammatory cytokine production and microglia profile in the absence of overt infection (sterile inflammation, development, aging) and inflammatory situation (LPS administration, stroke).

\section{B. Overview of DHA Anti-Inflammatory/ Proresolving Mechanisms}

Anti-inflammatory/resolution activities of n-3 PUFAs are potent with a variety of overlapping and/or additive mechanisms occurring either directly on the membrane, via modulation of signaling pathways or control of gene expression, or indirect through the synthesis of derivatives reviewed elsewhere (Calder, 2011; Serhan, 2017a).

1. Membrane and Signaling Effects. As described in the introduction, DHA is incorporated in membrane phospholipids. In direct link with its disordered molecular structure, DHA is believed to adopt a specific molecular orientation in the membrane likely to modify membrane domain organization and protein activity (reviewed in Shaikh, 2012). Notably, formation of DHAenriched nanodomains in the membrane or incorporation of DHA into lipid rafts, a membrane-signaling platform rich in cholesterol and sphingomyelin, disrupts receptor-signaling interactions. In glial cells, changes in membrane fluidity due to DHA level have consequences on several proinflammatory receptor localization and associated signaling cascades. De SmedtPeyrusse et al. (2008) reported that, in microglia, DHA impairs membrane location of the LPS receptors CD14 and Toll-like receptor (TLR)4, which in turn decreases proinflammatory activity of LPS. Rockett et al. (2011) showed that increased $n-3$ LC-PUFA consumption disrupts B cell lipid-raft clustering. The membrane reorganization consequence of DHA increase is in line with in vitro data showing that DHA modulates the activation of several proinflammatory transcription factors $(\mathrm{NF} \kappa \mathrm{B}$; mitogen-activated phosphate kinase 
p38; c-Jun N-terminal kinases) in microglia (De SmedtPeyrusse et al., 2008; Ma et al., 2009; Lu et al., 2013; Chang et al., 2015). In microglia, DHA upregulates peroxisome proliferator-activated receptor (PPAR) $\gamma$ nuclear translocation, a potent modulator of microglia (Ajmone-Cat et al., 2010; Corsi et al., 2015).

DHA directly modulates inflammatory gene expression via surface or intracellular receptors, as reported in inflammatory cells (Calder, 2011). Notably, DHA binds to G-coupled receptors (GPR) 120 and 40 and PPAR $\gamma$, and, in turn, DHA regulates their expression (Im, 2012; Yamashima, 2012; Calder, 2013, 2015). GPR120 and PPAR $\gamma$ mediate DHA anti-inflammatory activity (Calder, 2011), including in the brain, as described above. Overall, these results highlight that the antiinflammatory activity of DHA is partially attributable to its effect on cell membrane reorganization and/or through its effect on specific receptors. Although EPA is esterified in cell membranes, including those of microglial cells (De Smedt-Peyrusse et al., 2008), its effect on raft reorganization or GPR has not been extensively studied in relation to its anti-inflammatory activity (Williams et al., 2012).

\section{N-3 LC-PUFA Derivatives.}

a. Oxylipins. Some of the anti-inflammatory activities of n-3 PUFAs are attributed to eicosanoids (a subclass of oxylipins), the signaling molecule by the enzymatic and nonenzymatic oxidation of EPA and DHA (Fig. 3) (De Roos et al., 2009; Arita, 2012). The main EPA-derived mediators include 3-series prostaglandin (PG), 5-series leukotrienes (LT), and 3-series thromboxane (TX), and are reported to be relatively nonactive (Fig. 3). DHA is also converted into 3-series PG (Fig. 3). EPA- and DHA-derived eicosanoids are biologically less active than the one derived from AA (Calder, 2002). As an example, PGE3 is much less effective than PGE2 to induce IL-6 and cyclooxygenase (COX)-2 expression in macrophages, despite binding to the same receptor (Bagga et al., 2003). In addition, when copresent, EPA-derived eicosanoids antagonize those synthesized from AA. Moreover, EPA counteracts AA-derived eicosanoid production, as EPA is a competitive inhibitor for the enzymes involved (Calder, 2002). First, EPA inhibits the activity of $\Delta 5$-desaturase, converting dihomo $\gamma$-linolenic acid to AA. EPA also inhibits the activity of PLA2, thus preventing the release of AA; the activity of COX-2 generating the PG, prostacyclins, and TX (Needleman et al., 1979; Obata et al., 1999); and the activity of 5-lipoxygenases (LOX) that generates the LT (Sperling et al., 1993). Overall, EPA reduces both the proportion of AA and the production of proinflammatory eicosanoids derived from AA. DHA also is able to reduce the production of PGE2 and LTB4 derived from AA in stimulated peripheral blood mononuclear cells (Kelley et al., 1999). In addition, eicosanoids synthesized from AA and EPA act in competition as they share the same G protein-coupled receptors.
Recently, SPM derived from n-3 LC-PUFAs have gained much more attention. These lipid mediators have both anti-inflammatory and proresolving properties without immune suppression (Serhan et al., 2002, 2008, 2014). They act in physiologic doses around the nanomolar level as compared with DHA, which acts at micromolar levels. Among the resolvins, resolving D1 (RvD1, 7S,8R,17Strihydroxy-4Z,9E,11E,13Z,15E,19Z-docosahexaenoic acid) and resolvin E1 (RvE1, 5S,12R,18R-trihydroxy$6 \mathrm{Z}, 8 \mathrm{E}, 10 \mathrm{E}, 14 \mathrm{Z}, 16 \mathrm{E}$-eicosapentaenoic acid) are of particular interest in the resolution of inflammation because they actively turn off the inflammatory response (Fig. 3) (Fredman and Serhan, 2011). They are thought to underlie many of the beneficial effects attributed to their precursors (Calder, 2013; Serhan and Chiang, 2013; Bazinet and Laye, 2014; Headland and Norling, 2015). They act via cell surface G proteincoupled receptors: GPR32 and ALX/FPR2 for RvD1, and chemoattractant receptor 23 for RvE1 (Zhang and Spite, 2012). They were mainly studied in peripheral immune cells, both in vitro and in vivo. In vitro, they act on macrophages to stimulate the clearance of apoptotic cells and inflammatory debris, inhibit the expression of the proinflammatory cytokines, and block neutrophil infiltration (Arita et al., 2005; Schwab et al., 2007; Fredman and Serhan, 2011; Zhang and Spite, 2012). RvE1 inhibits the activity of $\mathrm{NF}_{\kappa} \mathrm{B}$ and the subsequent production of proinflammatory cytokines (Xu et al., 2013b; Rey et al., 2016). RvD1 also displays its anti-inflammatory activity through miRNA modulation (Rey et al., 2015). In vivo, RvD1 decreases proinflammatory cytokine production in acute models of kidney injury (Chen et al., 2014) or lung (Wang et al., 2011a, 2014; Zhou et al., 2013; Yaxin et al., 2014 ), and in a model of allergic airways (Rogerio et al., 2012). RvE1 also modifies cytokine production in experimental models of colitis (Arita et al., 2005) and peritonitis (Schwab et al., 2007) and significantly modulates the inflammatory profile and activation of microglia (Harrison et al., 2015).

SPMs derived from DHA include neuroprotectin D1 (NPD1) and maresin 1 (MaR1) (Bazan, 2006; Bannenberg and Serhan, 2010; Bazan et al., 2012). NPD1 protects the brain toward leukocyte infiltration, COX-2 expression, cytokine production, and microglia activation (Hong et al., 2003; Marcheselli et al., 2003, 2010; Lukiw et al., 2005; Orr et al., 2013). MaR1 reduces cytokine production in human peripheral blood lymphocytes (Chiurchiu et al., 2016). It protects against cerebral ischemia/reperfusion injury through the modulation of the proinflammatory response (Xian et al., 2016). It downregulates $\mathrm{A} \beta_{42}$-induced inflammation in human microglial cells in culture through the stimulation of $\mathrm{A} \beta$ phagocytosis (Zhu et al., 2016).

b. Endocannabinoids. N-3 LC-PUFAs can also exert their effect through the modulation of the eCB system, (Meijerink et al., 2013; Bazinet and Layé, 2014; Kuda, 2017; Nadjar et al., 2017). eCBs are synthesized from PUFA, the most well-known being anandamide (AEA) 


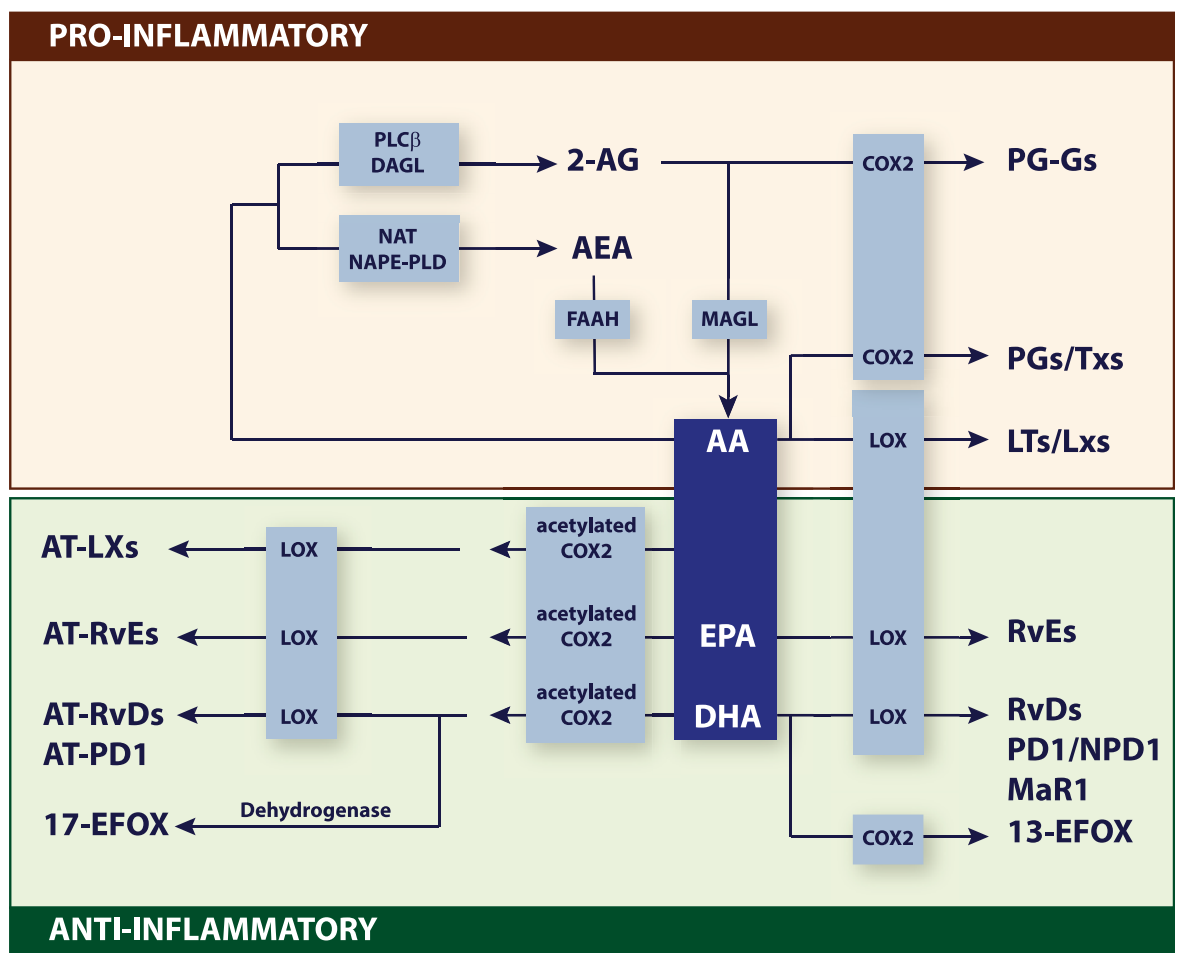

Fig. 3. Conversion of LC-PUFAs into lipid mediators. AA, DHA, and EPA released from the membrane can be metabolized into various classes of derivatives via COX and LOX activity. AA is always converted into proinflammatory metabolites, whereas DHA and EPA are precursors of antiinflammatory mediators. Only in situations in which COX-2 is acetylated (treatment with aspirin), LC-PUFAs (AA, DHA, and EPA) can be converted into AT mediators that are all anti-inflammatory. AA can also be metabolized into endocannabinoids (2-arachidonoyl and AEA) that are pro- or antiinflammatory depending on the receptor to which they bind.

and the 2-arachidonoyl derived from AA. However, n-3 LC-PUFAs are also precursors of DHA- and EPAderived eCBs, namely docosahexaenoyl ethanolamide (DHEA or synaptamide) and eicosapentaenoyl ethanolamide (EPEA). The formation of these compounds in mice is increased in various tissues, including the brain after consumption of a fish oil-rich diet and in the plasma of volunteers supplemented with DHA and EPA (see Meijerink et al., 2013 for review). Furthermore, the level of DHEA in the brain is higher than that of AEA even in animals fed a control diet (see Meijerink et al., 2013 for review). The immunomodulatory effect of DHEA has been demonstrated in the brain and at the periphery. Indeed, in the brain, Park et al. (2016b) showed that DHEA is a potent suppressor of LPSinduced neuroinflammation in mice, by enhancing cAMP/protein kinase A signaling and inhibiting $\mathrm{NF} \kappa \mathrm{B}$ activation. In macrophages, Meijerink et al. (2011, 2015) showed that DHEA modulates inflammation by reducing monocyte chemoattractant protein-1, nitric oxide (NO), and eicosanoid production. Moreover, Rossmeisl et al. (2012) suggested a possible role for DHEA in modulating inflammation in adipocytes. Importantly, DHEA can be oxidized to form derivatives with anti-inflammatory properties (Yang et al., 2011; Shinohara et al., 2012; Kuda, 2017).

eCBs bind mainly to the eCB receptors CB1 and CB2 (Piomelli and Sasso, 2014) that are expressed in neurons and glial cells and more specifically in microglial cells (Stella, 2009). In microglial cells, CB2 is more highly expressed than CB1 (Nunez et al., 2004). It was already shown that in inflammatory conditions eCBs act via $\mathrm{CB} 2$, with the role of $\mathrm{CB} 1$ remaining unclear (Mecha et al., 2015). The importance of CB2 in regulating microglia activity was demonstrated in vivo and in vitro. $\mathrm{CB} 2$ knockout $(\mathrm{KO})$ mice microglia lose their phagocytic activity, and microglia motility is reduced in presence of a CB2 antagonist (Walter et al., 2003).

All of these studies highlight the central role of $n-3$ LC-PUFA and their derivatives in the regulation of inflammation, with emerging data in the brain, especially through their effect on microglia.

\section{Microglia as a Target for n-3 PUFAs and SPMs}

Microglia are a glial cell of myeloid origin whose role is to maintain brain homeostasis in a sex-, age-, and region-dependent manner (Hanisch and Kettenmann, 2007; Tay et al., 2017). Microglia are a highly plastic and multitasking cell, important from brain development to pathologic conditions, via inflammatory and noninflammatory responses (Ransohoff and Brown, 2012). Any situation leading to undesirable microglial activity at different stages of life could severely impair brain function. During development, yolk sac-derived microglia colonize the brain and spread evenly in the whole 
CNS, where they shape neuronal circuits (Paolicelli et al., 2011; Schafer et al., 2012). In the adult brain, microglia sense the microenvironment with their processes in search for nonhomeostatic signals, and they also regulate neuronal architecture and function (Davalos et al., 2005; Nimmerjahn et al., 2005; Wake et al., 2009; Tremblay et al., 2010; Sipe et al., 2016). Under pathologic conditions, unusual/danger signals trigger microglial response, including release of inflammatory factors and/or redirection of its phagocytic activity to the clearance of hazardous factors (Ransohoff and Brown, 2012; Sierra et al., 2014; Tay et al., 2017). Understanding how n-3 PUFAs modulate microglial phenotypes and functions is a major challenge for future development of innovative lipid-based therapies with positive effects on physiology and behavior.

\section{A. Modulation of Microglial Function by n-3 PUFAs}

1. In Vitro Evidence. N-3 PUFAs are potent modulators of microglial functions (Nadjar et al., 2017). The first evidence came in 2007 from an in vitro study in which microglial cells (BV2 cell line) were incubated with or without EPA for 60 minutes prior to LPS application, and their inflammatory response was analyzed (Moon et al., 2007). EPA dose-dependently inhibited the expression of the two inflammatory enzymes, inducible NO synthase (iNOS) and COX-2, as well as the subsequent production of $\mathrm{NO}$ and $\mathrm{PGE}_{2}$ by BV2 cells. EPA also dampened the production of proinflammatory cytokines (IL- $1 \beta$, IL- 6 , and TNF- $\alpha$ ). This report was followed by another study in which primary cultures of rat microglia were incubated simultaneously with LPS and n-3 PUFAs (Liuzzi et al., 2007). The authors measured the LPS-mediated induction of the matrix metalloproteinase (MMP) 9 in presence or in absence of a mixture of EPA and DHA. MMP9 is an endopeptidase that degrades the extracellular matrix, and as such plays a role in inflammation by regulating processes such as cell motility, blood-brain barrier (BBB) disruption, cell infiltration, etc. Application of n-3 PUFAs concomitantly to LPS on microglial cells was sufficient to significantly reduce MMP9 expression and activity, in a dose-dependent manner (Liuzzi et al., 2007).

Since then, a total of 16 publications on various in vitro models brought converging evidence on the anti-inflammatory action of n-3 PUFAs on microglia (Nadjar et al., 2017). They also revealed new regulatory roles of n-3 PUFAs on these cells, such as modulation on microglial phenotype, migration, phagocytosis, autophagy, or lipid bodies accumulation, as well as some of the molecular mechanisms implicated (extensively reviewed in Nadjar et al., 2017). Briefly, whatever the inflammatory challenge applied on these cells (TLR3-4 or 7 agonists, $\mathrm{A} \beta$, interferon- $\gamma$, hypoxia, or myelin), all studies reported a dose-dependent decrease in the production of proinflammatory factors (cytokines and/or chemokines) when treated with n-3 PUFAs (De SmedtPeyrusse et al., 2008). N-3 PUFAs also inhibit the production and activity of the enzymes COX-2, iNOS, and the production of $\mathrm{NO}$ and reactive oxygen species (Moon et al., 2007; Lu et al., 2010; Antonietta AjmoneCat et al., 2012; Pettit et al., 2013; Chen et al., 2014; Corsi et al., 2015; Zendedel et al., 2015). This is correlated with a switch in microglial marker expression, from a proinflammatory to an anti-inflammatory phenotype (decreased CD40 and CD86, increased CD206) (Ebert et al., 2009; Chhor et al., 2013; Hjorth et al., 2013; Chen et al., 2014). The phagocytic capacity of microglia is also modulated by n-3 PUFAs in vitro. Using flow cytometry on the human microglial cell line CHME3, Hjorth et al. (2013) assessed the effects of DHA and EPA on microglial phagocytosis of the AD pathogen $\mathrm{A} \beta_{42}$. They showed that both DHA and EPA exacerbate $\mathrm{A} \beta_{42}$ engulfment by microglia in a dose- and time-dependent manner. Microglia employ a wide repertoire of mechanisms to phagocytose various types of cellular elements/debris (Sierra et al., 2013; Brown and Neher, 2014). Yet, the prophagocytic effects of n-3 PUFAs are likely to be generalizable to all stimuli, as 1 year later Chen et al. (2014) showed a significant increase in myelin engulfment by DHA- or EPAtreated microglia primary cultures. N-3 PUFAs also modulate microglia migration capacities. Using a Transwell migration assay, Ebert et al. (2009) showed that DHA dose-dependently inhibits LPS-activated microglial migration, whereas it does not affect the migratory abilities of BV2 cells in basal conditions. Very recently, by measuring the classic autophagy index LC3-I/LC3-II ratio (for the lipidated form of the microtubule-associated protein 1 light chain 3, LC3-II, and nonlipidated LC3, LC3-I), Inoue et al. (2017) showed that application of EPA plus DHA increases autophagy in MG6 microglial cells. Autophagy is an essential process for immune cell homeostasis that leads to dampening of inflammatory processes (Levine et al., 2011). Inoue et al. (2017) highlight it as a new process by which n-3 PUFAs modulate microglial inflammatory response. Finally, lipid bodies (LBs) are functionally active organelles that are formed within immune cells, such as macrophages, in response to different inflammatory stimuli and are sites for synthesis and storage of inflammatory factors (Melo et al., 2011). Ebert et al. (2009) were the first to demonstrate that DHA significantly reduces the accumulation of LBs that is usually observed in LPStreated microglia. These data were confirmed and extended a few years later by the group of Maysinger. Chang et al. (2015) showed in N9 cell line that DHA normalizes LPS-induced abnormalities in microglia, by promoting small LB formation and LB interaction with mitochondria, and by restoring mitochondrial function (Chang et al., 2015; Tremblay et al., 2016). 
Importantly, none of these studies reported detrimental effects of PUFAs on microglia viability, except at very high doses (Moon et al., 2007; Antonietta Ajmone-Cat et al., 2012; Nadjar et al., 2017). Moreover, although EPA and DHA are both efficient almost to the same extent when applied separately, their effects are most often potentiated when combined (Zhang et al., 2010; Hjorth et al., 2013; Chen et al., 2014; Kurtys et al., 2016; Inoue et al., 2017).

Some of the studies presented above explored the molecular mechanisms by which n-3 PUFAs modulate microglial functions. Our group demonstrated that DHA significantly downregulates the cell surface expression of CD14 and TLR4, the two coreceptors that bind LPS, in LPS-stimulated BV2 cells (De SmedtPeyrusse et al., 2008). Beyond the membrane effects of n-3 PUFAs, many studies have reported converging evidence on the modulatory role of $n-3$ PUFAs on signaling pathways. Indeed, the beneficial effects of n-3 PUFAs on inflammatory processes are attributable in part to their inhibitory action on inflammatory signaling pathways such as $\mathrm{NF}_{\kappa} \mathrm{B}$ (De SmedtPeyrusse et al., 2008; Zhang et al., 2010; Wang et al., 2015b; Inoue et al., 2017), mitogen-activated protein kinases (P38, c-Jun N-terminal kinases, or extracellular signal-regulated kinase 1/2) (Liuzzi et al., 2007; Antonietta Ajmone-Cat et al., 2012; Chang et al., 2015), or Akt (Liuzzi et al., 2007).

Finally, it was reported that DHA and EPA are natural ligands for several nuclear receptors, including peroxisome proliferator-activated receptors (PPARs) that are highly expressed in microglial cells (Xu et al., 1999; Zhang et al., 2014). These latter play an important role in the general transcriptional control of numerous cellular processes, including lipid homeostasis and inflammation (Clark, 2002). Several in vitro studies showed that DHA and EPA activate PPAR $\gamma$ in microglial cells as well, hence significantly decreasing the expression of inflammatory factors (Ebert et al., 2009; Antonietta Ajmone-Cat et al., 2012; Corsi et al., 2015; Wang et al., 2015; Kurtys et al., 2016).

Overall, the plethora of in vitro studies rather convincingly demonstrated the anti-inflammatory role of n-3 PUFAs. However, although they are very convenient to study molecular mechanisms, the relevance of in vitro models to study microglial function has been recently questioned (Hickman et al., 2013; Butovsky et al., 2014). By comparing gene expression in cultured microglia with in situ microglia and other myeloid cells, several groups showed that in vitro microglia do not express the same molecular signature as brain microglia and have a transcriptome signature that is closer to macrophages, putting into question the relevance of data presented above to the brain (Hickman et al., 2013; Butovsky et al., 2014). To evaluate the validity of in vitro studies, we will now review reports that assessed the effects of PUFAs on neuroinflammation in various physiologic and pathologic contexts. The data relating to their anti-inflammatory actions have been presented in the previous section. We will in this work focus on the evidence regarding microglial cells, as microglial activation was studied as a secondary outcome in most of these studies.

2. In Vivo Evidence. The first in vivo study showing a relationship between n-3 PUFAs and microglia was performed on aged rats supplemented with $125 \mathrm{mg} / \mathrm{d}$ EPA-containing chow for 4 weeks (Lynch et al., 2007). EPA supplementation was able to significantly reduce microglial activation marker expression [major histocompatibility complex (MHC)II, CD40] and microgliamediated production of IL- $1 \beta$. This was paralleled by an increase in the anti-inflammatory cytokine IL-4 expression, the complete inhibition of aging-induced synaptic plasticity impairment, and a decreased vulnerability to $\mathrm{A} \beta$ stimulus (Lynch et al., 2007). Concomitantly, Connor et al. (2007) demonstrated, in a model of retinal degeneration, that supplementation with n-6 PUFAs increases microglial production of TNF- $\alpha$ in the retina, as a plausible cause for vascular growth and pathology. These effects were prevented by increasing dietary n-3 PUFA intake (Connor et al., 2007).

Many studies have reported a close relationship between microglial function and n-3 PUFAs since then. N-3 PUFA supplementation reduces microglial activation and/or phenotype alteration in models of brain development (Kuperstein et al., 2008; Madore et al., 2014; Abiega et al., 2016), respiratory system development (Tenorio-Lopes et al., 2017), healthy aging (Grundy et al., 2014), ischemia (Zhang et al., 2010; Belayev et al., 2011; Okabe et al., 2011; Eady et al., 2012a,b, 2014; Chang et al., 2013; Zendedel et al., 2015; Jiang et al., 2016), spinal cord injury (Huang et al., 2007; Lim et al., 2013a,b; Paterniti et al., 2014; Tremoleda et al., 2016; Xu et al., 2016), Parkinson's disease (Muntane et al., 2010; Ji et al., 2012; Tian et al., 2015; Delattre et al., 2017; Mori et al., 2017), AD (Lynch et al., 2007; Hopperton et al., 2016; Serini and Calviello, 2016; Wen et al., 2016), systemic inflammation (Delpech et al., 2015b), traumatic brain injury (Pu et al., 2013; Harrison et al., 2015; Harvey et al., 2015; Desai et al., 2016), neuropathic pain model (Xu et al., 2013b; Manzhulo et al., 2015; Huang and Tsai, 2016), aging (Labrousse et al., 2012), demyelination (Chen et al., 2014), amyotrophic lateral sclerosis (Yip et al., 2013), retinal degeneration (Ebert et al., 2009; Mirza et al., 2013), or experimental autoimmune uveoretinitis (Saraswathy et al., 2006). In all these studies, n-3 PUFAs were provided under the form of DHA or EPA supplementation, a combination of EPA plus DHA, largely as fish oil, or the precursors of LC-PUFAs. Administration was made s.c., i.v., i.p., by gavage or via dietary approaches, acutely or chronically. Microglial response was evaluated by quantifying the number of cells or by measuring expression of some phenotype markers, including Iba-1, Arg1, Ym1/2, CD16, CD32, CD40, CD36, CD68, CD86, CD206, CD11b, and MHCII. 
Of all these studies, $90 \%$ found a significant decrease of microglial density and/or activation after exposure to n-3 PUFAs, as a criterion for decreased neuroinflammation, whereas $10 \%$ could not find any effect (Orr et al., 2013; Vauzour et al., 2015; Trepanier et al., 2016; Nadjar et al., 2017). Moreover, we showed that the sourcing of PUFAs (from plants or dairy products) has a differential impact on LPS-modulating microglial phenotype (Dinel et al., 2016). However, none of these studies ever addressed the intimate relationship between brain PUFA contents and microglial function. Notably, our group demonstrated that low dietary consumption of n-3 PUFA precursors over the perinatal period not only impairs microglia phenotype but also its morphologic dynamic (assessed by two-photon microscopy of microglial processes motility) in the postnatal developing brain (Madore et al., 2014). On the same model of developmental n-3 PUFA deficiency, we also showed that the phagocytic activity of microglia was enhanced in the offspring, as a consequence of an increased density in apoptotic cells (Abiega et al., 2016). It is important to highlight that these data are not in accordance with in vitro studies that show higher phagocytic activity in n-3 PUFA-treated cells (Hjorth et al., 2013; Chen et al., 2014), emphasizing even more the need for thorough in vivo work. To improve our knowledge of how PUFA specifically modulate microglia in vivo, new technological tools are required. The recent development of new tools to study these cells, such as CX3CR1-Cre mice, will surely provide informative results in the coming years (Wieghofer and Prinz, 2016).

\section{B. Modulation of Microglial Function by SPMs}

1. Lipid Derivatives Target Microglia. Hundreds of biologically active metabolites of DHA and EPA have been described in the literature (see details in previous section) (Dyall, 2015; Kuda, 2017) (Fig. 3). Briefly, DHA derivatives can be divided into oxygenated metabolites [SPMs, epoxides, electrophilic oxo-derivatives (EFOX), and neuroprostanes] and conjugates of DHA (ethanolamines, acylglycerols, docosahexaenoyl amides of amino acids or neurotransmitters, and branched DHA esters of hydroxy fatty acids). EPA can also be metabolized via oxygenation, hydroxylation, or peroxidation processes that lead to the production of eicosanoids. Some of them have been studies in relation to microglial functions, and data are summarized hereafter.

The EPA-derived RvE1 inhibits LPS-induced microgliosis and proinflammatory cytokine release [IL-6, TNF- $\alpha$, and IL- $1 \beta$ in microglial cell culture (primary cultures and BV2 cell line)], by inhibiting $\mathrm{NF}_{\kappa} \mathrm{B}$ pathway (Rey et al., 2016), and inhibits spinal cord microglial activation following peripheral nerve injury (Xu et al., 2013b). DHA-derived lipid mediators (resolvins of the D-series, MaR, and neuroprotectins) also modify microglial functions. RvD1 promotes anti-inflammatory phenotype in BV2 cells, enhancing Arg1 and Ym1 expression, IL-4 synthesis, and subsequent $\mathrm{NF}_{\kappa} \mathrm{B}$ and PPAR $\gamma$ activation and decreasing CD11b expression ( $\mathrm{Li}$ et al., 2014; Zhu et al., 2015), via the regulation of miRNA expression (Rey et al., 2016). In vivo, RvE1 and the aspirintriggered (AT) $17 R$-epimer of RvD1 (AT-RvD1) significantly modify microglial morphology in a model of traumatic brain injury, decreasing the proportion of $\mathrm{rod} /$ activated microglia at the expense of ramified microglia (Harrison et al., 2015). The DHA derivative MaR1 also modulates microglial response to $\mathrm{A} \beta_{42}$ application in vitro, downregulating $\mathrm{A} \beta_{42}$-mediated phenotype alterations (CD40 and CD11b expression) in CHME3 cells (Zhu et al., 2016). MaR1 also promotes $\mathrm{A} \beta_{42}$ phagocytosis by microglial cells in culture (Zhu et al., 2016). Finally, they provide the demonstration that microglia can produce SPMs [e.g., PD1, lipoxin A4 (LxA4), and RvD1] (Zhu et al., 2015). RvD2 is also a modulator of microglial cells in vitro, as shown by Tian et al. (2015). In this study, they incubated microglia with LPS and increasing doses of RvD2 for 24 hours. Using Western blot, they showed that RvD2 inhibits LPS-mediated activation of TLR4 and its downstream signaling pathway $\mathrm{NF}_{\kappa} \mathrm{B}$ (Tian et al., 2015). Finally, NPD1 signaling induces an increase of microglial ramification size typical of nonactivated phenotype and coincident with attenuation of retina structural alterations (Sheets et al., 2013), whereas the AT-NPD1 significantly reduces the number of ED1-positive cells (microglia/macrophages) in a model of cerebral ischemia (Bazan et al., 2012).

Even though this review focuses on the antiinflammatory effects of n-3 PUFAs in the brain and the complexity of the lipid-dependent inflammatory response, one should mention in this work that some AA-derived lipid mediators also display anti-inflammatory activity via the modulation of microglial function (Fig. 3). LxA4 for instance inhibits interferon- $\gamma$-mediated inflammatory response (TNF- $\alpha$ release and P38 mitogen-activated phosphate kinase activation) in primary cultures of microglia (Martini et al., 2016). It also dampens microglial proliferation, TNF- $\alpha$ upregulation, and the expression of microglial markers such as $\mathrm{P} 2 \mathrm{Y} 12$, in a model of spinal cord injury (Martini et al., 2016). In a transgenic model of $\mathrm{AD}$ (3xTg-AD mice), the AT-LxA4 significantly decreases the number of CD11b, Iba-1, and CD45-positive cells (presumably microglia) around the plaques (Medeiros et al., 2013; Dunn et al., 2015). In vitro experiments on LPS-treated BV2 cells revealed that AT-LxA4 inhibits $\mathrm{NF} \kappa \mathrm{B}$ signaling pathway and $\mathrm{NADPH}$ oxidase activity, hence reducing proinflammatory cytokines and reactive oxygen species production, respectively, as potential mechanisms to explain its anti-inflammatory action (Wang et al., 2011; Wu et al., 2012).

Another class of DHA-derived oxygenated metabolites has been linked to inflammation. DHA can be converted into EFOX by a COX-2-catalyzed mechanism (Groeger et al., 2010) (Fig. 3). Whereas EFOX have been shown to 
modulate macrophage inflammatory activity, no data are yet available on microglia. However, EFOX are natural ligands for PPAR $\gamma$ and modulate the Nrf2 and $\mathrm{NF}_{\kappa} \mathrm{B}$ inflammatory pathways (Groeger et al., 2010), all these molecules being highly expressed in microglial cells (Zhang et al., 2014). Hence, EFOX also look like good candidates to explain modulatory activity of DHA on microglial cells, claiming for more studies on these lipids.

Besides oxidation, DHA can be conjugated with alcohols and amines to form esters and amides, respectively (Kuda, 2017). Among all DHA conjugates, the amine conjugate $\mathrm{N}$-docosahexaenoyl dopamine has been shown to modulate microglial function in vitro (BV2 cells) (Wang et al., 2017). N-docosahexaenoyl dopamine dose-dependently ( 1 or $2 \mu \mathrm{M})$ inhibits LPSinduced IL-6 and CCL20 production in BV2 cells, whereas neither DHA nor dopamine alone (at the same, low concentrations, 1 or $2 \mu \mathrm{M}$ ) is able to produce the same effects. This was paralleled by a decreased production of $\mathrm{PGE}_{2}$, whereas COX-2 gene expression remained stable (Wang et al., 2017).

2. Lipid Derivatives and Their Receptors. Only few receptors for DHA and EPA derivatives have been determined to date. These include ALX/FPR2 and GPR32, both receptors for LxA4 and RvD1; ChemR23, receptor for RvE1; and LTB4R (or BLT1), receptor for LTB4 and RvE1 (Serhan et al., 2011). Most of these receptors have been found on microglial cells in vitro (Rey et al., 2016; Zhu et al., 2016). Data mining in the "Barres brain RNA-seq" database, which provides information on the transcriptome of glial cells (including microglia) and neurons sorted from adult cortex, provides the information that microglia in vivo also express the genes cmklr1 (for ChemR23), ltb4r1 (for LTB4R or BLT1), and fpr2 (for ALX/FPR2) at very high levels. Even more interestingly, they express these genes at much higher concentration than any other cell type (Zhang et al., 2014). Beyond receptors, some of these lipid mediators target PPARs, also highly expressed by microglia (Forman et al., 1997; Zhang et al., 2014). Hence, based on this evidence, it is highly likely that microglia are a target for EPA and DHA derivatives within the brain.

Overall, all of these reports highlight the modulatory activity of DHA and EPA derivatives on microglial functions. However, this promising field is still in its infancy and requires more studies to unravel the molecular mechanisms involved and validate the activity of these lipids in vivo.

\section{A Link between n-3 PUFAs and Microglial Extracellular Vesicles?}

Extracellular vesicles $(\mathrm{EVs})$ transport represents a fundamental mechanism of communication in the CNS. EVs are released from almost all cell brain types, including microglia, into the microenvironment and are involved in cell-to-cell communication (Potolicchio et al., 2005; Subra et al., 2010; Turola et al., 2012). EVs include exosomes, which are small vesicles $(40-100 \mathrm{~nm}$ in diameter) derived from the endosomal multivesicular bodies that fuse with the plasma membrane via exocytosis. They serve as shuttles for intercellular delivery of cargo, including specific lipids (Turola et al., 2012). Microglia-derived exosomes were discovered in 2005 in N9 microgial cell lines (Bianco et al., 2005; Potolicchio et al., 2005). Several studies have further shown that microglia-derived exosomes can deliver a proinflammatory signal on neighboring cells (Bianco et al., 2005; Verderio et al., 2012; Prada et al., 2013). A recent study elegantly showed that eCBs such as AEA can also be secreted through extracellular membrane vesicles produced by microglial cells and hence inhibit presynaptic transmission in target GABAergic neurons in a CB1dependent manner (Gabrielli et al., 2015).

Interestingly, lipidomic and proteomic analyses of exosomes from various cell types have shown that these EVs are not randomly filled with cellular content but rather display a highly specific pattern in terms of lipid and protein expression (Subra et al., 2010; Connolly et al., 2015; Haraszti et al., 2016). Specifically, exosomes contain free fatty acids, including AA and DHA (Haraszti et al., 2016), but also AA derivatives such as prostaglandins $\left(\mathrm{PGE}_{2}, \mathrm{PGJ}_{2}\right)$ (Subra et al., 2010). Exosomes also express specific proteins, including enzymes, such as $\mathrm{PLA}_{2}$ or FABP (Subra et al., 2010). Computer-based analyses of proteomic data also revealed that they specifically contain proteins involved in functions such as immune response, cell adhesion, or integrin signaling (Haraszti et al., 2016). Overall, exosomes are considered as signalosome carriers to neighboring cells (Subra et al., 2010).

Based on the currently available evidence, studies are needed to decipher the lipid and protein composition of microglial exosomes under various dietary situations. One might speculate that, depending on the amount of n-3 PUFAs, exosome composition might change, leading to differential effects in neighboring cells.

\section{Sex, Age, and Regional Differences in the Relationship between Microglia and n-3 PUFAs}

As already exposed in previous sections, n-3 PUFA distribution varies according to sex, age, and structure, and so do microglial functions. Hence, microglia/n-3 PUFA interactions could vary according to these factors, which would have to be considered to understand whether and how n-3 PUFAs modulate CNS homeostasis and neuroinflammation.

1. Evidence for Sexual Dimorphism of Microglia. The colonization of the brain by yolk sac-originating microglia takes place very early during development, even before formation of neurons, astrocytes, or oligodendrocytes. Once in the CNS, microglia then proliferate and spread evenly in all structures all along their development (Tay et al., 2017). Although entry of microglia in the CNS is likely to be sex-independent, postnatal 
microglial colonization and proliferation are sexdependent (McCarthy et al., 2015; Nelson and Lenz, 2017b). Indeed, male and female rats do not show sex differences in microglial number before the testosterone surge at embryonic day E17 (Schwarz et al., 2012). At the time of testicular androgen secretion onset, sex differences in microglia begin to emerge. At $\mathrm{P} 0$, females have a transient increase in the number of ameboid microglia and microglia with stout processes relative to males, in the CA3 region of the hippocampus, paraventricular nucleus of the hypothalamus, and amygdala (Schwarz et al., 2012). By P4, the situation is reversed with males showing greater numbers of ameboid microglia and microglia with stout or thick processes relative to females, in the amygdala, hippocampus, and cortex (Schwarz et al., 2012). These sex differences remain until adolescence period with females displaying more microglia with thick processes than males (Schwarz et al., 2012). Slighter sex differences have been reported in the cerebellum, with males having less ramified microglia than females, but no overall differences in ameboid microglia or total microglia during the first 3 weeks of life (Perez-Pouchoulen et al., 2015). At adulthood, the number of microglia is significantly higher in females than in males (as quantified at 3 , 14 , or 24 months old), at least in the dentate gyrus of the hippocampus (Mouton et al., 2002).

Microglia are also essential for CNS masculinization by standing at the interface of both endocrine and nervous systems during development (Lenz et al., 2013). In the preoptic area, an essential structure for brain masculinization, male neonates have $30 \%$ more microglia and twofold more ameboid microglia than females (Lenz et al., 2013). At the time of testicular surge, estradiol aromatized from testosterone promotes microglia-mediated $\mathrm{PGE}_{2}$ synthesis, a critical step in masculinization of neurons and behavior (Lenz et al., 2013). Using repeated central injections of liposomal clodronate (from P0 to P4) to selectively deplete microglia in the developing brain alters behavior, including sexual behavior, in male pups, juveniles, and adulthood (decreased number of and increased latency for mounts and intromissions in adults), whereas female behavior is unchanged (VanRyzin et al., 2016).

Besides cellular density and morphology, microglia exhibit a sexual dimorphism in gene expression profile (Crain et al., 2009, 2013; Crain and Watters, 2015). Microglia freshly isolated from males and females differentially express $\mathrm{P} 2 \mathrm{X}$ and $\mathrm{P} 2 \mathrm{Y}$ purinergic receptors (Crain et al., 2009). The functional significance of this differential expression is still unknown, yet purinergic receptors are involved in functional modal switch of microglia, i.e., transition from one phenotype/activity to another phenotype/activity (Koizumi et al., 2013). Female microglia also display higher expression of pro- and anti-inflammatory cytokines (IL-1 $\beta$, TNF- $\alpha$, IL-6, and IL-10) relative to males (Crain et al., 2013). This sexual dimorphism is structure-dependent as microglia from cerebral cortex of females expresses more iNOS mRNA than those of males, whereas no such difference is observed in the brainstem (Crain and Watters, 2015). Finally, microglia also display sexual dimorphisms in function. In female neonates, a higher number of microglia exhibit phagocytic phenotype as compared with males (Nelson and Lenz, 2017a,b). However, the molecular and cellular mechanisms of sexual dimorphism of microglia and consequences on brain function are still to be unraveled.

The dynamics of microglia across the developmental period suggest that gonadal hormones regulate sex differences in microglia. Microglia specifically express the anti-inflammatory estrogen receptor (ER) $\alpha$, as $\mathrm{ER} \beta$ was never found on these cells (Vegeto et al., 2003; Sierra et al., 2008; Crain et al., 2013; Crain and Watters, 2015). However, $\mathrm{ER} \alpha$ is expressed to the same extent in males and females at all ages, suggesting that sexual dimorphism of microglia is ER-independent (Crain et al., 2013).

2. Evidence for Regionalization of Microglia. Microglia are essential in monitoring the environment and sense variations, and react accordingly to maintain CNS homeostasis (Kettenmann et al., 2011). Hence, the local environment, such as BBB permeability or neuronal activity, is key in driving microglial phenotype. Lawson et al. (1990) described regional variations in microglial morphology and density as the first evidence for heterogeneity of these cells. More recently, using ex vivo flow cytometric analysis surface expression of CD11b, CD40, CD45, CD80, CD86, F4/80, TREM-2b, MHCII, CXCR3, CCR9, and CCR7, de Haas et al. (2008) showed that most of these immunoregulatory markers displayed region-specific differences in expression levels, confirming other studies (Mittelbronn et al., 2001; Buschmann et al., 2012; Doorn et al., 2015). Using genome-wide transcriptional profiling of adult microglia from various brain regions, Grabert et al., 2016) thoroughly addressed the question of regional heterogeneity of microglia and found that the mouse microglial transcriptome is regionally heterogeneous. Moreover, regional microglial heterogeneity in immunophenotype suggests differences in immune vigilance (Grabert et al., 2016). Overall, these data reveal microglia as highly diverse cells under steady-state conditions. In addition, only recently has it become clear that microglial sensitivity to stimuli may be region-specific (Lucin and Wyss-Coray, 2009; Ransohoff and Perry, 2009; Olah et al., 2011; Doorn et al., 2015), as a potential substrate for differential and evolving pattern of neuropathologies.

3. Evidence for Age Dependence of Microglia. Many groups have examined age-dependent modulation of microglial morphology, density, phenotype, and function (Tay et al., 2017). This literature is too vast to be described in an exhaustive way in this work. In substance, microglial activity is continuously evolving, in a structure and age-dependent manner, from 
guidance of axons or phagocytosis of neuronal elements during development (Paolicelli et al., 2011; Schafer et al., 2012; Squarzoni et al., 2014), to fine remodeling of neuronal circuits at adolescence and adulthood (Tremblay et al., 2010; Parkhurst et al., 2013) or control of neuroinflammation in normal and pathologic ageing (Kettenmann et al., 2011; Tay et al., 2017). This list is far from being exhaustive but shows that microglia are versatile cells, constantly adapting to the environment to maintain homeostasis.

In conclusion, age-, sex-, and region-specific variances in microglial function may allow differential responses to the same stimulus at different ages, perhaps contributing to altered CNS vulnerabilities and/or disease courses. Combined to age, sex, and region dependence of n-3 PUFA brain composition, microglia-lipid interactions are likely to be extremely diverse. Hence, more studies taking into account this complexity are needed to fully understand how n-3 PUFAs modulate microglial activity in time and space and in a sex-specific way.

\section{Pharmacological Considerations on the Use of LC-PUFAs or SPMs as Effective Anti- Inflammatory Drugs in the Brain-Clinical Use}

\section{A. LC-PUFA Dietary Interventions to Limit Neuroinflammation in Humans}

Considering the role of LC PUFA status, in particular DHA and/or EPA, to promote SPMs in the brain, the increase of these fatty acids in the brain using dietary approaches represents a potential strategy to control inadequate neuroinflammatory processes.

Several studies highlighted that increasing DHA and or EPA by oral administration leads to increase circulating SPMs. In healthy humans, basal plasma levels of DHA-derived SPMs are low (Markworth et al., 2016). Fish oil supplementation containing a mixture of EPA and DHA is reported to increase DHA metabolites (Schuchardt et al., 2014; Keelan et al., 2015; Mas et al., 2016; Zulyniak et al., 2016). D-series SPMs are also reported as increased by fish oil dietary supplementation (RvD1; Keenan et al., 2012; Mas et al., 2016), whereas other studies report no change (Zulyniak et al., 2013; Skarke et al., 2015). Changes in SPMs appear to be specific, as a 14-day oral intake of EPA $(2.7 \mathrm{mg} / \mathrm{d})$ leads to increased blood level of 18-HEPE, with no effect on RvE2 and 3 (Endo et al., 2014). A 7-day oral supplementation with purified n-3 DPA increases DHA metabolites (EpDPE, DiHDoPE, and MaR) as compared with oral olive oil (Markworth et al., 2016). Conversely, oral supplementation with fish oil or EPA, but not with n-3 DPA, decreases AA-derived LOX products (Fischer et al., 2014; Markworth et al., 2016). Although the rapid increase in SPMs linked to oral intake of LC-PUFAs is promising, whether this is also the case in the brain has not been evaluated in humans yet. Recent works report that SPMs are detectable in postmortem brain tissue and cerebrospinal fluid (CSF) samples, with a dramatic decrease in LxA4, RvD1, and $\mathrm{MaR}$ in the $\mathrm{CSF}$ and brain of $\mathrm{AD}$ patients as compared with control age-matched subjects (Wang et al., 2015).

One puzzling question is whether increases in dietary DHA intake are sufficient to increase brain DHA and target neuroinflammation in humans. As previously reviewed, the plasma unesterified pool of DHA is the principal source for brain DHA (Chen et al., 2015). Positron-emission tomography studies using $\mathrm{C}^{11}$-DHA showed that DHA half-life in the plasma of healthy humans is about 2 minutes, and the brain incorporation corresponds to $3.8 \mathrm{mg} / \mathrm{d}$ with a half-life of 2.5 years (Umhau et al., 2009). It is important to understand that this predicts a drop of $5 \%$ in the brain when DHA decreases in the plasma for 49 days. Dietary supplementation aims at maintaining high level of blood DHA to consequently increase its levels in the brain. However, the efficiency of DHA metabolism has to be taken into account to better predict brain DHA increase (Yassine et al., 2017). For example, lipoprotein APOE largely influences DHA half-life, suggesting that fish oil supplementation of APOE4 carriers (at risk of $\mathrm{AD}$ ) is less efficient to increase DHA in the brain (ChouinardWatkins and Plourde, 2014). Parenteral administration of DHA (Omegaven, LipoPlus, SMOFLipid containing $10 \%-15 \%$ fish oil) is also useful to rapidly increase plasma DHA but has been poorly researched in the context of neuroinflammatory diseases, but more commonly in peripheral inflammatory diseases (Hall et al., 2016; Klek, 2016).

1. LC-PUFA Dietary Intervention and Neuroinflammation in $A D$ Patients. Clinical trials using DHA in patients with moderate to severe $\mathrm{AD}$ are representative of current strategies using nutritional approaches to protect and/or treat neuroinflammation. The aim is not to perform an exhaustive review of trials (14 trials of "Alzheimer and DHA" currently declared on clinicaltrials.gov) or mechanistic evidence of DHA in pathologic pathways of $\mathrm{AD}$, as elegantly reviewed elsewhere (Devassy et al., 2016), but rather to highlight recent data questioning the use of DHA to protect or to treat $\mathrm{AD}$-related neuroinflammation.

Several epidemiologic studies report that patients suffering from AD display relatively low blood DHA (Conquer et al., 2000; Tully et al., 2003; Wang et al., 2008), and conversely, that poor DHA consumption is associated with increased risk for $\mathrm{AD}$ (Quinn et al., 2010). In addition to the protective effect of DHA on neuronal death and function, together with $\mathrm{A} \beta$ pathogenesis, neuroinflammatory processes occurring in $\mathrm{AD}$ are also targeted by DHA (Cole and Frautschy, 2010; Calon, 2011; Joffre et al., 2014). Neuroinflammation and microglia cell proliferation in $\mathrm{AD}$ patient brain surrounding amyloid deposit are prominent (recently reviewed in Perry et al., 2010). This is consistent with the observation that in the $3 \times \mathrm{Tg}-\mathrm{AD}$, an $\mathrm{AD}$ animal 
model, microglia number is increased before the apparition of $\mathrm{A} \beta$ deposition (Rodriguez et al., 2016). Microglia are involved in $\mathrm{A} \beta$ phagocytosis, therefore containing $\mathrm{A} \beta$-induced neuronal damage, except in APOE carrier (Mulder et al., 2014). Of note, APOE, which plays a critical role in cholesterol and phospholipid transport to neurons, has recently been highlighted as being important in microglia phagocytic activity of $\mathrm{A} \beta$ (Yeh et al., 2016). Triggering receptor expressed on myeloid cells 2 (TREM2), a transmembrane protein exclusively expressed in microglia and an $\mathrm{AD}$ risk gene (Lucin et al., 2013), binds APOE, especially after lipidation of this apolipoprotein and facilitates $\mathrm{A} \beta$ phagocytosis when coupled to lipoprotein (Walter, 2016). In addition, microglia inflammatory response, as exacerbated by aging or inflammatory insult, decreases microglia phagocytic activity and may promote $\mathrm{A} \beta$ aggregation and neuronal death (Heneka et al., 2015). Interestingly, microglial activation leading to increased $\mathrm{A} \beta$ phagocytosis and anti-inflammatory profile, is achieved through the use of agonists of several receptors (Yamanaka et al., 2012), in particular PPARs and retinoid X receptors, which are DHA receptors, as previously discussed. In this context, and in the frame of this review, a high brain DHA status is of interest to protect from neuroinflammation and for maintenance of optimal phagocytic activity of microglia. Recent work highlighted that dietary supplementation with $n-3$ PUFAs and antioxidants dramatically increases $\mathrm{A} \beta$ phagocytosis by monocytes (Fiala et al., 2015). As discussed before, increasing DHA levels via dietary means or genetic approaches potently reduces brain proinflammatory cytokine production in animal models of acute and chronic inflammation (Orr et al., 2013; Delpech et al., 2015a,b; Taha et al., 2017), aging (Labrousse et al., 2012; Moranis et al., 2012), or AD (Casali et al., 2015; Hopperton et al., 2016). Concomitantly, DHA potently promotes microglia phagocytic activity (Chen et al., 2014), including toward $\mathrm{A} \beta$ in vitro (Hjorth et al., 2013). Experimental evidence of n-3 PUFA-protective effects on neuroinflammation in animal models of $\mathrm{AD}$ is corroborated by several clinical studies. The OmegaD study, a prospective clinical trial using DHA and EPA (1.7 $\mathrm{g}$ DHA and $0.6 \mathrm{~g} \mathrm{EPA} / \mathrm{d}$ ), as primary intervention, shows that this supplementation reduces cognitive decline in very mild $\mathrm{AD}$ cases (Freund-Levi et al., 2006). At these doses, a 6-month dietary supplementation increases circulating DHA level in healthy subjects. Importantly, despite no significant increase in DHA in peripheral blood mononuclear cells (PBMC) of mild cognitive impairment patients, the dietary intervention restores the decrease of LxA4 and RvD1 production by these cells upon $\mathrm{A} \beta$ ex vivo treatment (Wang et al., 2015). However, DHA levels are not increased in the cerebral spinal fluid of supplemented subjects, although accompanied by decreased expression of proinflammatory genes and an increase in anti-inflammatory factors, including the soluble form of the type II IL-1 receptor, a decoy target for IL-1 (Vedin et al., 2008, 2012; FreundLevi et al., 2014). Despite these encouraging clinical data showing that primary intervention aiming at increasing brain DHA prevents from neuroinflammatory processes (Devassy et al., 2016), overall the results of LC n-3 PUFAs dietary supplementation on cognitive deficits, the main outcome of $\mathrm{AD}$ disease, are poor (Jiao et al., 2014). Some authors suggest that these interventions might not be beneficial when the disease is at advanced stages, with effectiveness at earlier stages of the disease, when resolution of inflammation is disturbed. Importantly, a large clinical trial with a multidomain intervention [multidomain Alzheimer prevention trial (MAPT)] highlighted that a 3-year supplementation with DHA plus EPA (800 and $225 \mathrm{mg}$, respectively) of nondemented elderly does not protect from cognitive decline, except in subgroup starting with a low n-3 PUFA index (Andrieu et al., 2017). The effectiveness of DHA in stimulating a phagocytic (noninflammatory) phenotype of microglia is consistent with this hypothesis (Hjorth et al., 2013). It is important to note that APOE 4 carriers, which represent $40 \%$ of $\mathrm{AD}$ patients, and patients with low $\mathrm{A} \beta$ levels in the CSF have a lower DHA brain transport, as revealed by identical plasma DHA and reduced DHA in the CSF after DHA supplementation (Yassine et al., 2017). Other studies report a lower DHA increased in APOE4 carriers as compared with noncarriers (Plourde and Cunnane, 2007; Chouinard-Watkins et al., 2013). All together, these data suggest that in humans, APOE4 carriers have an impairment in fatty acid homeostasis, even after DHA supplementation, further highlighting the necessity to pay attention to this allele when supplementing with PUFA (Chouinard-Watkins and Plourde, 2014; Hennebelle et al., 2014). However, a very recent study highlights that unesterified DHA uptake is increased in the brain of APOE4 carriers (Yassine et al., 2017). Noteworthily, no attention has been paid to APOE4 carriers in studying the efficiency of DHA supplementation on neuroinflammatory processes or microglia phagocytic activity of $A \beta$. This deserves attention, as it could help design personalized nutrition to specific subtypes of patients at risks of neuroinflammation and/or microglia activity impairment, such as Trem2, the complement receptor 1 , or cluster of differentiation 33, which are involved in microglial phagocytic activity and are regulated by DHA (Griciuc et al., 2013).

2. LC-PUFA Dietary Intervention and Neuroinflammation in Patients with Mood Disorders. In the last 20 years, epidemiologic studies have linked dietary PUFAs in the pathophysiology of mood disorders (recently reviewed in Bazinet and Layé, 2014; McNamara, 2015). In particular, dietary intake of food rich in $n-3$ LC-PUFAs (fish, seafood) is associated with reduced prevalence of major depression, postpartum depression, or bipolar disorder. In addition, patients suffering from 
mood disorders display reduced levels of EPA in erythrocyte and DHA in specific brain regions (Edwards et al., 1998). These observations are consistent with experimental studies linking low dietary intake of n-3 PUFAs, decreased brain DHA, emotional behavior disorders, and increased stress response (Harauma and Moriguchi, 2011; Lafourcade et al., 2011; Larrieu et al., 2012, 2014, 2016). Recent data from our group highlighted that neuropathological mechanisms linking brain DHA decrease and emotional/cognitive behavior disturbances involve eCB-dependent synaptic plasticity (Lafourcade et al., 2011; Bosch-Bouju et al., 2016; Thomazeau et al., 2016), glucocorticoid (Larrieu et al., 2014, 2016), and neuroinflammatory processes (Mingam et al., 2008; Labrousse et al., 2012; Moranis et al., 2012; Delpech et al., 2015a,b). In the scope of this review, neuroinflammation is implicated in the pathophysiology of mood disorders (Dantzer et al., 2008; Capuron and Miller, 2011), becoming a target of interest in the treatment of major depression, postpartum depression, and bipolar disorder. However, it has to be noted that inflammation contributes to symptoms only in a subpopulation of patients diagnosed with mood disorders, with noticeable increase of inflammatory markers (mainly C-reactive protein) in about one third of depressed patients (Raison and Miller, 2011). In addition to genetic factors, environmental factors (diet, adversity, etc.) are considered as important risk factors for inflammation and depression, with a specific attention given to n-3 PUFA metabolism and dietary content (Kiecolt-Glaser, 2010; Laye, 2010; Bazinet and Laye, 2014; Kiecolt-Glaser et al., 2015). Observational studies linked $n-6 / n-3$ PUFA ratio to IL-6 and TNF- $\alpha$ circuiting levels together with depressive symptoms in older adults and students undertaking an examination (Maes et al., 2000; Kiecolt-Glaser et al., 2007). Population-based study revealed a lower level of DHA only in depressed elderly with a C-reactive protein concentration $<1.5 \mathrm{mg} / \mathrm{l}$ (Tiemeier et al., 2003). Interestingly, low blood DHA levels predict depression incidence in depressive episode triggered by interferon- $\alpha$ administration in a subset of hepatitis patients (Su et al., 2010, 2014; Lotrich et al., 2013).

Dietary LC-PUFAs, DHA, and/or EPA have been used in 49 trials (mood disorders and omega3) referenced on clinical trials.gov., with mitigated and heterogeneous results as revealed by several meta-analysis (Lin et al., 2010; Bloch and Hannestad, 2012; Mocking et al., 2016). Based on meta-analyses, EPA has been suggested as a predictor of mood disorder treatment efficiency with supplements containing less than $60 \%$ of total EPA plus DHA as EPA (between 200 and $2200 \mathrm{mg} / \mathrm{d}$ ) or DHA alone being noneffective (Martins, 2009; Sublette et al., 2011; Mocking et al., 2016). However, few studies have studied the impact of dietary supplementation with LC-PUFAs on inflammation and depression. Medical students with no diagnosis of depression supplemented with $2085 \mathrm{mg}$ EPA plus $348 \mathrm{mg} \mathrm{DHA} / \mathrm{d}$ for 12 weeks have less LPS-induced IL-6 release in cultured PBMC and anxiety symptoms compared with control (Kiecolt-Glaser et al., 2011). Based on the observation that LC-PUFAs have anti-inflammatory activities and that they are efficient only in a subset of depressed patients, Rapaport et al. (2016) analyzed whether high EPA supplementation was more efficient in those with inflammation. Using several markers of inflammation as markers of inflammation, they found that patients with high IL-1ra and C-reactive protein and low adiponectin blood levels have a greater improvement in mood symptoms in response to a EPA-enriched dietary supplement (1060 mg EPA plus $260 \mathrm{mg}$ DHA/d, 8 weeks), whereas it was not the case when supplemented with a DHA-enriched dietary supplement (180 mg EPA plus $900 \mathrm{mg} \mathrm{DHA} / \mathrm{d}$ ). Additional studies with a higher number of patients are warranted to confirm this interesting first study. The mechanisms underlying the higher efficiency of high EPA rather than DHA dietary supplementation on inflammation and depressive symptoms are still poorly understood. It can be speculated that EPA preferentially targets directly or indirectly (through specific EPA-derived SPMs) immune cells and correct immune system dysfunctions, including in the brain. In this regard, a recent study indicates that patients diagnosed with major depression had a significant decrease in cytosolic PLA2 gene expression in PBMC when treated with EPA $(3.5 \mathrm{~g} / \mathrm{d})$, but not with DHA $(1.75 \mathrm{~g} / \mathrm{d})$ for 12 weeks, whereas both treatments improved depressive symptoms (Su et al., 2017). To our knowledge, the effect of EPA-derived SPMs has not been tested in depression accompanied by inflammation.

All together, these examples illustrate that in humans, targeting DHA and/or EPA represents a potent strategy to regulate microglia activity and to reduce chronic inflammation. Whether DHA or EPA administration via a parenteral route controls neuroinflammatory pathways efficiently has to be further studied in humans, and could represent a way to accelerate DHA access to the brain and local SPM production.

\section{B. The Use of SPMs or n-3 PUFA-Derived Fatty Amides to Target Brain Neuroinflammation in Humans}

Some data reveal that DHA and its SPMs are antiinflammatory in non-neural tissues (Serhan, 2017a), with indirect and direct evidence existing for their antiinflammatory effects in the brain, including on microglia (Marcheselli et al., 2003; Lukiw et al., 2005; Orr et al., 2013a; Rey et al., 2016). As mentioned above, SPMs are found in brain cells at pM, whereas DHA is at $\mathrm{nM}$, suggesting that the activity of SPMs requires less quantity than DHA. Some, but not all DHA and SPM receptors, have been identified, including very recently (see previous sections). Despite that some receptors are identified, affinity and function of these receptors are poorly known; hence, pharmacological use of SPMs is 
still in emergence (Chiurchiu et al., 2016). Recent studies revealed that DHA status has also to be considered in the effectiveness of SPM activity in inflammation (Chiurchiu et al., 2016). The challenge now will be to develop clinical applicable forms of SPMs to target the brain and especially microglia. Experimental studies mainly use intrathecal route of administration, which is poorly applicable to humans. The study of the route of administration, oral or i.v., is a necessary proof of concept of the utility of SPMs to treat neuroinflammation and to reduce associated symptoms. Noteworthily, age and sex, which are crucial in DHA metabolism, neuroinflammatory regulation, and drug activity, will also have to be taken into account.

Experimental data revealed that DHEA and EPEA, the main fatty acyl amides derived from DHA and EPA, respectively, display anti-inflammatory activities in microglia in vitro and in vivo (Meijerink et al., 2011, 2013; Park et al., 2016). However, no studies have been conducted in humans, probably due to the lack of knowledge of the mechanisms underlying their activity, but also to the difficulty to manipulate eCBs in humans (Fowler, 2015). Increasing n-3 PUFAs in the diet leads to the decreased formation of n- 6 PUFA-derived eCBs 2AG and AEA, whereas DHEA and/or EPEA increase (Watanabe et al., 2003; Banni and DiMarzo, 2010; Bosch-Bouju et al., 2016). Such a correlation is also reported in humans (Joosten et al., 2010; Jones et al., 2014; Pu et al., 2016). Recent data highlight that in humans, genetic variants of the AEA hydrolytic enzyme fatty acid amide hydrolase, but not of $N$-acyl phosphatidylethanolamine-specific phospholipase D, may also contribute to DHEA circulating level $(\mathrm{Pu}$ et al., 2016). DHEA is a substrate of fatty acid amide hydrolase, which degrades it into DHA (Kim et al., 2011). Whether plasma DHEA, which is a lipophilic factor that crosses the BBB, brain-derived DHEA, or both contribute to the anti-inflammatory activity of DHA remains to be investigated (Meijerink et al., 2013). Also, receptors mediating the anti-inflammatory effects of DHEA are poorly known. In macrophages, none of the classic eCB receptors (CB1, CB2, and PPAR) mediate the effect of DHEA on LPS-induced cytokine release (Meijerink et al., 2015). No studies have ever evaluated whether GPR110, a DHEA receptor recently identified as mediating its neurogenic effect (Lee et al., 2016), is involved in DHEA anti-inflammatory activity.

\section{Pharmacological Strategy to Promote Endogenous SPM Production in the Brain: Combination of PUFAs and Anti-Inflammatory Drugs}

Increases in COX-1 and COX-2 expression are a hallmark of brain inflammation and occurs in ischemic or traumatic brain injuries and neurodegenerative diseases such as $\mathrm{AD}$ (reviewed in McGeer and McGeer, 2007). Consequent rise in PGE and TX in endothelial, neuronal, and glial cells is believed to be causative of neurodegeneration (Farooqui et al., 2006; Phillis et al., 2006). Not only AA is converted to cyclic endoperoxydes by the action of COX, but also DHA and EPA, as described above. However, these latter are less prone to be metabolized through the COX pathway, and eicosanoid generated are less active than the ones generated from AA. Importantly, DHA and EPA reduce COX-2 activity, therefore reducing the production of inflammatory eicosanoids and TX from AA. The use of nonsteroidal anti-inflammatory drugs (NSAIDs), which block COX activity, is considered as attractive to counteract neurodegeneration associated to neuroinflammation, especially microglia. Of note, as COX-2 is also highly expressed in healthy neurons (Yamagata et al., 1993), NSAIDs have adverse effects on neuronal activity in noninflammatory conditions, whereas reduction of neuronal COX-2 activity in inflammatory condition improves pain. COX-3 is a more recently identified variant of COX-1 (Chandrasekharan et al., 2002), which is preferentially expressed in the brain and involved in pain and fever. In addition, to be sensitive to NSAIDs, COX-3 is inhibited by paracetamol (acetaminophen), whereas COX-1 and 2 are not (Botting, 2003). To the best of our knowledge, no specific effect of DHA has been reported on COX-3 activity. A new class of COX-2 inhibitors (tricyclics such as coxibs and nontricyclics) emerged, allowing the specific targeting of COX-2 (Zarghi and Kakhki, 2014).

Combination of NSAIDs and DHA or EPA has been proposed as an efficient strategy to prevent or treat neuroinflammatory pathways associated to neurodegenerative diseases (Pomponi et al., 2011), with no results in humans yet. In vitro, microglia treatment with DHA or aspirin or both reveals that the combination of aspirin and DHA promotes the antioxidant endogenous enzyme gluthatione production, with no potentiation on proinflammatory cytokine production (Pettit et al., 2013). Attention has been paid to aspirin, a NSAID, which acetylates COX-1 and COX-2. Whereas COX-1 acetylation leads to a loss of its activity, the acetylated form of COX-2 leads to the synthesis of AT-LxA4, primarily identified to limit neutrophil activation and recruitment to inflamed tissues (Serhan et al., 2002) with anti-inflammatory and proresolving activities (Ye et al., 2010; Martins et al., 2009). Importantly, low-dose aspirin treatment has a gender effect on AT-LxA4 production in healthy subjects (Chiang et al., 2006). In $\mathrm{AD}$ animal models, chronic administration of AT-LxA4 improves memory deficits through an $\mathrm{A} \beta$-independent mechanism (Medeiros et al., 2013; Dunn et al., 2015). In addition, this compound promotes the alternative phenotype of microglia, with a higher phagocytic activity toward $\mathrm{A} \beta$ (Ye et al., 2013) and reduces microglia activation (Wang et al., 2011) and neuropathic pain (Martini et al., 2016). A randomized trial with low-dose aspirin in $\mathrm{AD}$ patients did not observe a beneficial effect upon 2 years on cognitive outcomes, rather it increases risk of bleeding (Bentham et al., 2008). 
Since 2010, studies using aspirin in $\mathrm{AD}$ patients led to the conclusion that the beneficial effect of this drug on $\mathrm{AD}$ symptoms is unclear and that bleeding risks are high (Thoonsen et al., 2010). As high-dose DHA is recognized to affect blood fluidity, one could wonder whether it is safe to combine aspirin and DHA as a chronic treatment of neuroinflammation.

\section{The Use of COX or Lipoxygenase Inhibitors to Target Neuroinflammation: a Paradox?}

Clinical trials with NSAIDs on AD are overall disappointing with mitigated results. COX-2 generates both pro- and anti-inflammatory compounds with a balance depending on the ratio AA/DHA-EPA that is largely linked to nutritional status (Bazan et al., 2011; Mouchlis and Dennis, 2016; Serhan, 2017b); one could wonder about the beneficial effect of inhibiting this enzyme in the context of neuroinflammation. In humans, using a lipidomic approach, Ibuprofen (a nonselective inhibitor of COX) was shown to block exerciseinduced increase in prostanoids and leukotrienes, but also anti-inflammatory/proresolving lipid mediators, possibly explaining the mitigated beneficial effect of COX inhibitors (Markworth et al., 2016). Also, combination of DHA and NSAIDs should be considered cautiously as it could augment the production of leukotrienes that are proinflammatory, as recently suggested by an elegant in vitro study (Norris and Dennis, 2012). The analysis of DHA status, together with dietary patterns and genetic overview of alleles such as fatty acid desaturase 2, which influences fatty acid metabolism (Martinelli et al., 2008; Schuchardt et al., 2016), should help to phenotype $\mathrm{AD}$ patients and treat them with NSAIDs in combination or not with DHA. Such a strategy could be used in other diseases with an inflammatory component, such as depression, which overall show mitigated effect of DHA/EPA supplementation on symptoms, except when patients display a proinflammatory profile (Rapaport et al., 2016).

LOX are iron-containing dioxygenases, which oxygenate AA, DHA, and EPA into several derivatives with proinflammatory (leukotrienes, HETE) and antiinflammatory (resolvins, protectin D1) activities. Importantly, as AA and DHA compete for their metabolism into LOX-mediated derivatives, the quantity of these precursors is critical. A specific system, called suicidal inactivation, allows for the stopping of LOX activity after a certain number of cycles of oxygenation through specific oxidation of LOX amino acids (Kuhn and O'Donnell, 2006). LOX also participate to membrane lipid peroxidation with structural modifications as observed in the aged brain (Pratico et al., 2004). All together, these data suggest that LOX may be involved in pathologic mechanisms of brain diseases, such as $\mathrm{AD}$ through their pro-oxidative and proinflammatory signaling, but may also affect processes directly related to neurotoxic cascades dependent on $\mathrm{A} \beta$ and Tau. There are five existing LOX isoforms (5, 8, 12, and 15-LOX and 3 -LOX) with 5-LOX particularly expressed in the inflamed brain. When catalyzing AA, 5-LOX leads to the synthesis of the instable form LTA4 that is rapidly metabolized into LTB4 or LTC4 as observed in brain injury, multiple sclerosis, Parkinson's disease, or AD (Czapski et al., 2016). LOX-derived LTA4 synthesis is either occurring in a cell-specific manner or through endothelial cells or platelets that do not express LOX (Kuhn et al., 2015). In this last case, LTA4 produced by surrounding neutrophils is used to generate LTC4 via transcellular mechanism (Papayianni et al., 1996). Transcellular mechanisms have been described in neurons and glial cells to produce LTC, LTD, and LTE4 as neutrophils provide LTA4 (Farias et al., 2007). This suggests that brain entry of neutrophils is a critical step for local leukotriene production, as it is the case in traumatic brain injury (Jickling et al., 2015). In line with this, depletion in neutrophils in an animal model of AD improves memory (Zenaro et al., 2015). However, more work has to be done to understand the mechanisms underlying 5-LOX activity in $\mathrm{AD}$ as its expression modulates both $\mathrm{A} \beta$ and Tau processing (recently reviewed in Joshi and Praticò, 2015).

Zileuton and meclofenamate sodium are 5-LOX inhibitors. Long-term zileuton treatment potently reduces amyloidogenesis and improves memory of Tg2576 and 3xTg mice, used as animal models of AD (Chu and Pratico, 2011; Chu et al., 2013), which is in accordance with data obtained in 3xTg-KO 5-LOX mice (Giannopoulos et al., 2014). In vitro, inhibitors of 5-LOX are less potent than COX inhibitors to protect neurons against toxicity triggered by activated monocytic or microglial cells (Klegeris and McGeer, 2002, 2003). Dual COX/5-LOX inhibitors (licofelone and flavocoxid) show anti-inflammatory activities in several brain disease models such as stroke (Minutoli et al., 2015), experimental allergic encephalitis (Kong et al., 2016), muscular dystrophy, $\mathrm{AD}$ (Bitto et al., 2017), or sepsis (Bitto et al., 2012), with a direct effect on microglia (Kong et al., 2016). The recent discovery that 5-LOX not only metabolized AA, but also DPA, whose metabolites display anti-inflammatory activities, highlights the need to evaluate whether inhibiting this enzyme in the context of high n-3 PUFA status is beneficial under neuroinflammation. In addition, human microglia stimulate a 5-LOX resolution pathway when activated by classic pathogen-associated molecular patterns such as LPS, although it is not the case not when activated by $\mathrm{A} \beta$ (Zhu et al., 2016), suggesting that the nature of the stimulus is crucial in the mobilization of 5-LOXdependent resolution pathways in microglia.

In humans, 12/15-LOX expression is constitutive in several immune cells (macrophage, immature red blood cells, eosinophil, airway epithelial cells, T lymphocytes) (Nadel et al., 1991). Animal studies using genetic deletion of these enzymes reveal the importance of $12 / 15$-LOX 
products in the regulation of inflammation (reviewed in Kuhn and O'Donnell, 2006). Classic anti-inflammatory cytokines IL-4 and IL-13 activate 12/15-LOX expression in monocytes, which do not express these enzymes in noninflammatory conditions (Brinckmann and Kühn, 1997). 15-LOX-induced lipoxin LxA4 promotes a shift from acute inflammation to resolution (Levy et al., 2001). However, different isoforms of 15-LOX identified in humans play opposing roles in prostate cancer progression through LA and AA metabolic products, respectively, 13-hydroxyoctadecadienoic acid (promotion of cancer, 15-LOX1) and 15-HETE (inhibition of cancer, 15-LOX2) (Hu et al., 2013). The 17-series DHA metabolites, through the 15-LOX2, also inhibit cancer progression (O'Flaherty et al., 2012). Lipid peroxidation, a process that is particularly enhanced in the aging and neurodegenerative brain, is mainly driven by 15-LOX1 (Brash, 1999). Of importance, there is specificity for $12 / 15$-LOX as it can directly oxidize lipid membranes containing PUFAs, leading to the direct attack on organelles, such as mitochondria. As a result, 12/15-LOX are suspected to be involved in both proinflammatory and pro-oxidative processes and the synthesis of proresolving n-3 PUFAderived compounds.

The 12/15-LOX are the most abundant forms found in the brain (reviewed in Czapski et al., 2015). AA-derived $12 / 15$-LOX products are thought to participate in synaptictransmission. The expression of these enzymes is upregulated in the brain in inflammatory conditions. The 12/15-LOX and its metabolite hydroxyeicosatetraenoic acid are found in the postmortem brain and CSF of $\mathrm{AD}$ patients (Pratico et al., 2004; Yao et al., 2005). Animal studies suggest that HETE, in addition to promoting neuroinflammation, are involved in promoting $\mathrm{A} \beta$ and loss of synaptic functions, reinforcing the idea that blocking 12/15-LOX improves the pathology (Czapski et al., 2015). However, because of NPD1, a 15-LOX product of DHA with neuroprotective and antiinflammatory properties (Bazan, 2005) with a reduced production in the brain of $\mathrm{AD}$ mice model (Lukiw and Bazan, 2006), one could wonder whether blocking 12/15LOX activity is a valuable strategy to control neuroinflammation. Rather, the use of aspirin and DHA is proposed as a preventive strategy of $\mathrm{AD}$ (Pomponi et al., 2008). AT-NPD1 attenuates cerebral ischemic injury in rodents and reduces microglia number and activation (Bazan et al., 2012; Sheets et al., 2013).

\section{Conclusion}

Brain lipid metabolism relies on a complex integration of diet, peripheral metabolism, sex, genetics, and uptake into the brain. Brain PUFA contribute to microglial homeostasis and regulate their function in health and disease, especially their role in neuroinflammatory cascades. Brain PUFA metabolism is altered in neurologic conditions, and several drugs that target the brain appear to do so via altering brain lipid metabolism. Although the detailed mechanisms remain to be elucidated, the enzymatic production of bioactive mediators and the discovery of their receptors that regulate microglial signaling and function are promising targets for the development of novel neurotherapeutics.

\section{Authorship Contributions}

Wrote or contributed to the writing of the manuscript: Layé, Nadjar, Joffre, Bazinet.

\section{References}

Abiega O, Beccari S, Diaz-Aparicio I, Nadjar A, Layé S, Leyrolle Q, Gómez-Nicola D, Domercq M, Pérez-Samartín A, Sánchez-Zafra V, et al. (2016) Neuronal hyperactivity disturbs ATP microgradients, impairs microglial motility, and reduces phagocytic receptor expression triggering apoptosis/microglial phagocytosis uncoupling. PLoS Biol 14:e1002466.

Ajmone-Cat MA, Bernardo A, Greco A, and Minghetti L (2010) Non-steroidal antiinflammatory drugs and brain inflammation: effects on microglial functions. Pharmaceuticals (Basel) 3:1949-1965.

Alfano CM, Imayama I, Neuhouser ML, Kiecolt-Glaser JK, Smith AW, Meeske K, McTiernan A, Bernstein L, Baumgartner KB, Ulrich CM, et al. (2012) Fatigue, inflammation, and $\omega-3$ and $\omega-6$ fatty acid intake among breast cancer survivors. $J$ Clin Oncol 30:1280-1287.

Aloisi F (2001) Immune function of microglia. Glia 36:165-179.

Andrieu S, Guyonnet S, Coley N, Cantet C, Bonnefoy M, Bordes S, Bories L, Cufi MN, Dantoine T, Dartigues JF, et al.; MAPT Study Group (2017) Effect of long-term omega 3 polyunsaturated fatty acid supplementation with or without multidomain intervention on cognitive function in elderly adults with memory complaints (MAPT): a randomised, placebo-controlled trial. Lancet Neurol 16:377-389.

Antonietta Ajmone-Cat M, Lavinia Salvatori M, De Simone R, Mancini M, Biagioni S, Bernardo A, Cacci E, and Minghetti L (2012) Docosahexaenoic acid modulates inflammatory and antineurogenic functions of activated microglial cells. $J$ Neurosci Res 90:575-587.

Arita M (2012) Mediator lipidomics in acute inflammation and resolution. J Biochem 152:313-319.

Arita M, Yoshida M, Hong S, Tjonahen E, Glickman JN, Petasis NA, Blumberg RS, and Serhan CN (2005) Resolvin E1, an endogenous lipid mediator derived from omega-3 eicosapentaenoic acid, protects against 2,4,6-trinitrobenzene sulfonic acidinduced colitis. Proc Natl Acad Sci USA 102:7671-7676.

Bagga D, Wang L, Farias-Eisner R, Glaspy JA, and Reddy ST (2003) Differential effects of prostaglandin derived from omega- 6 and omega-3 polyunsaturated fatty acids on COX-2 expression and IL-6 secretion. Proc Natl Acad Sci USA 100: 1751-1756.

Bannenberg G and Serhan CN (2010) Specialized pro-resolving lipid mediators in the inflammatory response: an update. Biochim Biophys Acta 1801:1260-1273.

Banni S and Di Marzo V (2010) Effect of dietary fat on endocannabinoids and related mediators: consequences on energy homeostasis, inflammation and mood. $\mathrm{Mol}$ Nutr Food Res 54:82-92.

Bazan NG (2005) Neuroprotectin D1 (NPD1): a DHA-derived mediator that protects brain and retina against cell injury-induced oxidative stress. Brain Pathol 15: 159-166.

Bazan NG (2006) Cell survival matters: docosahexaenoic acid signaling, neuroprotection and photoreceptors. Trends Neurosci 29:263-271.

Bazan NG, Eady TN, Khoutorova L, Atkins KD, Hong S, Lu Y, Zhang C, Jun B Obenaus A, Fredman G, et al. (2012) Novel aspirin-triggered neuroprotectin D1 attenuates cerebral ischemic injury after experimental stroke. Exp Neurol 236 $122-130$.

Bazan NG, Molina MF, and Gordon WC (2011) Docosahexaenoic acid signalolipidomics in nutrition: significance in aging, neuroinflammation, macular degeneration, Alzheimer's, and other neurodegenerative diseases. Annu Rev Nutr 31: $321-351$.

Bazinet RP and Layé S (2014) Polyunsaturated fatty acids and their metabolites in brain function and disease. Nat Rev Neurosci 15:771-785.

Belayev L, Khoutorova L, Atkins KD, Eady TN, Hong S, Lu Y, Obenaus A, and Bazan NG (2011) Docosahexaenoic acid therapy of experimental ischemic stroke. Transl Stroke Res 2:33-41.

Bentham P, Gray R, Sellwood E, Hills R, Crome P, and Raftery J; AD2000 Collaborative Group (2008) Aspirin in Alzheimer's disease (AD2000): a randomised openlabel trial. Lancet Neurol 7:41-49.

Bianco F, Pravettoni E, Colombo A, Schenk U, Möller T, Matteoli M, and Verderio C (2005) Astrocyte-derived ATP induces vesicle shedding and IL-1 beta release from microglia. J Immunol 174:7268-7277.

Bitto A, Giuliani D, Pallio G, Irrera N, Vandini E, Canalini F, Zaffe D, Ottani A, Minutoli L, and Rinaldi M, et al. (2017) Effects of COX1-2/5-LOX blockade in Alzheimer transgenic 3xTg-AD mice. Inflamm Res 66:389-398.

Bitto A, Minutoli L, David A, Irrera N, Rinaldi M, Venuti FS, Squadrito F, and Altavilla D (2012) Flavocoxid, a dual inhibitor of COX-2 and 5-LOX of natural origin, attenuates the inflammatory response and protects mice from sepsis. Crit Care 16:R32.

Blais V and Rivest S (2003) [Role of the innate immune response in the brain]. Med Sci (Paris) 19:981-987.

Blanchard H, Pédrono F, Boulier-Monthéan N, Catheline D, Rioux V, and Legrand P (2013) Comparative effects of well-balanced diets enriched in $\alpha$-linolenic or linoleic 
acids on LC-PUFA metabolism in rat tissues. Prostaglandins Leukot Essent Fatty Acids 88:383-389.

Bloch MH and Hannestad J (2012) Omega-3 fatty acids for the treatment of depression: systematic review and meta-analysis. Mol Psychiatry 17:1272-1282.

Bosch-Bouju C, Larrieu T, Linders L, Manzoni OJ, and Layé S (2016) Endocannabinoidmediated plasticity in nucleus accumbens controls vulnerability to anxiety after social defeat stress. Cell Reports 16:1237-1242.

Botting R (2003) COX-1 and COX-3 inhibitors. Thromb Res 110:269-272.

Boudrault C, Bazinet RP, Kang JX, and Ma DW (2010) Cyclooxygenase-2 and n-6 PUFA are lower and DHA is higher in the cortex of fat-1 mice. Neurochem Int 56:585-589.

Bousquet M, Gue K, Emond V, Julien P, Kang JX, Cicchetti F, and Calon F (2011) Transgenic conversion of omega- 6 into omega-3 fatty acids in a mouse model of Parkinson's disease. J Lipid Res 52:263-271.

Brash AR (1999) Lipoxygenases: occurrence, functions, catalysis, and acquisition of substrate. $J$ Biol Chem 274:23679-23682.

Brinckmann R and Kühn H (1997) Regulation of 15-lipoxygenase expression by cytokines. Adv Exp Med Biol 400B:599-604.

Broadhurst CL, Wang Y, Crawford MA, Cunnane SC, Parkington JE, and Schmidt WF (2002) Brain-specific lipids from marine, lacustrine, or terrestrial food resources: potential impact on early African Homo sapiens. Comp Biochem Physiol B Biochem Mol Biol 131:653-673.

Brown GC and Neher JJ (2014) Microglial phagocytosis of live neurons. Nat Rev Neurosci 15:209-216.

Buckley CD, Gilroy DW, Serhan CN, Stockinger B, and Tak PP (2013) The resolution of inflammation. Nat Rev Immunol 13:59-66.

Burdge G (2004) Alpha-linolenic acid metabolism in men and women: nutritional and biological implications. Curr Opin Clin Nutr Metab Care 7:137-144.

Buschmann JP, Berger K, Awad H, Clarner T, Beyer C, and Kipp M (2012) Inflammatory response and chemokine expression in the white matter corpus callosum and gray matter cortex region during cuprizone-induced demyelination. J Mol Neurosci 48:66-76.

Butovsky O, Jedrychowski MP, Moore CS, Cialic R, Lanser AJ, Gabriely G, Koeglsperger T, Dake B, Wu PM, Doykan CE, et al. (2014) Identification of a unique TGF- $\beta$-dependent molecular and functional signature in microglia. Nat Neurosci 17:131-143.

Calder PC (2002) Dietary modification of inflammation with lipids. Proc Nutr Soc 61: $345-358$

Calder PC (2006) n-3 polyunsaturated fatty acids, inflammation, and inflammatory diseases. Am J Clin Nutr 83(6 Suppl):1505S-1519S.

Calder PC (2007) Immunomodulation by omega-3 fatty acids. Prostaglandins Leukot Essent Fatty Acids 77:327-335.

Calder PC (2011) Fatty acids and inflammation: the cutting edge between food and pharma. Eur J Pharmacol 668:S50-S58.

Calder PC (2013) Long chain fatty acids and gene expression in inflammation and immunity. Curr Opin Clin Nutr Metab Care 16:425-433.

Calder PC (2015) Marine omega-3 fatty acids and inflammatory processes: effects, mechanisms and clinical relevance. Biochim Biophys Acta 1851:469-484.

Calderini G, Bonetti AC, Battistella A, Crews FT, and Toffano G (1983) Biochemical changes of rat brain membranes with aging. Neurochem Res 8:483-492.

Calon F (2011) Omega-3 polyunsaturated fatty acids in Alzheimer's disease: key questions and partial answers. Curr Alzheimer Res 8:470-478.

Capuron L and Miller AH (2011) Immune system to brain signaling: neuropsychopharmacological implications. Pharmacol Ther 130:226-238.

Carrié I, Clément M, de Javel D, Francès H, and Bourre JM (2000) Specific phospholipid fatty acid composition of brain regions in mice: effects of n-3 polyunsaturated fatty acid deficiency and phospholipid supplementation. J Lipid Res 41:465-472.

Casali BT, Corona AW, Mariani MM, Karlo JC, Ghosal K, and Landreth GE (2015) Omega-3 fatty acids augment the actions of nuclear receptor agonists in a mouse model of Alzheimer's disease. J Neurosci 35:9173-9181.

Chandrasekharan NV, Dai H, Roos KL, Evanson NK, Tomsik J, Elton TS, and Simmons DL (2002) COX-3, a cyclooxygenase-1 variant inhibited by acetaminophen and other analgesic/antipyretic drugs: cloning, structure, and expression. Proc Natl Acad Sci USA 99:13926-13931.

Chang CY, Kuan YH, Li JR, Chen WY, Ou YC, Pan HC, Liao SL, Raung SL, Chang CJ, and Chen CJ (2013) Docosahexaenoic acid reduces cellular inflammatory response following permanent focal cerebral ischemia in rats. $J$ Nutr Biochem 24 2127-2137.

Chang PK, Khatchadourian A, McKinney RA, and Maysinger D (2015) Docosahexaenoic acid (DHA): a modulator of microglia activity and dendritic spine morphology. $J$ Neuroinflammation 12:34.

Chauveau F, Cho TH, Perez M, Guichardant M, Riou A, Aguettaz P, Picq M, Lagarde M, Berthezène Y, Nighoghossian N, et al. (2011) Brain-targeting form of docosahexaenoic acid for experimental stroke treatment: MRI evaluation and antioxidant impact. Curr Neurovasc Res 8:95-102.

Chen CT and Bazinet RP (2015) $\beta$-oxidation and rapid metabolism, but not uptake regulate brain eicosapentaenoic acid levels. Prostaglandins Leukot Essent Fatty Acids 92:33-40.

Chen CT, Kitson AP, Hopperton KE, Domenichiello AF, Trépanier MO, Lin LE, Ermini L, Post M, Thies F, and Bazinet RP (2015) Plasma non-esterified docosahexaenoic acid is the major pool supplying the brain. Sci Rep 5:15791.

Chen CT, Ma DW, Kim JH, Mount HT, and Bazinet RP (2008) The low density lipoprotein receptor is not necessary for maintaining mouse brain polyunsaturated fatty acid concentrations. J Lipid Res 49:147-152.

Chen S, Zhang H, Pu H, Wang G, Li W, Leak RK, Chen J, Liou AK, and Hu X (2014) n-3 PUFA supplementation benefits microglial responses to myelin pathology. Sci Rep 4:7458.

Chhor V, Le Charpentier T, Lebon S, Oré MV, Celador IL, Josserand J, Degos V, Jacotot E, Hagberg H, Sävman K, et al. (2013) Characterization of phenotype markers and neuronotoxic potential of polarised primary microglia in vitro. Brain Behav Immun 32:70-85.
Chiang N, Hurwitz S, Ridker PM, and Serhan CN (2006) Aspirin has a genderdependent impact on antiinflammatory 15-epi-lipoxin A4 formation: a randomized human trial. Arterioscler Thromb Vasc Biol 26:e14-e17.

Chiurchiù V, Leuti A, Dalli J, Jacobsson A, Battistini L, Maccarrone M, and Serhan CN (2016) Proresolving lipid mediators resolvin D1, resolvin D2, and maresin 1 are critical in modulating T cell responses. Sci Transl Med 8:353ra111.

Chouinard-Watkins R and Plourde M (2014) Fatty acid metabolism in carriers of apolipoprotein E epsilon 4 allele: is it contributing to higher risk of cognitive decline and coronary heart disease? Nutrients 6:4452-4471.

Chouinard-Watkins R, Rioux-Perreault C, Fortier M, Tremblay-Mercier J, Zhang Y, Lawrence P, Vohl MC, Perron P, Lorrain D, Brenna JT, et al. (2013) Disturbance in uniformly 13C-labelled DHA metabolism in elderly human subjects carrying the apoE epsilon4 allele. Br J Nutr 110:1751-1759.

Chu J, Li JG, Ceballos-Diaz C, Golde T, and Praticò D (2013) The influence of 5-lipoxygenase on Alzheimer's disease-related tau pathology: in vivo and in vitro evidence. Biol Psychiatry 74:321-328.

Chu J and Praticò D (2011) 5-Lipoxygenase as an endogenous modulator of amyloid $\beta$ formation in vivo. Ann Neurol 69:34-46.

Clandinin MT, Chappell JE, Leong S, Heim T, Swyer PR, and Chance GW (1980) Extrauterine fatty acid accretion in infant brain: implications for fatty acid requirements. Early Hum Dev 4:131-138.

Clark RB (2002) The role of PPARs in inflammation and immunity. J Leukoc Biol 71: $388-400$.

Cole GM and Frautschy SA (2010) DHA may prevent age-related dementia. $J$ Nutr 140:869-874.

Connolly KD, Guschina IA, Yeung V, Clayton A, Draman MS, Von Ruhland C, Ludgate M, James PE, and Rees DA (2015) Characterisation of adipocyte-derived extracellular vesicles released pre- and post-adipogenesis. J Extracell Vesicles 4: 29159

Connor KM, SanGiovanni JP, Lofqvist C, Aderman CM, Chen J, Higuchi A, Hong S, Pravda EA, Majchrzak S, Carper D, et al. (2007) Increased dietary intake of omega3 -polyunsaturated fatty acids reduces pathological retinal angiogenesis. Nat Med 13:868-873.

Connor WE, Neuringer M, and Lin DS (1990) Dietary effects on brain fatty acid composition: the reversibility of n-3 fatty acid deficiency and turnover of docosahexaenoic acid in the brain, erythrocytes, and plasma of rhesus monkeys. J Lipid Res 31:237-247.

Conquer JA, Tierney MC, Zecevic J, Bettger WJ, and Fisher RH (2000) Fatty acid analysis of blood plasma of patients with Alzheimer's disease, other types of dementia, and cognitive impairment. Lipids 35:1305-1312.

Corsi L, Dongmo BM, and Avallone R (2015) Supplementation of omega 3 fatty acids improves oxidative stress in activated BV2 microglial cell line. Int J Food Sci Nutr 66:293-299.

Cortie CH, Hulbert AJ, Hancock SE, Mitchell TW, McAndrew D, and Else PL (2015) Of mice, pigs and humans: an analysis of mitochondrial phospholipids from mammals with very different maximal lifespans. Exp Gerontol 70:135-143.

Crain JM, Nikodemova M, and Watters JJ (2009) Expression of P2 nucleotide receptors varies with age and sex in murine brain microglia. $J$ Neuroinflammation 6.24.

Crain JM, Nikodemova M, and Watters JJ (2013) Microglia express distinct M1 and M2 phenotypic markers in the postnatal and adult central nervous system in male and female mice. J Neurosci Res 91:1143-1151.

Crain JM and Watters JJ (2015) Microglial P2 purinergic receptor and immunomodulatory gene transcripts vary by region, sex, and age in the healthy mouse CNS. Transcr Open Access DOI: 10.4172/2329-8936.1000124 [published ahead of print].

Crawford MA, Bloom M, Broadhurst CL, Schmidt WF, Cunnane SC, Galli C, Gehbremeskel K, Linseisen F, Lloyd-Smith J, and Parkington J (1999) Evidence for the unique function of docosahexaenoic acid during the evolution of the modern hominid brain. Lipids 34 (Suppl):S39-S47.

Czapski GA, Czubowicz K, Strosznajder JB, and Strosznajder RP (2016) The lipoxygenases: their regulation and implication in Alzheimer's disease. Neurochem Res 41:243-257.

Dantzer R, O'Connor JC, Freund GG, Johnson RW, and Kelley KW (2008) From inflammation to sickness and depression: when the immune system subjugates the brain. Nat Rev Neurosci 9:46-56.

Davalos D, Grutzendler J, Yang G, Kim JV, Zuo Y, Jung S, Littman DR, Dustin ML, and Gan WB (2005) ATP mediates rapid microglial response to local brain injury in vivo. Nat Neurosci 8:752-758.

de Haas AH, Boddeke HW, and Biber K (2008) Region-specific expression of immunoregulatory proteins on microglia in the healthy CNS. Glia 56:888-894.

Delattre AM, Carabelli B, Mori MA, Kempe PG, Rizzo de Souza LE, Zanata SM, Machado RB, Suchecki D, Andrade da Costa BLS, Lima MMS, et al. (2017) Maternal omega-3 supplement improves dopaminergic system in pre- and postnatal inflammation-induced neurotoxicity in Parkinson's disease model. Mol Neurobiol 54:2090-2106

Delion S, Chalon S, Hérault J, Guilloteau D, Besnard JC, and Durand G (1994) Chronic dietary alpha-linolenic acid deficiency alters dopaminergic and serotoninergic neurotransmission in rats. $J$ Nutr 124:2466-2476.

Delpech JC, Madore C, Joffre C, Aubert A, Kang JX, Nadjar A, and Laye S (2015a) Transgenic increase in $n-3 / n-6$ fatty acid ratio protects against cognitive deficits induced by an immune challenge through decrease of neuroinflammation. Neuropsychopharmacology 40:525-536.

Delpech JC, Thomazeau A, Madore C, Bosch-Bouju C, Larrieu T, Lacabanne C, Remus-Borel J, Aubert A, Joffre C, Nadjar A, and Laye S (2015b) Dietary n-3 PUFAs deficiency increases vulnerability to inflammation-induced spatia memory impairment. Neuropsychopharmacology 40:2774-2787.

DeMar JC Jr, Lee HJ, Ma K, Chang L, Bell JM, Rapoport SI, and Bazinet RP (2006) Brain elongation of linoleic acid is a negligible source of the arachidonate in brain phospholipids of adult rats. Biochim Biophys Acta 1761:1050-1059. 
DeMar JC Jr, Ma K, Bell JM, and Rapoport SI (2004) Half-lives of docosahexaenoic acid in rat brain phospholipids are prolonged by 15 weeks of nutritional deprivation of n-3 polyunsaturated fatty acids. J Neurochem 91:1125-1137.

de Roos B, Mavrommatis Y, and Brouwer IA (2009) Long-chain n-3 polyunsaturated fatty acids: new insights into mechanisms relating to inflammation and coronary heart disease. $\mathrm{Br}$ J Pharmacol 158:413-428.

Desai A, Park T, Barnes J, Kevala K, Chen H, and Kim HY (2016) Reduced acute neuroinflammation and improved functional recovery after traumatic brain injury by $\alpha$-linolenic acid supplementation in mice. $J$ Neuroinflammation 13:253

De Smedt-Peyrusse V, Sargueil F, Moranis A, Harizi H, Mongrand S, and Layé S (2008) Docosahexaenoic acid prevents lipopolysaccharide-induced cytokine production in microglial cells by inhibiting lipopolysaccharide receptor presentation but not its membrane subdomain localization. J Neurochem 105:296-307.

Devassy JG, Leng S, Gabbs M, Monirujjaman M, and Aukema HM (2016) Omega-3 polyunsaturated fatty acids and oxylipins in neuroinflammation and management of Alzheimer disease. Adv Nutr 7:905-916.

Di Marzo V, Stella N, and Zimmer A (2015) Endocannabinoid signalling and the deteriorating brain. Nat Rev Neurosci 16:30-42.

Dinel AL, Rey C, Baudry C, Fressange-Mazda C, Le Ruyet P, Nadjar A, Pallet P, Joffre C, and Layé S (2016) Enriched dairy fat matrix diet prevents early life lipopolysaccharide-induced spatial memory impairment at adulthood. Prostaglandins Leukot Essent Fatty Acids 113:9-18.

DiRusso CC, Li H, Darwis D, Watkins PA, Berger J, and Black PN (2005) Comparative biochemical studies of the murine fatty acid transport proteins (FATP) expressed in yeast. J Biol Chem 280:16829-16837.

Doorn KJ, Brevé JJ, Drukarch B, Boddeke HW, Huitinga I, Lucassen PJ, and van Dam AM (2015) Brain region-specific gene expression profiles in freshly isolated rat microglia. Front Cell Neurosci 9:84.

Dunn HC, Ager RR, Baglietto-Vargas D, Cheng D, Kitazawa M, Cribbs DH, and Medeiros R (2015) Restoration of lipoxin A4 signaling reduces Alzheimer's disease-like pathology in the 3xTg-AD mouse model. J Alzheimers Dis 43:893-903.

Dyall SC (2015) Long-chain omega-3 fatty acids and the brain: a review of the independent and shared effects of EPA, DPA and DHA. Front Aging Neurosci 7:52.

Eady TN, Belayev L, Khoutorova L, Atkins KD, Zhang C, and Bazan NG (2012a) Docosahexaenoic acid signaling modulates cell survival in experimental ischemic stroke penumbra and initiates long-term repair in young and aged rats. PLoS One 7:e46151.

Eady TN, Khoutorova L, Atkins KD, Bazan NG, and Belayev L (2012b) Docosahexaenoic acid complexed to human albumin in experimental stroke: neuroprotective efficacy with a wide therapeutic window. Exp Transl Stroke Med 4:19.

Eady TN, Khoutorova L, Obenaus A, Mohd-Yusof A, Bazan NG, and Belayev L (2014) Docosahexaenoic acid complexed to albumin provides neuroprotection after experimental stroke in aged rats. Neurobiol Dis 62:1-7.

Ebert S, Weigelt K, Walczak Y, Drobnik W, Mauerer R, Hume DA, Weber BH, and Langmann T (2009) Docosahexaenoic acid attenuates microglial activation and delays early retinal degeneration. J Neurochem 110:1863-1875.

Edwards R, Peet M, Shay J, and Horrobin D (1998) Omega-3 polyunsaturated fatty acid levels in the diet and in red blood cell membranes of depressed patients. $J$ Affect Disord 48:149-155.

Elsherbiny ME, Emara M, and Godbout R (2013) Interaction of brain fatty acidbinding protein with the polyunsaturated fatty acid environment as a potential determinant of poor prognosis in malignant glioma. Prog Lipid Res 52:562-570.

Endo J, Sano M, Isobe Y, Fukuda K, Kang JX, Arai H, and Arita M (2014) 18-HEPE an n-3 fatty acid metabolite released by macrophages, prevents pressure overloadinduced maladaptive cardiac remodeling. J Exp Med 211:1673-1687.

Extier A, Langelier B, Perruchot MH, Guesnet P, Van Veldhoven PP, Lavialle M, and Alessandri JM (2010) Gender affects liver desaturase expression in a rat model of n-3 fatty acid repletion. $J$ Nutr Biochem 21:180-187.

Farias SE, Zarini S, Precht T, Murphy RC, and Heidenreich KA (2007) Transcellular biosynthesis of cysteinyl leukotrienes in rat neuronal and glial cells. J Neurochem 103:1310-1318

Farooqui AA, Ong WY, and Horrocks LA (2006) Inhibitors of brain phospholipase A2 activity: their neuropharmacological effects and therapeutic importance for the treatment of neurologic disorders. Pharmacol Rev 58:591-620.

Farzaneh-Far R, Harris WS, Garg S, Na B, and Whooley MA (2009) Inverse association of erythrocyte n-3 fatty acid levels with inflammatory biomarkers in patients with stable coronary artery disease: the Heart and Soul Study. Atherosclerosis 205 538-543.

Favrelière S, Perault MC, Huguet F, De Javel D, Bertrand N, Piriou A, and Durand G (2003) DHA-enriched phospholipid diets modulate age-related alterations in rat hippocampus. Neurobiol Aging 24:233-243.

Ferrucci L, Cherubini A, Bandinelli S, Bartali B, Corsi A, Lauretani F, Martin A, Andres-Lacueva C, Senin U, and Guralnik JM (2006) Relationship of plasma polyunsaturated fatty acids to circulating inflammatory markers. $J$ Clin Endocrinol Metab 91:439-446.

Fiala M, Halder RC, Sagong B, Ross O, Sayre J, Porter V, and Bredesen DE (2015) $\omega-3$ Supplementation increases amyloid- $\beta$ phagocytosis and resolvin D1 in patients with minor cognitive impairment. FASEB J 29:2681-2689.

Fischer R, Konkel A, Mehling H, Blossey K, Gapelyuk A, Wessel N, von Schacky C, Dechend R, Muller DN, Rothe M, et al. (2014) Dietary omega-3 fatty acids modulate the eicosanoid profile in man primarily via the CYP-epoxygenase pathway. $J$ Lipid Res 55:1150-1164.

Forman BM, Chen J, and Evans RM (1997) Hypolipidemic drugs, polyunsaturated fatty acids, and eicosanoids are ligands for peroxisome proliferator-activated receptors alpha and delta. Proc Natl Acad Sci USA 94:4312-4317.

Fowler CJ (2015) The potential of inhibitors of endocannabinoid metabolism for drug development: a critical review. Handb Exp Pharmacol 231:95-128.

Fredman G and Serhan CN (2011) Specialized proresolving mediator targets for $\mathrm{RvE} 1$ and RvD1 in peripheral blood and mechanisms of resolution. Biochem $J \mathbf{4 3 7}$ : 185-197.
Freund-Levi Y, Eriksdotter-Jönhagen M, Cederholm T, Basun H, Faxén-Irving G, Garlind A, Vedin I, Vessby B, Wahlund LO, and Palmblad J (2006) Omega-3 fatty acid treatment in 174 patients with mild to moderate Alzheimer disease: OmegAD study: a randomized double-blind trial. Arch Neurol 63:1402-1408.

Freund-Levi Y, Vedin I, Hjorth E, Basun H, Faxén Irving G, Schultzberg M, Eriksdotter M, Palmblad J, Vessby B, Wahlund LO, et al. (2014) Effects of supplementation with omega-3 fatty acids on oxidative stress and inflammation in patients with Alzheimer's disease: the OmegAD study. J Alzheimers Dis 42 : 823-831.

Gabrielli M, Battista N, Riganti L, Prada I, Antonucci F, Cantone L, Matteoli M, Maccarrone M, and Verderio C (2015) Active endocannabinoids are secreted on extracellular membrane vesicles. EMBO Rep 16:213-220.

Geppert J, Min Y, Neville M, Lowy C, and Ghebremeskel K (2010) Gender-specific fatty acid profiles in platelet phosphatidyl-choline and -ethanolamine. Prostaglandins Leukot Essent Fatty Acids 82:51-56.

Giannopoulos PF, Chu J, Joshi YB, Sperow M, Li JG, Kirby LG, and Praticò D (2014) Gene knockout of 5-lipoxygenase rescues synaptic dysfunction and improves memory in the triple-transgenic model of Alzheimer's disease. Mol Psychiatry 19: 511-518.

Giedd JN, Blumenthal J, Jeffries NO, Castellanos FX, Liu H, Zijdenbos A, Paus T, Evans AC, and Rapoport JL (1999) Brain development during childhood and adolescence: a longitudinal MRI study. Nat Neurosci 2:861-863.

Giltay EJ, Gooren LJ, Toorians AW, Katan MB, and Zock PL (2004) Docosahexaenoic acid concentrations are higher in women than in men because of estrogenic effects Am J Clin Nutr 80:1167-1174.

Grabert K, Michoel T, Karavolos MH, Clohisey S, Baillie JK, Stevens MP, Freeman TC, Summers KM, and McColl BW (2016) Microglial brain region-dependent diversity and selective regional sensitivities to aging. Nat Neurosci 19:504-516.

Griciuc A, Serrano-Pozo A, Parrado AR, Lesinski AN, Asselin CN, Mullin K, Hooli B, Choi SH, Hyman BT, and Tanzi RE (2013) Alzheimer's disease risk gene CD33 inhibits microglial uptake of amyloid beta. Neuron 78:631-643.

Groeger AL, Cipollina C, Cole MP, Woodcock SR, Bonacci G, Rudolph TK, Rudolph V, Freeman BA, and Schopfer FJ (2010) Cyclooxygenase-2 generates antiinflammatory mediators from omega-3 fatty acids. Nat Chem Biol 6:433-441.

Grundy T, Toben C, Jaehne EJ, Corrigan F, and Baune BT (2014) Long-term omega-3 supplementation modulates behavior, hippocampal fatty acid concentration, neuronal progenitor proliferation and central TNF- $\alpha$ expression in 7 month old unchallenged mice. Front Cell Neurosci 8:399.

Hall TC, Bilku DK, Neal CP, Cooke J, Fisk HL, Calder PC, and Dennison AR (2016) The impact of an omega-3 fatty acid rich lipid emulsion on fatty acid profiles in critically ill septic patients. Prostaglandins Leukot Essent Fatty Acids 112:1-11.

Hamazaki K, Maekawa M, Toyota T, Dean B, Hamazaki T, and Yoshikawa T (2015) Fatty acid composition of the postmortem prefrontal cortex of patients with schizophrenia, bipolar disorder, and major depressive disorder. Psychiatry Res 227: 353-359.

Hamazaki K, Maekawa M, Toyota T, Iwayama Y, Dean B, Hamazaki T, and Yoshikawa T (2016) Fatty acid composition and fatty acid binding protein expression in the postmortem frontal cortex of patients with schizophrenia: a casecontrol study. Schizophr Res 171:225-232.

Hamilton JA (1998) Fatty acid transport: difficult or easy? J Lipid Res 39:467-481. Hanisch UK and Kettenmann H (2007) Microglia: active sensor and versatile effector cells in the normal and pathologic brain. Nat Neurosci 10:1387-1394.

Haraszti RA, Didiot MC, Sapp E, Leszyk J, Shaffer SA, Rockwell HE, Gao F, Narain NR, DiFiglia M, Kiebish MA, et al. (2016) High-resolution proteomic and lipidomic analysis of exosomes and microvesicles from different cell sources. J Extracell Vesicles 5:32570.

Harauma A and Moriguchi T (2011) Dietary n-3 fatty acid deficiency in mice enhances anxiety induced by chronic mild stress. Lipids 46:409-416.

Harrison JL, Rowe RK, Ellis TW, Yee NS, O'Hara BF, Adelson PD, and Lifshitz J (2015) Resolvins AT-D1 and E1 differentially impact functional outcome, posttraumatic sleep, and microglial activation following diffuse brain injury in the mouse. Brain Behav Immun 47:131-140.

Harvey LD, Yin Y, Attarwala IY, Begum G, Deng J, Yan HQ, Dixon CE, and Sun D (2015) Administration of DHA reduces endoplasmic reticulum stress-associated inflammation and alters microglial or macrophage activation in traumatic brain injury. ASN Neuro DOI: 10.1177/1759091415618969 [published ahead of print].

He C, Qu X, Cui L, Wang J, and Kang JX (2009) Improved spatial learning performance of fat- 1 mice is associated with enhanced neurogenesis and neuritogenesis by docosahexaenoic acid. Proc Natl Acad Sci USA 106:11370-11375.

Headland SE and Norling LV (2015) The resolution of inflammation: principles and challenges. Semin Immunol 27:149-160.

Heneka MT, Carson MJ, El Khoury J, Landreth GE, Brosseron F, Feinstein DL, Jacobs AH, Wyss-Coray T, Vitorica J, Ransohoff RM, et al. (2015) Neuroinflammation in Alzheimer's disease. Lancet Neurol 14:388-405.

Hennebelle M, Plourde M, Chouinard-Watkins R, Castellano CA, Barberger-Gateau $\mathrm{P}$, and Cunnane SC (2014) Ageing and apoE change DHA homeostasis: relevance to age-related cognitive decline. Proc Nutr Soc 73:80-86.

Hickman SE, Kingery ND, Ohsumi TK, Borowsky ML, Wang LC, Means TK, and El Khoury J (2013) The microglial sensome revealed by direct RNA sequencing. Nat Neurosci 16:1896-1905.

Hjorth E, Zhu M, Toro VC, Vedin I, Palmblad J, Cederholm T, Freund-Levi Y, FaxenIrving $\mathrm{G}$, Wahlund LO, Basun $\mathrm{H}$, et al. (2013) Omega-3 fatty acids enhance phagocytosis of Alzheimer's disease-related amyloid- $\beta 42$ by human microglia and decrease inflammatory markers. J Alzheimers Dis 35:697-713.

Hong S, Gronert K, Devchand PR, Moussignac RL, and Serhan CN (2003) Novel docosatrienes and 17S-resolvins generated from docosahexaenoic acid in murine brain, human blood, and glial cells: autacoids in anti-inflammation. $J$ Biol Chem 278:14677-14687.

Hopperton KE, Trépanier MO, Giuliano V, and Bazinet RP (2016) Brain omega-3 polyunsaturated fatty acids modulate microglia cell number and morphology in 
response to intracerebroventricular amyloid- $\beta$ 1-40 in mice. $J$ Neuroinflammation 13:257.

Hu Y, Sun H, O'Flaherty JT, and Edwards IJ (2013) 15-Lipoxygenase-1-mediated metabolism of docosahexaenoic acid is required for syndecan-1 signaling and apoptosis in prostate cancer cells. Carcinogenesis 34:176-182.

Huang CT and Tsai YJ (2016) Docosahexaenoic acid confers analgesic effects after median nerve injury via inhibition of c-Jun $\mathrm{N}$-terminal kinase activation in microglia. J Nutr Biochem 29:97-106.

Huang WL, King VR, Curran OE, Dyall SC, Ward RE, Lal N, Priestley JV, and MichaelTitus AT (2007) A combination of intravenous and dietary docosahexaenoic acid significantly improves outcome after spinal cord injury. Brain 130:3004-3019.

Igarashi M, DeMar JC Jr, Ma K, Chang L, Bell JM, and Rapoport SI (2007) Docosahexaenoic acid synthesis from alpha-linolenic acid by rat brain is unaffected by dietary n-3 PUFA deprivation. J Lipid Res 48:1150-1158.

Im DS (2012) Omega-3 fatty acids in anti-inflammation (pro-resolution) and GPCRs Prog Lipid Res 51:232-237.

Inoue T, Tanaka M, Masuda S, Ohue-Kitano R, Yamakage H, Muranaka K, Wada H, Kusakabe T, Shimatsu A, Hasegawa K, et al. (2017) Omega-3 polyunsaturated fatty acids suppress the inflammatory responses of lipopolysaccharide-stimulated mouse microglia by activating SIRT1 pathways. Biochim Biophys Acta 1862 $552-560$.

Jay AG. and Hamilton JA (2016) The enigmatic membrane fatty acid transporter CD36: new insights into fatty acid binding and their effects on uptake of oxidized LDL. Prostaglandins Leukot Essent Fatty Acids DOI: 10.1016/j.plefa.2016.05.005 [published ahead of print].

Ji A, Diao H, Wang X, Yang R, Zhang J, Luo W, Cao R, Cao Z, Wang F, and Cai T (2012) n-3 Polyunsaturated fatty acids inhibit lipopolysaccharide-induced microglial activation and dopaminergic injury in rats. Neurotoxicology 33:780-788.

Jia Z, Pei Z, Maiguel D, Toomer CJ, and Watkins PA (2007) The fatty acid transport protein (FATP) family: very long chain acyl-CoA synthetases or solute carriers? J Mol Neurosci 33:25-31.

Jiang X, Pu H, Hu X, Wei Z, Hong D, Zhang W, Gao Y, Chen J, and Shi Y (2016) A post-stroke therapeutic regimen with omega-3 polyunsaturated fatty acids that promotes white matter integrity and beneficial microglial responses after cerebral ischemia. Transl Stroke Res 7:548-561.

Jiao J, Li Q, Chu J, Zeng W, Yang M, and Zhu S (2014) Effect of n-3 PUFA supplementation on cognitive function throughout the life span from infancy to old age: a systematic review and meta-analysis of randomized controlled trials. Am J Clin Nutr 100:1422-1436.

Jickling GC, Liu D, Ander BP, Stamova B, Zhan X, and Sharp FR (2015) Targeting neutrophils in ischemic stroke: translational insights from experimental studies. $J$ Cereb Blood Flow Metab 35:888-901.

Joffre C, Grégoire S, De Smedt V, Acar N, Bretillon L, Nadjar A, and Layé S (2016) Modulation of brain PUFA content in different experimental models of mice. Prostaglandins Leukot Essent Fatty Acids 114:1-10.

Joffre C, Nadjar A, Lebbadi M, Calon F, and Laye S (2014) n-3 LCPUFA improves cognition: the young, the old and the sick. Prostaglandins Leukot Essent Fatty Acids 91:1-20.

Jones PJ, Lin L, Gillingham LG, Yang H, and Omar JM (2014) Modulation of plasma $\mathrm{N}$-acylethanolamine levels and physiological parameters by dietary fatty acid composition in humans. J Lipid Res 55:2655-2664

Joosten MM, Balvers MG, Verhoeckx KC, Hendriks HF, and Witkamp RF (2010) Plasma anandamide and other $\mathrm{N}$-acylethanolamines are correlated with their corresponding free fatty acid levels under both fasting and non-fasting conditions in women. Nutr Metab 7:49.

Joshi YB and Praticò D (2015) The 5-lipoxygenase pathway: oxidative and inflammatory contributions to the Alzheimer's disease phenotype. Front Cell Neurosci 8:436.

Keelan JA, Mas E, D’Vaz N, Dunstan JA, Li S, Barden AE, Mark PJ, Waddell BJ, Prescott SL, and Mori TA (2015) Effects of maternal n-3 fatty acid supplementation on placental cytokines, pro-resolving lipid mediators and their precursors. $R e$ production 149:171-178.

Keenan AH, Pedersen TL, Fillaus K, Larson MK, Shearer GC, and Newman JW (2012) Basal omega-3 fatty acid status affects fatty acid and oxylipin responses to high-dose n3-HUFA in healthy volunteers. J Lipid Res 53:1662-1669.

Kelley DS, Taylor PC, Nelson GJ, Schmidt PC, Ferretti A, Erickson KL, Yu R, Chandra RK, and Mackey BE (1999) Docosahexaenoic acid ingestion inhibits natural killer cell activity and production of inflammatory mediators in young healthy men. Lipids 34:317-324.

Kettenmann H, Hanisch UK, Noda M, and Verkhratsky A (2011) Physiology of microglia. Physiol Rev 91:461-553.

Kidd PM (2007) Omega-3 DHA and EPA for cognition, behavior, and mood: clinical findings and structural-functional synergies with cell membrane phospholipids. Altern Med Rev 12:207-227.

Kiecolt-Glaser JK (2010) Stress, food, and inflammation: psychoneuroimmunology and nutrition at the cutting edge. Psychosom Med 72:365-369.

Kiecolt-Glaser JK, Belury MA, Andridge R, Malarkey WB, and Glaser R (2011) Omega-3 supplementation lowers inflammation and anxiety in medical students: a randomized controlled trial. Brain Behav Immun 25:1725-1734.

Kiecolt-Glaser JK, Belury MA, Porter K, Beversdorf DQ, Lemeshow S, and Glaser R (2007) Depressive symptoms, omega-6:omega-3 fatty acids, and inflammation in older adults. Psychosom Med 69:217-224.

Kiecolt-Glaser JK, Derry HM, and Fagundes CP (2015) Inflammation: depression fans the flames and feasts on the heat. Am J Psychiatry 172:1075-1091.

Kim HY, Spector AA, and Xiong ZM (2011) A synaptogenic amide N-docosahexaenoylethanolamide promotes hippocampal development. Prostaglandins Other Lipid Mediat 96:114-120.

Kitajka K, Sinclair AJ, Weisinger RS, Weisinger HS, Mathai M, Jayasooriya AP Halver JE, and Puskás LG (2004) Effects of dietary omega-3 polyunsaturated fatty acids on brain gene expression. Proc Natl Acad Sci USA 101:10931-10936.
Klegeris A and McGeer PL (2002) Cyclooxygenase and 5-lipoxygenase inhibitors protect against mononuclear phagocyte neurotoxicity. Neurobiol Aging 23:787-794. Klegeris A and McGeer PL (2003) Toxicity of human monocytic THP-1 cells and microglia toward SH-SY5Y neuroblastoma cells is reduced by inhibitors of 5-lipoxygenase and its activating protein FLAP. J Leukoc Biol 73:369-378.

Klek S (2016) Omega-3 fatty acids in modern parenteral nutrition: a review of the current evidence. J Clin Med DOI: 10.3390/jcm5030034 [published ahead of print] Koizumi S, Ohsawa K, Inoue K, and Kohsaka S (2013) Purinergic receptors in microglia: functional modal shifts of microglia mediated by P2 and P1 receptors. Glia 61:47-54.

Kong W, Hooper KM, and Ganea D (2016) The natural dual cyclooxygenase and 5 -lipoxygenase inhibitor flavocoxid is protective in EAE through effects on Th1/ Th17 differentiation and macrophage/microglia activation. Brain Behav Immun 53:59-71.

Kuda O (2017) Bioactive metabolites of docosahexaenoic acid. Biochimie 136:12-20. Kuhn H, Banthiya S, and van Leyen K (2015) Mammalian lipoxygenases and their biological relevance. Biochim Biophys Acta 1851:308-330.

Kühn H and O'Donnell VB (2006) Inflammation and immune regulation by $12 / 15$ lipoxygenases. Prog Lipid Res 45:334-356.

Kuperstein F, Eilam R, and Yavin E (2008) Altered expression of key dopaminergic regulatory proteins in the postnatal brain following perinatal n-3 fatty acid dietary deficiency. $J$ Neurochem 106:662-671.

Kurtys E, Eisel UL, Verkuyl JM, Broersen LM, Dierckx RA, and de Vries EF (2016) The combination of vitamins and omega-3 fatty acids has an enhanced antiinflammatory effect on microglia. Neurochem Int 99:206-214.

Labrousse VF, Nadjar A, Joffre C, Costes L, Aubert A, Grégoire S, Bretillon L, and Layé S (2012) Short-term long chain omega3 diet protects from neuroinflammatory processes and memory impairment in aged mice. PLoS One 7: e36861.

Lafourcade M, Larrieu T, Mato S, Duffaud A, Sepers M, Matias I, De Smedt-Peyrusse V, Labrousse VF, Bretillon L, Matute C, et al. (2011) Nutritional omega-3 deficiency abolishes endocannabinoid-mediated neuronal functions. Nat Neurosci 14: $345-350$.

Lagarde M, Bernoud N, Brossard N, Lemaitre-Delaunay D, Thiès F, Croset M, and Lecerf $J$ (2001) Lysophosphatidylcholine as a preferred carrier form of docosahexaenoic acid to the brain. J Mol Neurosci 16:201-204, discussion 215-221.

Lalancette-Hébert M, Julien C, Cordeau P, Bohacek I, Weng YC, Calon F, and Kriz J (2011) Accumulation of dietary docosahexaenoic acid in the brain attenuates acute immune response and development of postischemic neuronal damage. Stroke 42: $2903-2909$

Larrieu T, Hilal ML, De Smedt-Peyrusse V, Sans N, and Layé S (2016) Nutritional omega-3 deficiency alters glucocorticoid receptor-signaling pathway and neuronal morphology in regionally distinct brain structures associated with emotional deficits. Neural Plast 2016:8574830.

Larrieu T, Hilal ML, Fourrier C, De Smedt-Peyrusse V, Sans N, Capuron L, and Layé $\mathrm{S}$ (2014) Nutritional omega-3 modulates neuronal morphology in the prefrontal cortex along with depression-related behaviour through corticosterone secretion. Transl Psychiatry 4:e437.

Larrieu T, Madore C, Joffre C, and Layé S (2012) Nutritional n-3 polyunsaturated fatty acids deficiency alters cannabinoid receptor signaling pathway in the brain and associated anxiety-like behavior in mice. J Physiol Biochem 68:671-681.

Lawson LJ, Perry VH, Dri P, and Gordon S (1990) Heterogeneity in the distribution and morphology of microglia in the normal adult mouse brain. Neuroscience 39: $151-170$

Layé S (2010) Polyunsaturated fatty acids, neuroinflammation and well being. Prostaglandins Leukot Essent Fatty Acids 82:295-303.

Ledesma MD, Martin MG, and Dotti CG (2012) Lipid changes in the aged brain effect on synaptic function and neuronal survival. Prog Lipid Res 51:23-35.

Lee JW, Huang BX, Kwon H, Rashid MA, Kharebava G, Desai A, Patnaik S, Marugan J, and Kim HY (2016) Orphan GPR110 (ADGRF1) targeted by $\mathrm{N}$-docosahexaenoylethanolamine in development of neurons and cognitive function. Nat Commun 7:13123.

Lenz KM, Nugent BM, Haliyur R, and McCarthy MM (2013) Microglia are essential to masculinization of brain and behavior. $J$ Neurosci 33:2761-2772.

Levine B, Mizushima N, and Virgin HW (2011) Autophagy in immunity and inflammation. Nature 469:323-335.

Levy BD, Clish CB, Schmidt B, Gronert K, and Serhan CN (2001) Lipid mediator class switching during acute inflammation: signals in resolution. Nat Immunol 2 : $612-619$.

Lewinska A, Zebrowski J, Duda M, Gorka A, and Wnuk M (2015) Fatty acid profile and biological activities of linseed and rapeseed oils. Molecules 20:22872-22880

Li L, Wu Y, Wang Y, Wu J, Song L, Xian W, Yuan S, Pei L, and Shang Y (2014) Resolvin D1 promotes the interleukin-4-induced alternative activation in BV-2 microglial cells. J Neuroinflammation 11:72.

Lim SN, Gladman SJ, Dyall SC, Patel U, Virani N, Kang JX, Priestley JV, and Michael-Titus AT (2013a) Transgenic mice with high endogenous omega-3 fatty acids are protected from spinal cord injury. Neurobiol Dis 51:104-112.

Lim SN, Huang W, Hall JC, Michael-Titus AT, and Priestley JV (2013b) Improved outcome after spinal cord compression injury in mice treated with docosahexaenoic acid. Exp Neurol 239:13-27.

Lin PY, Huang SY, and Su KP (2010) A meta-analytic review of polyunsaturated fatty acid compositions in patients with depression. Biol Psychiatry 68:140-147.

Lin YH, Brown JA, DiMartino C, Dahms I, Salem N Jr, and Hibbeln JR (2016) Differences in long chain polyunsaturates composition and metabolism in male and female rats. Prostaglandins Leukot Essent Fatty Acids 113:19-27.

Little SJ, Lynch MA, Manku M, and Nicolaou A (2007) Docosahexaenoic acid-induced changes in phospholipids in cortex of young and aged rats: a lipidomic analysis. Prostaglandins Leukot Essent Fatty Acids 77:155-162.

Liuzzi GM, Latronico T, Rossano R, Viggiani S, Fasano A, and Riccio P (2007) Inhibitory effect of polyunsaturated fatty acids on MMP-9 release from microglial 
cells-implications for complementary multiple sclerosis treatment. Neurochem Res 32:2184-2193.

López GH, Ilincheta de Boschero MG, Castagnet PI, and Giusto NM (1995) Ageassociated changes in the content and fatty acid composition of brain glycerophospholipids. Comp Biochem Physiol B Biochem Mol Biol 112:331-343.

Lotrich FE, Sears B, and McNamara RK (2013) Elevated ratio of arachidonic acid to long-chain omega-3 fatty acids predicts depression development following interferon-alpha treatment: relationship with interleukin-6. Brain Behav Immun 31:48-53.

Lo Van A, Sakayori N, Hachem M, Belkouch M, Picq M, Lagarde M, Osumi N and Bernoud-Hubac N (2016) Mechanisms of DHA transport to the brain and potential therapy to neurodegenerative diseases. Biochimie 130:163-167.

Lu DY, Tsao YY, Leung YM, and Su KP (2010) Docosahexaenoic acid suppresses neuroinflammatory responses and induces heme oxygenase-1 expression in BV-2 microglia: implications of antidepressant effects for $\omega-3$ fatty acids. Neuropsychopharmacology 35:2238-2248.

Lu Y, Zhao LX, Cao DL, and Gao YJ (2013) Spinal injection of docosahexaenoic acid attenuates carrageenan-induced inflammatory pain through inhibition of microglia-mediated neuroinflammation in the spinal cord. Neuroscience 241:22-31.

Lucas M, Asselin G, Mérette C, Poulin MJ, and Dodin S (2009) Validation of an FFQ for evaluation of EPA and DHA intake. Public Health Nutr 12:1783-1790.

Lucin KM, O’Brien CE, Bieri G, Czirr E, Mosher KI, Abbey RJ, Mastroeni DF, Rogers J, Spencer B, Masliah E, et al. (2013) Microglial beclin 1 regulates retromer trafficking and phagocytosis and is impaired in Alzheimer's disease. Neuron 79: $873-886$.

Lucin KM and Wyss-Coray T (2009) Immune activation in brain aging and neurodegeneration: too much or too little? Neuron 64:110-122.

Lukiw WJ and Bazan NG (2000) Neuroinflammatory signaling upregulation in Alzheimer's disease. Neurochem Res 25:1173-1184.

Lukiw WJ and Bazan NG (2006) Survival signalling in Alzheimer's disease. Biochem Soc Trans 34:1277-1282.

Lukiw WJ, Cui JG, Marcheselli VL, Bodker M, Botkjaer A, Gotlinger K, Serhan CN, and Bazan NG (2005) A role for docosahexaenoic acid-derived neuroprotectin D1 in neural cell survival and Alzheimer disease. J Clin Invest 115:2774-2783.

Lynch AM, Loane DJ, Minogue AM, Clarke RM, Kilroy D, Nally RE, Roche OJ, O'Connell F, and Lynch MA (2007) Eicosapentaenoic acid confers neuroprotection in the amyloid-beta challenged aged hippocampus. Neurobiol Aging 28:845-855.

Ma QL, Yang F, Rosario ER, Ubeda OJ, Beech W, Gant DJ, Chen PP, Hudspeth B, Chen C, Zhao Y, et al. (2009) Beta-amyloid oligomers induce phosphorylation of tau and inactivation of insulin receptor substrate via c-Jun N-terminal kinase signaling: suppression by omega-3 fatty acids and curcumin. $J$ Neurosci 29:9078-9089.

Madore C, Nadjar A, Delpech JC, Sere A, Aubert A, Portal C, Joffre C, and Layé S (2014) Nutritional n-3 PUFAs deficiency during perinatal periods alters brain innate immune system and neuronal plasticity-associated genes. Brain Behav Immun 41:22-31.

Maes M, Christophe A, Bosmans E, Lin A, and Neels H (2000) In humans, serum polyunsaturated fatty acid levels predict the response of proinflammatory cytokines to psychologic stress. Biol Psychiatry 47:910-920.

Magnusardottir AR, Steingrimsdottir L, Thorgeirsdottir H, Gunnlaugsson G, and Skuladottir GV (2009) Docosahexaenoic acid in red blood cells of women of reproductive age is positively associated with oral contraceptive use and physical activity. Prostaglandins Leukot Essent Fatty Acids 80:27-32.

Malvy D, Preziosi P, Galan P, Roussel AM, Favier A, Briancon S, and Hercberg S (1999) La consommation de lipides en France: contribution à l'équilibre nutritionnel (données préliminaires de l'étude SU.VI.MAX). Ol Corps Gras Lipides 6:21-25

Manzhulo IV, Ogurtsova OS, Lamash NE, Latyshev NA, Kasyanov SP, and Dyuizen IV (2015) Analgetic effect of docosahexaenoic acid is mediated by modulating the microglia activity in the dorsal root ganglia in a rat model of neuropathic pain. Acta Histochem 117:659-666.

Marcheselli VL, Hong S, Lukiw WJ, Tian XH, Gronert K, Musto A, Hardy M, Gimenez JM, Chiang N, Serhan CN, et al. (2003) Novel docosanoids inhibit brain ischemia-reperfusion-mediated leukocyte infiltration and pro-inflammatory gene expression. J Biol Chem 278:43807-43817.

Marcheselli VL, Mukherjee PK, Arita M, Hong S, Antony R, Sheets K, Winkler JW, Petasis NA, Serhan CN, and Bazan NG (2010) Neuroprotectin D1/protectin D1 stereoselective and specific binding with human retinal pigment epithelial cells and neutrophils. Prostaglandins Leukot Essent Fatty Acids 82:27-34.

Markworth JF, Kaur G, Miller EG, Larsen AE, Sinclair AJ, Maddipati KR, and Cameron-Smith D (2016) Divergent shifts in lipid mediator profile following supplementation with n-3 docosapentaenoic acid and eicosapentaenoic acid FASEB J 30:3714-3725.

Martin DS, Lonergan PE, Boland B, Fogarty MP, Brady M, Horrobin DF, Campbell VA, and Lynch MA (2002) Apoptotic changes in the aged brain are triggered by interleukin-1beta-induced activation of p38 and reversed by treatment with eicosapentaenoic acid. J Biol Chem 277:34239-34246.

Martinelli N, Girelli D, Malerba G, Guarini P, Illig T, Trabetti E, Sandri M, Friso S, Pizzolo F, Schaeffer L, et al. (2008) FADS genotypes and desaturase activity estimated by the ratio of arachidonic acid to linoleic acid are associated with in flammation and coronary artery disease. Am J Clin Nutr 88:941-949.

Martini AC, Berta T, Forner S, Chen G, Bento AF, Ji RR, and Rae GA (2016) Lipoxin A4 inhibits microglial activation and reduces neuroinflammation and neuropathic pain after spinal cord hemisection. $J$ Neuroinflammation 13:75.

Martins JG (2009) EPA but not DHA appears to be responsible for the efficacy of omega-3 long chain polyunsaturated fatty acid supplementation in depression: evidence from a meta-analysis of randomized controlled trials. J Am Coll Nutr 28: $525-542$

Martins V, Valença SS, Farias-Filho FA, Molinaro R, Simões RL, Ferreira TP, e Silva PM, Hogaboam CM, Kunkel SL, Fierro IM, et al. (2009) ATLa, an aspirin-triggered lipoxin A4 synthetic analog, prevents the inflammatory and fibrotic effects of bleomycin-induced pulmonary fibrosis. J Immunol 182:5374-5381.
Mas E, Barden A, Burke V, Beilin LJ, Watts GF, Huang RC, Puddey IB, Irish AB, and Mori TA (2016) A randomized controlled trial of the effects of n-3 fatty acids on resolvins in chronic kidney disease. Clin Nutr 35:331-336.

Mashek DG, Li LO, and Coleman RA (2007) Long-chain acyl-CoA synthetases and fatty acid channeling. Future Lipidol 2:465-476.

McCarthy MM, Pickett LA, VanRyzin JW, and Kight KE (2015) Surprising origins of sex differences in the brain. Horm Behav 76:3-10.

McGeer PL and McGeer EG (2007) NSAIDs and Alzheimer disease: epidemiological, animal model and clinical studies. Neurobiol Aging 28:639-647.

McNamara RK (2015) Mitigation of inflammation-induced mood dysregulation by long-chain omega-3 fatty acids. J Am Coll Nutr 34 Suppl 1:48-55.

McNamara RK, Able J, Jandacek R, Rider T, and Tso P (2009) Inbred C57BL/6J and $\mathrm{DBA} / 2 \mathrm{~J}$ mouse strains exhibit constitutive differences in regional brain fatty acid composition. Lipids 44:1-8.

McNamara RK, Jandacek R, Rider T, Tso P, Cole-Strauss A, and Lipton JW (2010) Omega-3 fatty acid deficiency increases constitutive pro-inflammatory cytokine production in rats: relationship with central serotonin turnover. Prostaglandins Leukot Essent Fatty Acids 83:185-191.

McNamara RK, Liu Y, Jandacek R, Rider T, and Tso P (2008) The aging human orbitofrontal cortex: decreasing polyunsaturated fatty acid composition and associated increases in lipogenic gene expression and stearoyl-CoA desaturase activity. Prostaglandins Leukot Essent Fatty Acids 78:293-304.

Mecha M, Feliú A, Carrillo-Salinas FJ, Rueda-Zubiaurre A, Ortega-Gutiérrez S, de Sola RG, and Guaza C (2015) Endocannabinoids drive the acquisition of an alternative phenotype in microglia. Brain Behav Immun 49:233-245.

Medeiros R, Kitazawa M, Passos GF, Baglietto-Vargas D, Cheng D, Cribbs DH, and LaFerla FM (2013) Aspirin-triggered lipoxin A4 stimulates alternative activation of microglia and reduces Alzheimer disease-like pathology in mice. Am J Pathol 182:1780-1789.

Meijerink J, Balvers M, and Witkamp R (2013) N-Acyl amines of docosahexaenoic acid and other n-3 polyunsatured fatty acids: from fishy endocannabinoids to potential leads. $\mathrm{Br} J$ Pharmacol 169:772-783.

Meijerink J, Plastina P, Vincken JP, Poland M, Attya M, Balvers M, Gruppen H, Gabriele B, and Witkamp RF (2011) The ethanolamide metabolite of DHA, docosahexaenoylethanolamine, shows immunomodulating effects in mouse peritoneal and RAW264.7 macrophages: evidence for a new link between fish oil and inflammation. Br J Nutr 105:1798-1807.

Meijerink J, Poland M, Balvers MG, Plastina P, Lute C, Dwarkasing J, van Norren K, and Witkamp RF (2015) Inhibition of COX-2-mediated eicosanoid production plays a major role in the anti-inflammatory effects of the endocannabinoid N-docosahexaenoylethanolamine (DHEA) in macrophages. Br J Pharmacol 172:24-37.

Melo RC, D'Avila H, Wan HC, Bozza PT, Dvorak AM, and Weller PF (2011) Lipid bodies in inflammatory cells: structure, function, and current imaging techniques. $J$ Histochem Cytochem 59:540-556.

Meyer BJ, Mann NJ, Lewis JL, Milligan GC, Sinclair AJ, and Howe PR (2003) Dietary intakes and food sources of omega- 6 and omega-3 polyunsaturated fatty acids. Lipids 38:391-398

Mingam R, De Smedt V, Amédée T, Bluthé RM, Kelley KW, Dantzer R, and Layé S (2008a) In vitro and in vivo evidence for a role of the P2X7 receptor in the release of IL-1 beta in the murine brain. Brain Behav Immun 22:234-244.

Mingam R, Moranis A, Bluthé RM, De Smedt-Peyrusse V, Kelley KW, Guesnet P, Lavialle M, Dantzer R, and Layé S (2008b) Uncoupling of interleukin-6 from its signalling pathway by dietary n-3-polyunsaturated fatty acid deprivation alters sickness behaviour in mice. Eur J Neurosci 28:1877-1886.

Minutoli L, Marini H, Rinaldi M, Bitto A, Irrera N, Pizzino G, Pallio G, Calò M, Adamo EB, Trichilo V, et al. (2015) A dual inhibitor of cyclooxygenase and 5 -lipoxygenase protects against kainic acid-induced brain injury. Neuromolecular Med 17:192-201.

Mirza M, Volz C, Karlstetter M, Langiu M, Somogyi A, Ruonala MO, Tamm ER, Jägle H, and Langmann T (2013) Progressive retinal degeneration and glial activation in the CLN6 (nclf) mouse model of neuronal ceroid lipofuscinosis: a beneficial effect of DHA and curcumin supplementation. PLoS One 8:e75963.

Mitchell RW and Hatch GM (2011) Fatty acid transport into the brain: of fatty acid fables and lipid tails. Prostaglandins Leukot Essent Fatty Acids 85:293-302.

Mittelbronn M, Dietz K, Schluesener HJ, and Meyermann R (2001) Local distribution of microglia in the normal adult human central nervous system differs by up to one order of magnitude. Acta Neuropathol 101:249-255.

Mocking RJ, Harmsen I, Assies J, Koeter MW, Ruhé HG, and Schene AH (2016) Meta-analysis and meta-regression of omega-3 polyunsaturated fatty acid supplementation for major depressive disorder. Transl Psychiatry 6:e756.

Moon DO, Kim KC, Jin CY, Han MH, Park C, Lee KJ, Park YM, Choi YH, and Kim GY (2007) Inhibitory effects of eicosapentaenoic acid on lipopolysaccharide-induced activation in BV2 microglia. Int Immunopharmacol 7:222-229.

Moranis A, Delpech JC, De Smedt-Peyrusse V, Aubert A, Guesnet P, Lavialle M, Joffre C, and Layé S (2012) Long term adequate n-3 polyunsaturated fatty acid diet protects from depressive-like behavior but not from working memory disruption and brain cytokine expression in aged mice. Brain Behav Immun 26:721-731.

Morgane PJ, Austin-LaFrance R, Bronzino J, Tonkiss J, Díaz-Cintra S, Cintra L, Kemper T, and Galler JR (1993) Prenatal malnutrition and development of the brain. Neurosci Biobehav Rev 17:91-128.

Mori MA, Delattre AM, Carabelli B, Pudell C, Bortolanza M, Staziaki PV, Visentainer JV, Montanher PF, Del Bel EA, and Ferraz AC (2017) Neuroprotective effect of omega-3 polyunsaturated fatty acids in the 6-OHDA model of Parkinson's disease is mediated by a reduction of inducible nitric oxide synthase. Nutr Neurosci 21:1-11.

Moriguchi T, Loewke J, Garrison M, Catalan JN, and Salem N Jr (2001) Reversal of docosahexaenoic acid deficiency in the rat brain, retina, liver, and serum. $J$ Lipid Res 42:419-427.

Mouchlis VD and Dennis EA (2016) Membrane and inhibitor interactions of intracellular phospholipases A2. Adv Biol Regul 61:17-24. 
Moullé VS, Cansell C, Luquet S, and Cruciani-Guglielmacci C (2012) The multiple roles of fatty acid handling proteins in brain. Front Physiol 3:385.

Mouton PR, Long JM, Lei DL, Howard V, Jucker M, Calhoun ME, and Ingram DK (2002) Age and gender effects on microglia and astrocyte numbers in brains of mice. Brain Res 956:30-35.

Mulder SD, Nielsen HM, Blankenstein MA, Eikelenboom P, and Veerhuis R (2014) Apolipoproteins $\mathrm{E}$ and $\mathrm{J}$ interfere with amyloid-beta uptake by primary human astrocytes and microglia in vitro. Glia 62:493-503.

Muntané G, Janué A, Fernandez N, Odena MA, Oliveira E, Boluda S, Portero-Otin M, Naudí A, Boada J, Pamplona R, et al. (2010) Modification of brain lipids but not phenotype in alpha-synucleinopathy transgenic mice by long-term dietary n-3 fatty acids. Neurochem Int 56:318-328.

Nadel JA, Conrad DJ, Ueki IF, Schuster A, and Sigal E (1991) Immunocytochemical localization of arachidonate 15-lipoxygenase in erythrocytes, leukocytes, and airway cells. J Clin Invest 87:1139-1145.

Nadjar A, Leyrolle Q, Joffre C, and Laye S (2017) Bioactive lipids as new class of microglia modulators: when nutrition meets neuroimmunology. Prog Neuro-psychopharmacol Biol Psychitary 79:19-26.

Needleman P, Raz A, Minkes MS, Ferrendelli JA, and Sprecher H (1979) Triene prostaglandins: prostacyclin and thromboxane biosynthesis and unique biological properties. Proc Natl Acad Sci USA 76:944-948.

Nelson LH and Lenz KM (2017a) Microglia depletion in early life programs persistent changes in social, mood-related, and locomotor behavior in male and female rats. Behav Brain Res 316:279-293.

Nelson LH and Lenz KM (2017b) The immune system as a novel regulator of sex differences in brain and behavioral development. J Neurosci Res 95:447-461.

Nguyen LN, Ma D, Shui G, Wong P, Cazenave-Gassiot A, Zhang X, Wenk MR, Goh EL, and Silver DL (2014) Mfsd2a is a transporter for the essential omega-3 fatty acid docosahexaenoic acid. Nature 509:503-506.

Nimmerjahn A, Kirchhoff F, and Helmchen F (2005) Resting microglial cells are highly dynamic surveillants of brain parenchyma in vivo. Science $\mathbf{3 0 8}: 1314-1318$

Norris PC and Dennis EA (2012) Omega-3 fatty acids cause dramatic changes in TLR4 and purinergic eicosanoid signaling. Proc Natl Acad Sci USA 109:8517-8522.

Núñez E, Benito C, Pazos MR, Barbachano A, Fajardo O, González S, Tolón RM, and Romero J (2004) Cannabinoid CB2 receptors are expressed by perivascular microglial cells in the human brain: an immunohistochemical study. Synapse 53: 208-213.

O'Flaherty JT, Hu Y, Wooten RE, Horita DA, Samuel MP, Thomas MJ, Sun H, and Edwards IJ (2012) 15-Lipoxygenase metabolites of docosahexaenoic acid inhibit prostate cancer cell proliferation and survival. PLoS One 7:e45480.

Obata T, Nagakura T, Masaki T, Maekawa K, and Yamashita K (1999) Eicosapentaenoic acid inhibits prostaglandin D2 generation by inhibiting cyclooxygenase-2 in cultured human mast cells. Clin Exp Allergy 29:1129-1135.

Ochiai Y, Uchida Y, Ohtsuki S, Tachikawa M, Aizawa S, and Terasaki T (2017) The blood-brain barrier fatty acid transport protein 1 (FATP1/SLC27A1) supplies docosahexaenoic acid to the brain, and insulin facilitates transport. J Neurochem 141:400-412.

Okabe N, Nakamura T, Toyoshima T, Miyamoto O, Lu F, and Itano T (2011) Eicosapentaenoic acid prevents memory impairment after ischemia by inhibiting inflammatory response and oxidative damage. J Stroke Cerebrovasc Dis 20:188-195.

Olah M, Biber K, Vinet J, and Boddeke HW (2011) Microglia phenotype diversity. CNS Neurol Disord Drug Targets 10:108-118.

Orr SK and Bazinet RP (2008) The emerging role of docosahexaenoic acid in neuroinflammation. Curr Opin Investig Drugs 9:735-743.

Orr SK, Palumbo S, Bosetti F, Mount HT, Kang JX, Greenwood CE, Ma DW, Serhan $\mathrm{CN}$, and Bazinet RP (2013a) Unesterified docosahexaenoic acid is protective in neuroinflammation. $J$ Neurochem 127:378-393.

Orr SK, Tong JY, Kang JX, Ma DW, and Bazinet RP (2010) The fat-1 mouse has brain docosahexaenoic acid levels achievable through fish oil feeding. Neurochem Res $\mathbf{3 5}$ : 811-819.

Orr SK, Trépanier MO, and Bazinet RP (2013b) n-3 Polyunsaturated fatty acids in animal models with neuroinflammation. Prostaglandins Leukot Essent Fatty Acids 88:97-103

Orsavova J, Misurcova L, Ambrozova JV, Vicha R, and Mlcek J (2015) Fatty acids composition of vegetable oils and its contribution to dietary energy intake and dependence of cardiovascular mortality on dietary intake of fatty acids. Int $J \mathrm{Mol}$ Sci 16:12871-12890.

Pan Y, Scanlon MJ, Owada Y, Yamamoto Y, Porter CJ, and Nicolazzo JA (2015) Fatty acid-binding protein 5 facilitates the blood-brain barrier transport of docosahexaenoic acid. Mol Pharm 12:4375-4385.

Pan Y, Short JL, Choy KH, Zeng AX, Marriott PJ, Owada Y, Scanlon MJ, Porter CJ, and Nicolazzo JA (2016) Fatty acid-binding protein 5 at the blood-brain barrier regulates endogenous brain docosahexaenoic acid levels and cognitive function. $J$ Neurosci 36:11755-11767.

Paolicelli RC, Bolasco G, Pagani F, Maggi L, Scianni M, Panzanelli P, Giustetto M, Ferreira TA, Guiducci E, Dumas L, et al. (2011) Synaptic pruning by microglia is necessary for normal brain development. Science 333:1456-1458.

Papayianni A, Serhan CN, and Brady HR (1996) Lipoxin A4 and B4 inhibit leukotriene-stimulated interactions of human neutrophils and endothelial cells. $J$ Immunol 156:2264-2272.

Park SW, Hah JH, Oh SM, Jeong WJ, and Sung MW (2016a) 5-Lipoxygenase mediates docosahexaenoyl ethanolamide and $\mathrm{N}$-arachidonoyl-L-alanine-induced reactive oxygen species production and inhibition of proliferation of head and neck squamous cell carcinoma cells. BMC Cancer 16:458.

Park T, Chen H, Kevala K, Lee JW, and Kim HY (2016b) N-Docosahexaenoylethanolamine ameliorates LPS-induced neuroinflammation via cAMP/PKA-dependent signaling. $J$ Neuroinflammation 13:284.

Parkhurst CN, Yang G, Ninan I, Savas JN, Yates JR III, Lafaille JJ, Hempstead BL, Littman DR, and Gan WB (2013) Microglia promote learning-dependent synapse formation through brain-derived neurotrophic factor. Cell 155:1596-1609.
Paterniti I, Impellizzeri D, Di Paola R, Esposito E, Gladman S, Yip P, Priestley JV, Michael-Titus AT, and Cuzzocrea S (2014) Docosahexaenoic acid attenuates the early inflammatory response following spinal cord injury in mice: in-vivo and in-vitro studies. J Neuroinflammation 11:6.

Perez-Pouchoulen M, VanRyzin JW, and McCarthy MM (2015) Morphological and phagocytic profile of microglia in the developing rat cerebellum $(1,2,3)$. eNeuro DOI: 10.1523/ENEURO.0036-15.2015 [published ahead of print].

Perry VH, Nicoll JA, and Holmes C (2010) Microglia in neurodegenerative disease. Nat Rev Neurol 6:193-201.

Pettit LK, Varsanyi C, Tadros J, and Vassiliou E (2013) Modulating the inflammatory properties of activated microglia with docosahexaenoic acid and aspirin. Lipids Health Dis 12:16.

Phillis JW, Horrocks LA, and Farooqui AA (2006) Cyclooxygenases, lipoxygenases, and epoxygenases in CNS: their role and involvement in neurological disorders. Brain Res Brain Res Rev 52:201-243.

Piomelli D and Sasso O (2014) Peripheral gating of pain signals by endogenous lipid mediators. Nat Neurosci 17:164-174.

Plourde M and Cunnane SC (2007) Extremely limited synthesis of long chain polyunsaturates in adults: implications for their dietary essentiality and use as supplements. Appl Physiol Nutr Metab 32:619-634.

Pomponi M, Di Gioia A, Bria P, and Pomponi MF (2008) Fatty aspirin: a new perspective in the prevention of dementia of Alzheimer's type? Curr Alzheimer Res 5:422-431.

Pomponi MF, Gambassi G, Pomponi M, Di Gioia A, and Masullo C (2011) Why docosahexaenoic acid and aspirin supplementation could be useful in women as a primary prevention therapy against Alzheimer's disease? Ageing Res Rev 10: 124-131.

Potolicchio I, Carven GJ, Xu X, Stipp C, Riese RJ, Stern LJ, and Santambrogio L (2005) Proteomic analysis of microglia-derived exosomes: metabolic role of the aminopeptidase CD13 in neuropeptide catabolism. J Immunol 175:2237-2243.

Prada I, Furlan R, Matteoli M, and Verderio C (2013) Classical and unconventional pathways of vesicular release in microglia. Glia 61:1003-1017.

Praticò D, Zhukareva V, Yao Y, Uryu K, Funk CD, Lawson JA, Trojanowski JQ and Lee VM (2004) 12/15-Lipoxygenase is increased in Alzheimer's disease: possible involvement in brain oxidative stress. Am J Pathol 164:1655-1662.

Pu H, Guo Y, Zhang W, Huang L, Wang G, Liou AK, Zhang J, Zhang P, Leak RK Wang Y, et al. (2013) Omega-3 polyunsaturated fatty acid supplementation improves neurologic recovery and attenuates white matter injury after experimental traumatic brain injury. J Cereb Blood Flow Metab 33:1474-1484

Pu S, Eck P, Jenkins DJ, Connelly PW, Lamarche B, Kris-Etherton PM, West SG, Liu $\mathrm{X}$, and Jones PJ (2016) Interactions between dietary oil treatments and genetic variants modulate fatty acid ethanolamides in plasma and body weight composition. Br J Nutr 115:1012-1023.

Quinn JF, Raman R, Thomas RG, Yurko-Mauro K, Nelson EB, Van Dyck C, Galvin JE, Emond J, Jack CR Jr, Weiner M, et al. (2010) Docosahexaenoic acid supplementation and cognitive decline in Alzheimer disease: a randomized trial. JAMA 304:1903-1911.

Rahman T, Taha AY, Song BJ, Orr SK, Liu Z, Chen CT, and Bazinet RP (2010) The very low density lipoprotein receptor is not necessary for maintaining brain polyunsaturated fatty acid concentrations. Prostaglandins Leukot Essent Fatty Acids 82:141-145.

Raison CL and Miller AH (2011) Is depression an inflammatory disorder? Curr Psychiatry Rep 13:467-475.

Ransohoff RM and Brown MA (2012) Innate immunity in the central nervous system. $J$ Clin Invest 122:1164-1171.

Ransohoff RM and Perry VH (2009) Microglial physiology: unique stimuli, specialized responses. Annu Rev Immunol 27:119-145.

Rapaport MH, Nierenberg AA, Schettler PJ, Kinkead B, Cardoos A, Walker R, and Mischoulon D (2016) Inflammation as a predictive biomarker for response to omega-3 fatty acids in major depressive disorder: a proof-of-concept study. Mol Psychiatry 21:71-79.

Rapoport SI (2008) Brain arachidonic and docosahexaenoic acid cascades are selectively altered by drugs, diet and disease. Prostaglandins Leukot Essent Fatty Acids 79:153-156.

Rapoport SI, Chang MC, and Spector AA (2001) Delivery and turnover of plasmaderived essential PUFAs in mammalian brain. J Lipid Res 42:678-685.

Rey C, Na djar A, Buaud B, Vaysse C, Aubert A, Pallet V, Laye S, and Joffre C (2016) Resolvin D1 and E1 promote resolution of inflammation in microglial cells in vitro. Brain Behav Immun 55:249-259.

Rockett BD, Franklin A, Harris M, Teague H, Rockett A, and Shaikh SR (2011) Membrane raft organization is more sensitive to disruption by (n-3) PUFA than nonraft organization in EL4 and B cells. J Nutr 141:1041-1048.

Rodríguez JJ, Butt AM, Gardenal E, Parpura V, and Verkhratsky A (2016) Complex and differential glial responses in Alzheimer's disease and ageing. Curr Alzheimer Res 13:343-358.

Rogerio AP, Haworth O, Croze R, Oh SF, Uddin M, Carlo T, Pfeffer MA, Priluck R, Serhan CN, and Levy BD (2012) Resolvin D1 and aspirin-triggered resolvin D1 promote resolution of allergic airways responses. J Immunol 189:1983-1991.

Rossmeisl M, Jilkova ZM, Kuda O, Jelenik T, Medrikova D, Stankova B, Kristinsson B, Haraldsson GG, Svensen H, Stoknes I, et al. (2012) Metabolic effects of n-3 PUFA as phospholipids are superior to triglycerides in mice fed a high-fat diet: possible role of endocannabinoids. PLoS One 7:e38834.

Salem N Jr and Kuratko CN (2014) A reexamination of krill oil bioavailability studies. Lipids Health Dis 13:137.

Saraswathy S, Wu G, and Rao NA (2006) Retinal microglial activation and chemotaxis by docosahexaenoic acid hydroperoxide. Invest Ophthalmol Vis Sci 47: $3656-3663$.

Schafer DP, Lehrman EK, Kautzman AG, Koyama R, Mardinly AR, Yamasaki R, Ransohoff RM, Greenberg ME, Barres BA, and Stevens B (2012) Microglia sculpt postnatal neural circuits in an activity and complement-dependent manner. Neuron 74:691-705. 
Schroeder F, McIntosh AL, Martin GG, Huang H, Landrock D, Chung S, Landrock KK, Dangott LJ, Li S, Kaczocha M, et al. (2016) Fatty acid binding protein-1 (FABP1) and the human FABP1 T94A variant: roles in the endocannabinoid system and dyslipidemias. Lipids 51:655-676.

Schuchardt JP, Köbe T, Witte V, Willers J, Gingrich A, Tesky V, Pantel J, Rujescu D, Illig T, Flöel A, et al. (2016) Genetic variants of the FADS gene cluster are associated with erythrocyte membrane LC PUFA levels in patients with mild cognitive impairment. J Nutr Health Aging 20:611-620.

Schuchardt JP, Schneider I, Willenberg I, Yang J, Hammock BD, Hahn A, and Schebb NH (2014) Increase of EPA-derived hydroxy, epoxy and dihydroxy fatty acid levels in human plasma after a single dose of long-chain omega-3 PUFA. Prostaglandins Other Lipid Mediat 109-111:23-31.

Schwab JM, Chiang N, Arita M, and Serhan CN (2007) Resolvin E1 and protectin D1 activate inflammation-resolution programmes. Nature 447:869-874.

Schwarz JM, Sholar PW, and Bilbo SD (2012) Sex differences in microglial colonization of the developing rat brain. J Neurochem 120:948-963.

Serhan CN (2014) Pro-resolving lipid mediators are leads for resolution physiology. Nature 510:92-101.

Serhan CN (2017a) Discovery of specialized pro-resolving mediators marks the dawn of resolution physiology and pharmacology. Mol Aspects Med DOI: 10.1016/ j.mam.2017.03.001 [published ahead of print].

Serhan CN (2017b) Treating inflammation and infection in the 21st century: new hints from decoding resolution mediators and mechanisms. FASEB $J$ 31: 1273-1288.

Serhan CN and Chiang N (2013) Resolution phase lipid mediators of inflammation: agonists of resolution. Curr Opin Pharmacol 13:632-640.

Serhan CN, Chiang N, Dalli J, and Levy BD (2014) Lipid mediators in the resolution of inflammation. Cold Spring Harb Perspect Biol 7:a016311.

Serhan CN, Hong S, Gronert K, Colgan SP, Devchand PR, Mirick G, and Moussignac RL (2002) Resolvins: a family of bioactive products of omega-3 fatty acid transformation circuits initiated by aspirin treatment that counter proinflammation signals. J Exp Med 196:1025-1037.

Serhan CN, Krishnamoorthy S, Recchiuti A, and Chiang N (2011) Novel antiinflammatory-pro-resolving mediators and their receptors. Curr Top Med Chem 11:629-647.

Serhan CN, Yacoubian S, and Yang R (2008) Anti-inflammatory and proresolving lipid mediators. Annu Rev Pathol 3:279-312.

Serini S and Calviello G (2016) Reduction of oxidative/nitrosative stress in brain and its involvement in the neuroprotective effect of n-3 PUFA in Alzheimer's disease. Curr Alzheimer Res 13:123-134.

Shaikh SR (2012) Biophysical and biochemical mechanisms by which dietary N-3 polyunsaturated fatty acids from fish oil disrupt membrane lipid rafts. J Nutr Biochem 23:101-105.

Sheets KG, Jun B, Zhou Y, Zhu M, Petasis NA, Gordon WC, and Bazan NG (2013) Microglial ramification and redistribution concomitant with the attenuation of choroidal neovascularization by neuroprotectin D1. Mol Vis 19:1747-1759.

Shinohara M, Mirakaj V, and Serhan CN (2012) Functional metabolomics reveals novel active products in the DHA metabolome. Front Immunol 3:81.

Sierra A, Abiega O, Shahraz A, and Neumann H (2013) Janus-faced microglia: beneficial and detrimental consequences of microglial phagocytosis. Front Cell Neurosci 7:6

Sierra A, Gottfried-Blackmore A, Milner TA, McEwen BS, and Bulloch K (2008) Steroid hormone receptor expression and function in microglia. Glia 56:659-674.

Sierra A, Tremblay ME, and Wake H (2014) Never-resting microglia: physiological roles in the healthy brain and pathological implications. Front Cell Neurosci 8:240.

Simopoulos AP (2002) The importance of the ratio of omega-6/omega-3 essential fatty acids. Biomed Pharmacother 56:365-379.

Simopoulos AP (2011) Evolutionary aspects of diet: the omega-6/omega-3 ratio and the brain. Mol Neurobiol 44:203-215.

Sipe GO, Lowery RL, Tremblay ME, Kelly EA, Lamantia CE, and Majewska AK (2016) Microglial P2Y12 is necessary for synaptic plasticity in mouse visual cortex. Nat Commun 7:10905.

Skarke C, Alamuddin N, Lawson JA, Li X, Ferguson JF, Reilly MP, and FitzGerald GA (2015) Bioactive products formed in humans from fish oils. J Lipid Res 56 $1808-1820$

Solito E and Sastre M (2012) Microglia function in Alzheimer's disease. Front Pharmacol 3:14

Song C, Phillips AG, Leonard BE, and Horrobin DF (2004) Ethyl-eicosapentaenoic acid ingestion prevents corticosterone-mediated memory impairment induced by central administration of interleukin-1beta in rats. Mol Psychiatry 9:630-638.

Sperling RI, Benincaso AI, Knoell CT, Larkin JK, Austen KF, and Robinson DR (1993) Dietary omega-3 polyunsaturated fatty acids inhibit phosphoinositide formation and chemotaxis in neutrophils. $J$ Clin Invest 91:651-660.

Sprecher H (2000) Metabolism of highly unsaturated n-3 and n-6 fatty acids. Biochim Biophys Acta 1486:219-231.

Squarzoni P, Oller G, Hoeffel G, Pont-Lezica L, Rostaing P, Low D, Bessis A, Ginhoux $\mathrm{F}$, and Garel S (2014) Microglia modulate wiring of the embryonic forebrain. Cell Reports 8:1271-1279.

Stella N (2009) Endocannabinoid signaling in microglial cells. Neuropharmacology 56 (Suppl 1):244-253.

Strobel C, Jahreis G, and Kuhnt K (2012) Survey of n-3 and n-6 polyunsaturated fatty acids in fish and fish products. Lipids Health Dis 11:144.

Su KP, Huang SY, Peng CY, Lai HC, Huang CL, Chen YC, Aitchison KJ, and Pariante CM (2010) Phospholipase A2 and cyclooxygenase 2 genes influence the risk of interferon-alpha-induced depression by regulating polyunsaturated fatty acids levels. Biol Psychiatry 67:550-557.

Su KP, Lai HC, Yang HT, Su WP, Peng CY, Chang JP, Chang HC, and Pariante CM (2014) Omega-3 fatty acids in the prevention of interferon-alpha-induced depression: results from a randomized, controlled trial. Biol Psychiatry $\mathbf{7 6}$ : $559-566$.
Su KP, Yang HT, Chang JP, Shih YH, Guu TW, Kumaran SS, Gałecki P, Walczewska A and Pariante CM (2017) Eicosapentaenoic and docosahexaenoic acids have different effects on peripheral phospholipase A2 gene expressions in acute depressed patients. Prog Neuropsychopharmacol Biol Psychiatry DOI: 10.1016/ j.pnpbp.2017.06.020 [published ahead of print].

Sublette ME, Ellis SP, Geant AL, and Mann JJ (2011) Meta-analysis of the effects of eicosapentaenoic acid (EPA) in clinical trials in depression. J Clin Psychiatry 72 1577-1584.

Subra C, Grand D, Laulagnier K, Stella A, Lambeau G, Paillasse M, De Medina P, Monsarrat B, Perret B, Silvente-Poirot S, et al. (2010) Exosomes account for vesicle-mediated transcellular transport of activatable phospholipases and prostaglandins. J Lipid Res 51:2105-2120.

Taber L, Chiu CH, and Whelan J (1998) Assessment of the arachidonic acid content in foods commonly consumed in the American diet. Lipids 33:1151-1157.

Taha AY, Blanchard HC, Cheon Y, Ramadan E, Chen M, Chang L, and Rapoport SI (2017) Dietary linoleic acid lowering reduces lipopolysaccharide-induced increase in brain arachidonic acid metabolism. Mol Neurobiol 54:4303-4315.

Taha AY, Cheon Y, Faurot KF, Macintosh B, Majchrzak-Hong SF, Mann JD, Hibbeln JR, Ringel A, and Ramsden CE (2014) Dietary omega-6 fatty acid lowering increases bioavailability of omega-3 polyunsaturated fatty acids in human plasma lipid pools. Prostaglandins Leukot Essent Fatty Acids 90:151-157.

Tay TL, Savage JC, Hui CW, Bisht K, and Tremblay ME (2017) Microglia across the lifespan: from origin to function in brain development, plasticity and cognition. J Physiol 595:1929-1945.

Tenorio-Lopes L, Baldy C, Jochmans-Lemoine A, Mercier O, Pothier-Piccinin O, Seaborn T, Joseph V, Marc I, and Kinkead R (2017) Consequences of maternal omega-3 polyunsaturated fatty acid supplementation on respiratory function in rat pups. J Physiol 595:1637-1655.

Thies F, Pillon C, Moliere P, Lagarde M, and Lecerf J (1994) Preferential incorporation of sn-2 lysoPC DHA over unesterified DHA in the young rat brain. Am J Physiol 267:R1273-R1279.

Thomazeau A, Bosch-Bouju C, Manzoni O, and Laye S (2016) Nutritional n-3 PUFA deficiency abolishes endocannabinoid gating of hippocampal long-term potentiation. Cerebral Cortex 27:2571-2579.

Thoonsen H, Richard E, Bentham P, Gray R, van Geloven N, De Haan RJ, Van Gool WA, and Nederkoorn PJ (2010) Aspirin in Alzheimer's disease: increased risk of intracerebral hemorrhage: cause for concern? Stroke 41:2690-2692.

Tian Y, Zhang Y, Zhang R, Qiao S, and Fan J (2015) Resolvin D2 recovers neural injury by suppressing inflammatory mediators expression in lipopolysaccharideinduced Parkinson's disease rat model. Biochem Biophys Res Commun 460: 799-805.

Tiemeier H, van Tuijl HR, Hofman A, Kiliaan AJ, and Breteler MM (2003) Plasma fatty acid composition and depression are associated in the elderly: the Rotterdam Study. Am J Clin Nutr 78:40-46.

Tremblay ME, Lowery RL, and Majewska AK (2010) Microglial interactions with synapses are modulated by visual experience. PLoS Biol 8:e1000527.

Tremblay ME, Zhang I, Bisht K, Savage JC, Lecours C, Parent M, Titorenko V, and Maysinger D (2016) Remodeling of lipid bodies by docosahexaenoic acid in activated microglial cells. $J$ Neuroinflammation 13:116.

Tremoleda JL, Thau-Zuchman O, Davies M, Foster J, Khan I, Vadivelu KC, Yip PK Sosabowski J, Trigg W, and Michael-Titus AT (2016) In vivo PET imaging of the neuroinflammatory response in rat spinal cord injury using the TSPO tracer [(18)F]GE-180 and effect of docosahexaenoic acid. Eur J Nucl Med Mol Imaging 43: $1710-1722$

Trépanier MO, Hopperton KE, Orr SK, and Bazinet RP (2016) N-3 polyunsaturated fatty acids in animal models with neuroinflammation: an update. Eur J Pharmacol 785:187-206

Tully AM, Roche HM, Doyle R, Fallon C, Bruce I, Lawlor B, Coakley D, and Gibney MJ (2003) Low serum cholesteryl ester-docosahexaenoic acid levels in Alzheimer's disease: a case-control study. Br J Nutr 89:483-489.

Turola E, Furlan R, Bianco F, Matteoli M, and Verderio C (2012) Microglial microvesicle secretion and intercellular signaling. Front Physiol 3:149.

Umhau JC, Zhou W, Carson RE, Rapoport SI, Polozova A, Demar J, Hussein N, Bhattacharjee AK, Ma K, Esposito G, et al. (2009) Imaging incorporation of circulating docosahexaenoic acid into the human brain using positron emission tomography. J Lipid Res 50:1259-1268.

VanRyzin JW, Yu SJ, Perez-Pouchoulen M and McCarthy MM (2016) Temporary depletion of microglia during the early postnatal period induces lasting sexdependent and sex-independent effects on behavior in rats. eNeuro DOI: 10.1523/ ENEURO.0297-16.2016 [published ahead of print].

Vauzour D, Martinsen A, and Layé S (2015) Neuroinflammatory processes in cognitive disorders: is there a role for flavonoids and n-3 polyunsaturated fatty acids in counteracting their detrimental effects? Neurochem Int 89:63-74.

Vedin I, Cederholm T, Freund Levi Y, Basun H, Garlind A, Faxén Irving G, Jönhagen ME, Vessby B, Wahlund LO, and Palmblad J (2008) Effects of docosahexaenoic acid-rich n-3 fatty acid supplementation on cytokine release from blood mononuclear leukocytes: the OmegAD study. Am J Clin Nutr 87:1616-1622.

Vedin I, Cederholm T, Freund-Levi Y, Basun H, Garlind A, Irving GF, EriksdotterJönhagen M, Wahlund LO, Dahlman I, and Palmblad J (2012) Effects of DHA-rich n-3 fatty acid supplementation on gene expression in blood mononuclear leukocytes: the OmegAD study. PLoS One 7:e35425.

Vegeto E, Belcredito S, Etteri S, Ghisletti S, Brusadelli A, Meda C, Krust A, Dupont S, Ciana P, Chambon P, et al. (2003) Estrogen receptor-alpha mediates the brain antiinflammatory activity of estradiol. Proc Natl Acad Sci USA 100:9614-9619.

Verderio C, Muzio L, Turola E, Bergami A, Novellino L, Ruffini F, Riganti L, Corradini I, Francolini M, Garzetti L, et al. (2012) Myeloid microvesicles are a marker and therapeutic target for neuroinflammation. Ann Neurol 72:610-624.

Wake H, Moorhouse AJ, Jinno S, Kohsaka S, and Nabekura J (2009) Resting microglia directly monitor the functional state of synapses in vivo and determine the fate of ischemic terminals. J Neurosci 29:3974-3980. 
Walter J (2016) The triggering receptor expressed on myeloid cells 2: a molecular link of neuroinflammation and neurodegenerative diseases. $J$ Biol Chem 291: 4334-4341.

Walter L, Franklin A, Witting A, Wade C, Xie Y, Kunos G, Mackie K, and Stella N (2003) Nonpsychotropic cannabinoid receptors regulate microglial cell migration. J Neurosci 23:1398-1405.

Wang B, Gong X, Wan JY, Zhang L, Zhang Z, Li HZ, and Min S (2011a) Resolvin D1 protects mice from LPS-induced acute lung injury. Pulm Pharmacol Ther 24: 434-441.

Wang L, Chen K, Liu K, Zhou Y, Zhang T, Wang B, and Mi M (2015a) DHA inhibited AGEs-induced retinal microglia activation via suppression of the PPAR $\gamma / \mathrm{NF}_{\kappa} \mathrm{B}$ pathway and reduction of signal transducers in the AGEs/RAGE axis recruitment into lipid rafts. Neurochem Res 40:713-722.

Wang Q, Zheng X, Cheng Y, Zhang YL, Wen HX, Tao Z, Li H, Hao Y, Gao Y, Yang LM, et al. (2014) Resolvin D1 stimulates alveolar fluid clearance through alveolar epithelial sodium channel, Na,K-ATPase via ALX/cAMP/PI3K pathway in lipopolysaccharide-induced acute lung injury. J Immunol 192:3765-3777.

Wang W, Shinto L, Connor WE, and Quinn JF (2008) Nutritional biomarkers in Alzheimer's disease: the association between carotenoids, n-3 fatty acids, and dementia severity. J Alzheimers Dis 13:31-38.

Wang X, Hjorth E, Vedin I, Eriksdotter M, Freund-Levi Y, Wahlund LO, Cederholm T, Palmblad J, and Schultzberg M (2015b) Effects of n-3 FA supplementation on the release of proresolving lipid mediators by blood mononuclear cells: the OmegAD study. $J$ Lipid Res 56:674-681.

Wang X, Zhu M, Hjorth E, Cortes-Toro V, Eyjolfsdottir H, Graff C, Nennesmo I, Palmblad J, Eriksdotter M, and Sambamurti K, et al. (2015c) Resolution of in flammation is altered in Alzheimer's disease. Alzheimers Dement 11:40-50 e41-42.

Wang Y, Plastina P, Vincken JP, Jansen R, Balvers M, Ten Klooster JP, Gruppen H, Witkamp R, and Meijerink J (2017) N-docosahexaenoyl dopamine, an endocannabinoid-like conjugate of dopamine and the n-3 fatty acid docosahexaenoic acid, attenuates lipopolysaccharide-induced activation of microglia and macrophages via COX-2. ACS Chem Neurosci 8:548-557.

Wang YP, Wu Y, Li LY, Zheng J, Liu RG, Zhou JP, Yuan SY, Shang Y, and Yao SL (2011b) Aspirin-triggered lipoxin A4 attenuates LPS-induced pro-inflammatory responses by inhibiting activation of $\mathrm{NF}-\mathrm{\kappa B}$ and MAPKs in BV-2 microglial cells. $J$ Neuroinflammation 8:95.

Watanabe S, Doshi M, and Hamazaki T (2003) n-3 Polyunsaturated fatty acid (PUFA) deficiency elevates and n-3 PUFA enrichment reduces brain 2-arachidonoylglycerol level in mice. Prostaglandins Leukot Essent Fatty Acids 69:51-59.

Wen MXJ, Ding L, Zhang L, Du L, Wang J, Wang Y, and Xue C (2016) Eicosapentaenoic acid-enriched phospholipids improve A $\beta 1-40$-induced cognitive deficiency in a rat model of Alzheimer's disease. J Funct Foods 24:537-548.

Wieghofer P and Prinz M (2016) Genetic manipulation of microglia during brain development and disease. Biochim Biophys Acta 1862:299-309.

Williams JA, Batten SE, Harris M, Rockett BD, Shaikh SR, Stillwell W, and Wassall SR (2012) Docosahexaenoic and eicosapentaenoic acids segregate differently between raft and nonraft domains. Biophys $J$ 103:228-237.

Witkamp R (2016) Fatty acids, endocannabinoids and inflammation. Eur J Pharmacol 785:96-107.

Woodroofe MN (1995) Cytokine production in the central nervous system. Neurology 45(6 Suppl 6)S6-S10.

Woodroofe MN and Cuzner ML (1993) Cytokine mRNA expression in inflammatory multiple sclerosis lesions: detection by non-radioactive in situ hybridization. Cytokine 5:583-588.

Wu Y, Zhai H, Wang Y, Li L, Wu J, Wang F, Sun S, Yao S, and Shang Y (2012) Aspirin-triggered lipoxin $\mathrm{A}_{4}$ attenuates lipopolysaccharide-induced intracellular ROS in BV2 microglia cells by inhibiting the function of NADPH oxidase. Neurochem Res 37:1690-1696.

Xian W, Wu Y, Xiong W, Li L, Li T, Pan S, Song L, Hu L, Pei L, Yao S, et al. (2016) The pro-resolving lipid mediator Maresin 1 protects against cerebral ischemia/ reperfusion injury by attenuating the pro-inflammatory response. Biochem Biophys Res Commun 472:175-181.

Xiao Y, Huang Y, and Chen ZY (2005) Distribution, depletion and recovery of docosahexaenoic acid are region-specific in rat brain. Br J Nutr 94:544-550.

Xu D, Omura T, Masaki N, Arima H, Banno T, Okamoto A, Hanada M, Takei S, Matsushita S, Sugiyama E, et al. (2016) Increased arachidonic acid-containing phosphatidylcholine is associated with reactive microglia and astrocytes in the spinal cord after peripheral nerve injury. Sci Rep 6:26427.

Xu HE, Lambert MH, Montana VG, Parks DJ, Blanchard SG, Brown PJ, Sternbach DD, Lehmann JM, Wisely GB, Willson TM, et al. (1999) Molecular recognition of fatty acids by peroxisome proliferator-activated receptors. Mol Cell 3:397-403

Xu S, Jay A, Brunaldi K, Huang N, and Hamilton JA (2013a) CD36 enhances fatty acid uptake by increasing the rate of intracellular esterification but not transport across the plasma membrane. Biochemistry 52:7254-7261.

Xu ZZ, Berta T, and Ji RR (2013b) Resolvin E1 inhibits neuropathic pain and spinal cord microglial activation following peripheral nerve injury. $J$ Neuroimmune Pharmacol 8:37-41.
Yamagata K, Andreasson KI, Kaufmann WE, Barnes CA, and Worley PF (1993) Expression of a mitogen-inducible cyclooxygenase in brain neurons: regulation by synaptic activity and glucocorticoids. Neuron 11:371-386.

Yamanaka M, Ishikawa T, Griep A, Axt D, Kummer MP, and Heneka MT (2012) PPAR $\gamma / R X R \alpha$-induced and CD36-mediated microglial amyloid- $\beta$ phagocytosis results in cognitive improvement in amyloid precursor protein/presenilin 1 mice. J Neurosci 32:17321-17331.

Yamashima T (2012) 'PUFA-GPR40-CREB signaling' hypothesis for the adult primate neurogenesis. Prog Lipid Res 51:221-231.

Yang R, Fredman G, Krishnamoorthy S, Agrawal N, Irimia D, Piomelli D, and Serhan CN (2011) Decoding functional metabolomics with docosahexaenoyl ethanolamide (DHEA) identifies novel bioactive signals. $J$ Biol Chem 286: 31532-31541.

Yao Y, Clark CM, Trojanowski JQ, Lee VM, and Praticò D (2005) Elevation of 12/15 lipoxygenase products in $\mathrm{AD}$ and mild cognitive impairment. Ann Neurol 58: 623-626.

Yassine HN, Croteau E, Rawat V, Hibbeln JR, Rapoport SI, Cunnane SC, and Umhau JC (2017) DHA brain uptake and APOE4 status: a PET study with [1-(11)C]-DHA. Alzheimers Res Ther 9:23.

Yaxin W, Shanglong Y, Huaqing S, Hong L, Shiying Y, Xiangdong C, Ruidong L, Xiaoying W, Lina G, and Yan W (2014) Resolvin D1 attenuates lipopolysaccharide induced acute lung injury through CXCL-12/CXCR4 pathway. J Surg Res 188: 213-221.

Ye XH, Wu Y, Guo PP, Wang J, Yuan SY, Shang Y, and Yao SL (2010) Lipoxin A4 analogue protects brain and reduces inflammation in a rat model of focal cerebral ischemia reperfusion. Brain Res 1323:174-183.

Yeh FL, Wang Y, Tom I, Gonzalez LC, and Sheng M (2016) TREM2 binds to apolipoproteins, including APOE and CLU/APOJ, and thereby facilitates uptake of amyloid-beta by microglia. Neuron 91:328-340.

Yip PK, Pizzasegola C, Gladman S, Biggio ML, Marino M, Jayasinghe M, Ullah F, Dyall SC, Malaspina A, Bendotti C, et al. (2013) The omega-3 fatty acid eicosapentaenoic acid accelerates disease progression in a model of amyotrophic lateral sclerosis. PLoS One 8:e61626.

Yurko-Mauro K, Kralovec J, Bailey-Hall E, Smeberg V, Stark JG, and Salem N Jr (2015) Similar eicosapentaenoic acid and docosahexaenoic acid plasma levels achieved with fish oil or krill oil in a randomized double-blind four-week bioavailability study. Lipids Health Dis 14:99.

Zarghi A and Kakhki S (2014) Design, synthesis, and biological evaluation of new 2-phenyl-4H-chromen-4-one derivatives as selective cyclooxygenase-2 inhibitors. Sci Pharm 83:15-26.

Zenaro E, Pietronigro E, Della Bianca V, Piacentino G, Marongiu L, Budui S, Turano E, Rossi B, Angiari S, Dusi S, et al. (2015) Neutrophils promote Alzheimer's disease-like pathology and cognitive decline via LFA-1 integrin. Nat Med 21: 880-886.

Zendedel A, Habib P, Dang J, Lammerding L, Hoffmann S, Beyer C, and Slowik A (2015) Omega-3 polyunsaturated fatty acids ameliorate neuroinflammation and mitigate ischemic stroke damage through interactions with astrocytes and microglia. J Neuroimmunol 278:200-211.

Zhang MJ and Spite M (2012) Resolvins: anti-inflammatory and proresolving mediators derived from omega-3 polyunsaturated fatty acids. Annu Rev Nutr $\mathbf{3 2}$ 203-227.

Zhang W, Hu X, Yang W, Gao Y, and Chen J (2010) Omega-3 polyunsaturated fatty acid supplementation confers long-term neuroprotection against neonata hypoxic-ischemic brain injury through anti-inflammatory actions. Stroke 41 2341-2347.

Zhang Y, Appelkvist EL, Kristensson K, and Dallner G (1996) The lipid compositions of different regions of rat brain during development and aging. Neurobiol Aging 17: 869-875.

Zhang Y, Chen K, Sloan SA, Bennett ML, Scholze AR, O'Keeffe S, Phatnani HP, Guarnieri P, Caneda C, Ruderisch N, et al. (2014) An RNA-sequencing transcriptome and splicing database of glia, neurons, and vascular cells of the cerebral cortex. J Neurosci 34:11929-11947.

Zhou L, Zang G, Zhang G, Wang H, Zhang X, Johnston N, Min W, Luke P, Jevnikar A, Haig A, et al. (2013) MicroRNA and mRNA signatures in ischemia reperfusion injury in heart transplantation. PLoS One 8:e79805.

Zhu M, Wang X, Hjorth E, Colas RA, Schroeder L, Granholm AC, Serhan CN, and Schultzberg M (2016) Pro-resolving lipid mediators improve neuronal survival and increase A $\beta 42$ phagocytosis. Mol Neurobiol 53:2733-2749.

Zhu M, Wang X, Schultzberg M, and Hjorth E (2015) Differential regulation of resolution in inflammation induced by amyloid- $\beta 42$ and lipopolysaccharides in human microglia. J Alzheimers Dis 43:1237-1250.

Zulyniak MA, Perreault M, Gerling C, Spriet LL, and Mutch DM (2013) Fish oil supplementation alters circulating eicosanoid concentrations in young healthy men. Metabolism 62:1107-1113.

Zulyniak MA, Roke K, Gerling C, Logan SL, Spriet LL, and Mutch DM (2016) Fish oil regulates blood fatty acid composition and oxylipin levels in healthy humans: a comparison of young and older men. Mol Nutr Food Res 60:631-641. 